Florida International University FIU Digital Commons

FIU Electronic Theses and Dissertations

University Graduate School

$10-27-2011$

\title{
The Role of Emotional Intelligence in College Students' Success
}

Joyce G. Walsh-Portillo

Florida International University, jportill@broward.edu

DOI: $10.25148 /$ etd.FI11120510

Follow this and additional works at: https://digitalcommons.fiu.edu/etd

Part of the Higher Education Administration Commons

\section{Recommended Citation}

Walsh-Portillo, Joyce G., "The Role of Emotional Intelligence in College Students' Success" (2011). FIU Electronic Theses and Dissertations. 491.

https://digitalcommons.fiu.edu/etd/491

This work is brought to you for free and open access by the University Graduate School at FIU Digital Commons. It has been accepted for inclusion in FIU Electronic Theses and Dissertations by an authorized administrator of FIU Digital Commons. For more information, please contact dcc@fiu.edu. 


\section{FLORIDA INTERNATIONAL UNIVERSITY}

Miami, Florida

THE ROLE OF EMOTIONAL INTELLIGENCE

IN COLLEGE STUDENTS' SUCCESS

A dissertation submitted in partial fulfillment of the requirements for the degree of DOCTOR OF EDUCATION

in

HIGHER EDUCATION ADMINISTRATION

by

Joyce Walsh-Portillo

2011 
To: Dean Delia C. García

College of Education

This dissertation, written by Joyce Walsh-Portillo, and entitled The Role of Emotional Intelligence in College Students' Success, having been approved in respect to style and intellectual content, is referred to you for judgment.

We have read this dissertation and recommend that it be approved.

Glenda Musoba

Thomas G. Reio, Jr.

Joy Blanchard

Benjamin Baez, Major Professor

Date of Defense: October 27, 2011

The dissertation of Joyce Walsh-Portillo is approved.

Dean Delia C. García

College of Education

Dean Lakshmi N. Reddi

University Graduate School.

Florida International University, 2011 
C Copyright 2011 by Joyce Walsh-Portillo

All rights reserved. 


\section{DEDICATION}

I dedicate this dissertation to my parents, Ruth and Jack, whose integrity has always been my inspiration; to my family, friends and colleagues, who never failed to encourage and support me; to our son, Mario Gerardo, whose good humor has always been welcome company, and finally, to my husband, Mario José, whose belief in me has been unfailing. I am grateful to God for all the blessings in my life especially for all my companions on this journey. 


\section{ACKNOWLEDGMENTS}

I wish to express my heartfelt appreciation to Ben Baez, my Chair, for his encouragement, direction, and sensitivity. His no-nonsense cut-to-the-chase approach was a breath of fresh air during this entire process. He focused on the important matters at the right time and kept me focused on what was necessary during each step of the process. I also wish to express my gratitude to Glenda Musoba who, along with Ben, has been a wonderful and patient mentor and professor. I appreciate Thomas Reio's candor and support and Joy Blanchard's willingness to become part of the committee when needed. 


\title{
ABSTRACT OF THE DISSERTATION \\ THE ROLE OF EMOTIONAL INTELLIGENCE IN \\ COLLEGE STUDENTS' SUCCESS
}

\author{
by \\ Joyce Walsh-Portillo \\ Florida International University, 2011 \\ Miami, Florida \\ Professor Benjamin Baez, Major Professor
}

The purpose of this study was to determine if higher academic performance was positively correlated to higher emotional intelligence among traditional age male and female college students enrolled in an Introduction to Business course at a large multicampus state college in Florida. The Bar-On 2004 (Emotional Quotient Inventory) EQ-i 133-item inventory was used to assess students' emotional intelligence. Within the scope of this ex-post facto study, a quasi-experimental design was included to further determine if emotional intelligence could be increased through the inclusion of a curricular component on emotional intelligence. Four groups of students $(N=111)$ participated in the three-phase study over two semesters.

The first phase (pre-intervention) was limited to students with an established GPA and an attempted-to-completed credit hour ratio within the institution $(N=82)$. Results showed a slight positive correlation between the two factors and the students' emotional intelligence pretest assessment scores. The second phase of the study involved establishing a control and an experimental group in each of two semesters to compare the attainment of overall emotional intelligence scores as measured by the EQ-i. The third phase of the study examined four measures of academic success (GPA, the attempted-to- 
completed credit hour ratio, grade in the business course, and persistence in college) to determine if these factors were positively correlated with the students' posttest EQ-i scores. The study also included a research question to determine if significant differences in overall EQ-i scores existed between male and female students during the three phases.

Findings from the study indicated that (a) there was a slight positive correlation in the pre-intervention stage between emotional intelligence and traditional measures of academic success specifically, GPA and the attempted-to-completed credit hour ratio; (b) curricular intervention made a significant difference at the $p<.05$ level, with an .5 effect size, in one semester but failed to meet that threshold in the following semester with the second pair of groups; (c) at the post-intervention phase, the four measures of traditional academic success yielded a low positive correlation with the students' emotional intelligence assessment scores, and (d) female students showed significant gains in their overall EQ-i scores. 


\section{TABLE OF CONTENTS}

CHAPTER

I. INTRODUCTION 1

Community College Students 5

First Year College Students and Emotional Intelligence 10

$\begin{array}{ll}\text { Purpose of the Study } & 12\end{array}$

$\begin{array}{ll}\text { Delimitations } & 13\end{array}$

Research Questions 13

Definitions $\quad 15$

II. LITERATURE REVIEW 17

$\begin{array}{ll}\text { Emotional Intelligence and College Students } & 18\end{array}$

Emotional Intelligence as its Own Construct 19

Leading Theorists $\quad 22$

Emotional Intelligence and The Big Five $\quad 24$

Assessment Instruments: ECI, MSCEIT and EQ-i 26

Emotional Intelligence and Higher Education 32

Community College Students and Emotional Intelligence 39

Conclusion $\quad 42$

III. METHODOLOGY 44

$\begin{array}{ll}\text { Participants } & 44\end{array}$

$\begin{array}{lr}\text { Setting } & 48\end{array}$

$\begin{array}{ll}\text { Research Design } & 51\end{array}$

Research Instrumentation $\quad 51$

$\begin{array}{ll}\text { Three-Phase Study } & 55\end{array}$

Phase One (Pre-Intervention) 55

Phase Two (Intervention) 58

$\begin{array}{ll}\text { Phase Three (Post-Intervention) } & 65\end{array}$

$\begin{array}{ll}\text { Research Questions } & 67\end{array}$

$\begin{array}{lll}\text { IV. RESULTS } & 70\end{array}$

$\begin{array}{ll}\text { Phase One (Pre-Intervention) } & 70\end{array}$

$\begin{array}{ll}\text { Demographics for all Participants } & 71\end{array}$

Pre-Intervention of all Groups $\quad 72$

$\begin{array}{ll}\text { Phase Two (Intervention) } & 74\end{array}$

Phase Three (Post-Intervention) 82

EQ-i Pretest and Posttest Results by Gender 87

$\begin{array}{ll}\text { V. DISCUSSION } & 90\end{array}$

Discussion of Overall Findings $\quad 94$

Phase One: Summary of Findings 96

Phase Two: Summary of Findings $\quad 97$ 
Phase Three: Summary of Findings

Findings Related to Gender

100

Limitations

104

Policy and Practice

105

Implications for Future Studies

107

REFERENCES

110

APPENDICES

120

VITA

134 


\section{LIST OF TABLES}

TABLE

PAGE

1. Course Syllabus (EQ-i component) 62

2. Numbers,Gender and Mean Age of Students Participating 71

3. Pre EQ-i Scores, Pre-GPA and Pre-Attempted-to-Completed Credit Hour Ratio 73

4. Groups, Mean Pre-EQ-i Scores, SD, and Gender Breakdown 75

5. Pre and Posttest Scores for All Participants with Mean and SD and Gender 78

6. EQ-i Posttest Results, Controlling for Pre EQ-i Scores 81

7. ANOVA EQ-i Posttest between Groups 81

8. Post hoc Test (Bonferroni) 82

9. Post EQ-i Scores, Post GPA and Attempted-to-Completed Credit Hour Ratio 85

10. Paired Sample t-test Pre and Post by Gender 88

11. One-Way ANOVA EQ-i Post by Gender 89 


\section{LIST OF FIGURES}

FIGURE

PAGE

1. Number of Male and Female Participants by Age

2. Pre EQ-i and Pre GPA Scores

3. Pre EQ-i and Pre Credit Success Ratio

4. Mean Pre EQ-i by Gender

5. EQ-i Pre and Posttest Scores by Individual Groups

6. EQ-i Pre and Posttest Scores: Experimental and Control Groups

7. Post EQ-i and Post GPA Scores

8. Post EQ-i and Post Credit Success Ratio

9. Post EQ-i and Course Grade

10. Correlations of Post EQ-i Scores and Academic Factors

11. Mean Pre and Post EQ-i Scores by Gender

88 


\section{CHAPTER I}

\section{INTRODUCTION}

When the National Defense Education Act was enacted in 1958, going to college became not only a possibility, but an expectation to "to ensure the security of the Nation through the fullest development of the mental resources and technical skills of its young men and women..." (Ebert Flattau, Bracken, Van Atta, Bandeh-Ahmadi, de la Cruz, \& Sullivan, p. ES-1, 2006). Baby boomers (those born between 1946 and 1964) were raised not only to expect the opportunity to attend college, but to receive government assistance in terms of grants and financial aid and to eventually contribute to the growth and prosperity of the United States. Going to college was no longer perceived as a right for the privileged class, but one's duty to patriotism and country (Bowen, 1977; Thelin, 2004; Trow, 1989). Those young men and women, baby boomers, now have offspring of their own who have grown up in an environment of institutional choices, dynamic technology, and complex financing.

Since the 1950s, the field of higher education has become increasingly competitive and diverse (Adelman, 1999; Pascarella \& Terenzini, 2005). Students have a plethora of choices including online degree programs as well as on campus programs from highly selective 4-year institutions to open access 2-year colleges. Economic uncertainty and shifting demographics have wrought many changes in the world of higher education, especially in the last few decades. Academically competent high school seniors who may have previously enrolled in 4-year institution might now instead choose a 2-year college to secure an Associate of Arts degree before transferring to a 4-year institution. Underprepared high school graduates may also be enrolled in a 2-year 
institution taking college preparatory classes in reading, English, and math before they are deemed college-ready. Two-year institutions attract a wide spectrum of students, among them more traditional-age, academically prepared students who are also choosing to begin their college studies at a 2-year institution (Akst, 2007; Melguizo \& Dowd, 2009; Porter, 2006; Strauss \& Volkwein, 2002).

For those college bound high school seniors seeking admission at selective universities and colleges, there are at least two factors, which will be of paramount importance for acceptance to the 4-year college of their choice: a qualifying grade point average (GPA) and either competitive scholastic aptitude reasoning test scores (SAT), administered by the College Board and scored by the Educational Testing Service (ETS), or the competitive American College Testing (ACT) scores. The pressure begins to mount as early as middle school and certainly throughout any college preparatory program in high school. Although other elements, such as well-written essays, a successful interview, and an impressive resume, are supporting factors in the college acceptance process, having the academic and personal discipline to persist in a rigorous higher education program is also crucial. Students must be able to keep up academically while still managing all the other demands that come with young adulthood, including initial separation from family and friends, social pressures, as well as possibly, employment. The familiar routine of high school is replaced with the freedom of many choices. It is not only a question of having what it takes to be accepted into college, but having what it takes to persist.

Institutions of higher education have too much at stake to risk accepting students who may not be qualified, so GPAs and standardized test scores become gatekeeper 
factors when reviewing applications, and rightfully so, as a student's track record in high school has certainly borne out its correlation to on-going success in college (Astin, 1993; Pascarella \& Terenzini, 2005; Strauss \& Volkwein, 2002). It is that time-consuming, expensive recruiting and selection process that drives the most competitive universities and colleges' initial enrollment. Institutions of higher education are heavily invested in retaining those students who are admitted. However, with so much at risk and so great an initial investment, why do public colleges and universities continue to lose about 30\% (ACT, 2007a, 2009) of their students between the first and second years of college? Perhaps, the most perplexing aspect is that the dropout rates have been fairly consistent since the mid-1980s (ACT, 2007a, 2009) despite a real increase in student support services. These include First-Year Experience (FYE) seminars, Student Life Skills (SLS) courses, orientation programs, student and peer mentoring, at-risk identification programs, diversity awareness, and a host of other programs that seem to have had mixed results (Codjoe \& Helms, 2005; Coll \& Stewart, 2008; Lorenzetti, 2006; McCracken, 2008; Wartman \& Savage, 2008).

The cost of student attrition in the first year can be summed up in a number of ways: the loss of the university or college's initial investment in the student, loss of future tuition revenue for the university or college, personal potential earning loss to the student who may be relegated to a lower level entry position in the job market, and a larger cost in loss to society, which absorbs an unprepared worker (Veenstra, 2009). Student affairs deans and other college administrators are barraged with an increasing number of challenges, including less government funding coupled with a diverse student population, requiring more resources from human social services to technology training (Archibald, 
2008; Greene, Huerta, \& Richards, 2007; Misra \& McMahon, 2006; Sutherland, Hamilton, \& Goodman, 2007).

One of the most striking aspects of today's college students is that in many ways they are non-traditional, especially in the community college setting. This point was effectively presented in a 2002 report on non-traditional undergraduates, published by the U.S. Department of Education, which states:

The "traditional" undergraduate - characterized here as one who earns a high school diploma, enrolls full time immediately after finishing high school, depends on parents for financial support, and either does not work during the school year or works part time-is the exception rather than the rule. In 1999-2000, just 27 percent of undergraduates met all of these criteria. Thus, 73 percent of all undergraduates were in some way "nontraditional." Comparable data for a generation ago are not available, but the fact that much of the change in demographic characteristics and enrollment patterns described above occurred in the 1970s (U.S. Department of Education, 2002b) suggests that this is not a recent phenomenon (p.1).

College administrators have identified some of the factors that are inevitable reasons for dropping out: financial hardship, mismatched students and programs, illness, poor time management, isolation, excessive socializing, and partying. First-year college orientation programs aggressively address many of the issues identified by administrators, faculty, and student advisors to proactively deter students from falling into the precarious patterns that may lead them to withdrawal, suspension, or abandonment of their studies (Hoover, 2008; Pascarella \& Terenzini, 2005). The burden for all institutions of higher education is not only to identify poor habits and attitudes, as well as risky behaviors, for example, excessive partying and skipping classes, among others, but provide students with information and tools to raise their chances of persistence. 


\section{Community College Students}

The students who participated in this research were enrolled in a state college in an Introduction to Business course. The sample had potential for diversity in terms of academic preparation, racial and ethnic backgrounds, and program enrollment. Students included those who may have been exploring the possibility of selecting a major in business or those preparing to transfer an elective to a 4-year institution, or those just beginning their college studies without an established college track.

Community college students face even greater challenges in general compared to students attending 4-year institutions. In an atmosphere of open enrollment and lack of college readiness, students are confronted with more daunting issues, such as not being able to access many of the support services typically available on the campuses of 4-year institutions due to employment or family obligations, or even something as simple as unreliable transportation. This lack of engagement among faculty, staff, and students is one that community college administrators strive to address in a number of ways. Of the more than 900,000 community college students enrolled in Florida (Florida Department of Education, 2008), only 32\% were full time, defined as enrolled in 12 credits or more per semester. The average age of the student was 25 and minority enrollment was $60 \%$ in 2008. The average age of students at this state college is 27 , with a median age of 23 . The minority enrollment of reporting students is 70\% (See Appendix A).

Many students are not academically prepared for college work, so they must complete remediation in English, reading, and/or mathematics before beginning college level courses. The No Child Left Behind Act of 2001 has not realized its initial goals in spite of the resources that have been devoted to the initiative and many students graduate 
from high school unprepared for college level work (Giambo, 2010; Haifeng \& Cowen, 2009; Ravtich, 2009). This puts an additional strain on the community colleges in particular whose open access policy attracts less-prepared students. There is an ominous view of the lack of consistency and rigor in high school programs, thus perpetuating the need for remediation (ACT, 2007b).

The challenge to prepare a competitive workforce is further complicated by the number of immigrants and non-native speakers of English who are also entering the state colleges. Faculty, advisors, and administrators are faced with a myriad of additional challenges requiring attention, including language barriers, cultural differences, social adjustment, and familiarity with the higher education system in this country.

In addition, many adult learners, typically in the career and technical programs, are coming back to college to get higher level training and skills after having been laid off or downsized to acquire a more competitive employment profile. With an open admission policy requiring a high school diploma or a GED, state or community colleges do not have the luxury of turning away students due to lack of academic preparation. Institutions and students are required, more often than not, to commit to a program of remediation in English, reading, and/or mathematics. However, despite the perception that a state or community colleges' scope is limited to remedial or technical education, there is a also a growing segment in the student population of traditional age, 4-year degree track students who begin their college education at a local state or community college institution (Melguizo \& Dowd, 2009; Porter, 2006; Strauss \& Volkwein, 2002).

Traditional age students (18-24) may choose a community college for a number of reasons, most of which are practical realities. Community colleges provide a 
comparatively inexpensive education and students may choose to live at home and continue to work. The income may help to support themselves, and/or other family members, or to offset the cost of books, other course-related materials, software, and additional collateral expenses. There are also traditional age community college students who may also be returning to college after a failed attempt in a 4-year institution due to any number of previously mentioned reasons.

For those students who are enrolled in a traditional Associate of Art (A.A.) program with intentions of transferring to a 4-year college or university upon program completion, the success rate in terms of graduation and persistence is more optimistic. During the academic year 2007-2008 in Florida, 907,753 students were enrolled in the state's community colleges (FLDOE, 2008). Of the 86,970 degrees and certificates awarded statewide, 48,763 or $56 \%$ were conferred to A.A. candidates seeking to transfer to 4-year institutions (see Appendix B).

At the college where this research was conducted, approximately 3,000 or $60 \%$ of the students enrolled in an A.A. program completed it within 6 years. However, the majority of all certificate or degree-seeking students entering this particular community college are not "college ready," with more than $70 \%$ requiring remediation in at least one of three areas (math, reading, or English). The number of students requiring remediation is higher at this college compared to other state or community colleges in the state (See Appendix C). College administrators know that students need more academic support to be successful, but perhaps there are other non-academic factors (besides socio-economic aspects), which might contribute to student success. 
Could an awareness of emotional intelligence assist community college students with their scholarly and professional endeavors? Emotional intelligence is defined as "an array of non-cognitive capabilities, competencies, and skills that influence one's ability to succeed in coping with environmental demands and pressures" (Bar-On, 2004, p. 14). Those non-cognitive capabilities, competencies, and skills include emotional selfawareness, interpersonal skills, stress management, adaptability, and general mood.

There is very little research available on community college students and emotional intelligence; however, at least two doctoral studies have explored this population (Izaguirre, 2008; La Civita, 2003) using the same instrument for emotional intelligence assessment used for this research. LaCivita focused on 80 at-risk students in a community college; Izaguirre focused on the specific subscales and correlated those results of the assessment instrument, Bar-On 133-item 2004 Emotional Quotient Inventory (EQ-i), to specific demographic factors such as marital status. The focus proposed for this study differed in that overall emotional intelligence, rather than specific subscales, was assessed in a sample of students with varying degrees of academic preparation and readiness.

A student who is able to relate on an interpersonal basis with faculty, peers, and the college community at large will be better prepared to initiate and maintain vital interpersonal relationships while in college, and in the future, in a professional environment (Cherniss \& Goleman, 2001). A student who knows himself (herself) well enough to keep impulses in check and delay gratification, control anger, and maintain composure will probably be more successful in the classroom and beyond (Bastian, Burns, \& Nettlebeck, 2005; Bellack, 1999; Cherniss \& Goleman, 2001; Glass, 2007; 
Hamachek, 2000; Jaegar, 2004; Liptak, 2005; Shapiro, 1997; Zeidner, Matthews, \&

Roberts, 2009). A student who is able to juggle the demands and rigor that becoming a young adult entails such as striking a balance among developing independent living skills, limiting excessive personal diversion, and cultivating strong academic skills will more likely be a better student and more prepared to enter a professional working environment.

A priority in community colleges is certainly to prepare weak students in the academic realm and because so many of the community college students enter the system with the challenges already identified, it would be easy to hypothesize that without the reading, math, and English competencies in place, having emotional intelligence might not matter much anyway. The question becomes then, "What if emotional intelligence supports students in their academic pursuits?" Certainly, increased self awareness, impulse control, and problem-solving abilities could possibly translate into greater perseverance, motivation, and achievement, which hopefully would then result in a higher level of persistence and academic success. Hughes, Karp, and O'Gara (2009) state:

Offering an array of services enables community colleges to meet the varied needs of their students. The prevailing philosophy is that such services can increase student success and persistence to a degree by providing them with additional resources and opportunities that help them become integrated into the college environment (Bailey and Alfonso, 2005). In addition, providing student services can be seen as compensatory, helping disadvantaged students overcome their potential lack of information, cultural capital, or academic preparedness. Despite recognized importance of support services for nontraditional students, researchers have pointed out that the efficacy of these services has not been demonstrated. (para. 5) 
College administrators, and student affairs deans in particular, are beginning to weigh the costs and benefits of various interventions in student support services. While college administrators continue to chip away at the possible causes of student dropout, failures, or withdrawal, it may be possible that we are trying to address a deficiency that was present when the student enrolled, not after he or she began college studies. It may have nothing to do with grades or potential, but rather an emotional maturity and awareness that could support them throughout their first (and second) years of college.

\section{First Year College Students and Emotional Intelligence}

In spite of the great number of resources allocated to first year students at community colleges, no real improvement in retention has been realized in the last 2 decades (Culp, 2005; Hughes, Karp, \& O'Gara, 2009; Lipka, 2006). Although institutions of higher learning have requested and obtained a plethora of support services, the diversity of the first year college student is constantly changing in the dynamic and fast-paced environment of college admissions. Today's students present different challenges from a generation ago, or even 10 years ago, but one thing has remained constant: student dropout rates have remained fairly consistent for the past couple of decades (See Appendix D). That is a frustrating and costly reality for all concerned, including students, parents, college administrators, and taxpayers. Students who fail or withdraw from classes must pay to repeat those courses; financial aid is threatened by poor performance, and many students give up and default on loans, ultimately resulting in an additional burden for taxpayers. Colleges know that students who come in poorly prepared academically are at greater risk of failure and dropping out, but what about those who drop out who are academically prepared and "college-ready"? What if an 
additional filter were in place that could detect students who might be "at-risk" outside of the academic realm-those whose emotional intelligence might be lower in problemsolving, stress tolerance, or impulse control? Overall emotional intelligence assessment for incoming students might provide additional indicators of readiness for the complex environment of higher education.

One avenue of research that has yielded significant results in emotional intelligence has shown up in the literature in K-12 (Elksnin \& Elksnin, 2003; Morales, 2008; Obiakor, 2001; Shelton, 2003) as well as in the professional arena (Bellack, 1999; Cherniss \& Goleman, 2001; Glass, 2007; Liptak, 2005). Research on emotional intelligence and its possible significance in the traditional age college student is in its infancy.

In spite of the technological advances in the last 30 years, today's college students must still contend with aspects that technology cannot address: emotional selfawareness, interpersonal skills, adaptability, impulse control, and many other uniquely human challenges. Even academically competent students may be in jeopardy when entering college if certain aspects of emotional competence are lacking. Recent studies (Crossman, 2007; LaCivita, 2003; Parker et al., 2005; Schutte \& Malouff, 2002) suggest that students are under an increasing level of stress and their ability to manage that stress, adapt to a rapidly changing and dynamic environment while managing to keep impulse control in check are all factors that may jeopardize a first year student's successful transition to the second year of college.

Understanding emotional intelligence, using a reliable assessment of emotional intelligence, and studying the correlation of traditional measures of academic success 
such as GPA and persistence might help institutions identify students who are at risk of dropping out or failing for nonacademic reasons beyond those which have already been identified such as financial hardship. Identifying at risk students might be particularly significant at the community college where even fewer studies related to emotional intelligence have been conducted.

\section{Purpose of the Study}

This purpose of this study was to ascertain whether there is a significant statistical correlation between traditional measures of academic success (GPA, the ratio of attempted-to-completed credit hours, course grades, and persistence in college) and students' total emotional intelligence assessment scores as measured by a well documented instrument with good validity and reliability estimates: the Emotional Quotient Inventory (EQ-i) developed by Reuven Bar-On (1997). Certainly managing interpersonal relationships, setbacks, anxiety, and impulses, as well as other aspects of emotional intelligence, are all part of college life, yet very little has been studied about its correlation to persistence and academic success. The strongest predictor of academic success is prior academic success, but there is still much unexplained variance in academic success in these studies (Astin, 1993; Bar-On \& Parker, 2000; Pascarella \& Terenzini, 2005; Strauss \& Volkwein, 2002; Zeidner et al., 2009). Correlating four measures of academic success (a) GPA, (b) attempted-to-completed credit hour ratio, (c) grade in the business course, and (d) persistence in college with an assessment in emotional intelligence formed the basis for this study. It was hypothesized that greater academic success would be positively correlated with higher emotional intelligence. 


\section{Delimitations of the Study}

The students who participated in this study were commuter students at a large urban multi-campus Level-Two institution. Although there are a limited number of Bachelor's programs offered at the college, almost all students were enrolled in 2-year programs. The participants in the study were traditional age students with a mean age of 20.2 for men and 20.8 for women. The students were enrolled in an Introduction to Business course, which is an elective, and those who completed the assessment were awarded 3\% extra credit toward the overall grade in the course. The four sections were convenience samples as the professor for all four sections was also the researcher. All pretests and posttests were conducted in a laboratory setting with the supervisor of the professor. Only those students who completed the pretest and the posttest were included in the study.

\section{Research Questions}

1. Is there a significant relationship between academic success (higher GPA, higher ratio of attempted-to-completed credit hours) and pre-intervention emotional intelligence as measured by the Bar-On EQ-i?

This question generated other questions:

a. Is there a significant relationship between pre-intervention EI and GPA?

b. Is there a significant relationship between pre-intervention EI and attempted -tocompleted-credit hour ratio?

2. Is there a significant increase in emotional intelligence assessment scores after a semester-long academic intervention?

This question generated other questions: 
a. Can emotional intelligence be taught as estimated by treatment effect?

b. Are the EQ-i gains significantly different between a control group and an experimental group?

c. Can the study be replicated, as estimated by treatment effect?

3. Is there a significant relationship between academic success and post-intervention emotional intelligence as measured by the EQ-i?

This question generated other questions:

a. Is there a significant relationship between post-intervention emotional intelligence as measured by the EQ-i and cumulative GPA?

b. Is there a significant relationship between post-intervention emotional intelligence as measured by the EQ-i and course grade?

c. Is there a significant relationship between post-intervention emotional intelligence as measured by the EQ-i and attempted and completed course credits?

4. Is there a significant relationship between gender and emotional intelligence as measured by the EQ-i?

This question generated other questions:

a. Which gender has higher pre-intervention emotional intelligence?

b. Which gender has higher pre-intervention emotional intelligence in the experimental group?

c. Which gender has higher pre-intervention emotional intelligence in the control group?

d. Does intervention have a greater impact on either gender's results? 
e. Are the gains more significant for male or female students post-intervention?

\section{Definitions}

Academic persistence is continuous enrollment from semester to semester toward graduation, as reported by the college Registrar.

Attempted credit hours are the credit hours for which the student registered and received a grade from " $\mathrm{A}$ " (4.0) to "F" $(0.0)$ or a "W" for withdrawal.

Academic success is achieving a minimum average grade of a 2.0 ("C") on a grading scale of 4.0 (“A”).

ACT is the standardized test, which began in the 1950s as the American College Testing Program (now administered by the College Board and scored by Educational Testing Services) and used to determine high school students' academic preparation. Bar-On EQ-i is the 133-item self-reported assessment of emotional intelligence designed by Reuven Bar-On 2004.

Completed credit hours are the number of hours reported by the college registrar for which the student enrolled at the local institution and received a passing grade from "A" (4.0) to "D" (1.0) without consideration of transfer credits from previous institutions Emotional intelligence (EI) is "an array of non-cognitive capabilities, competencies, and skills that influence one's ability to succeed in coping with environmental demands and pressures" (Bar On, 2004, p. 14); the definition for the EQ-I 133-item self-assessment instrument used in this study.

Emotional Quotient (EQ) is used indistinctly in the field for emotional intelligence.

Fall semester is a 16-week semester from August to December. 
Forgiveness policy allows students to repeat a course in which they received a "D" or an "F" and calculates the higher final grade into the GPA, removing the arithmetic impact of the original grade.

Gender is self-identified descriptors as "male" or "female".

Grade in the course is a final grade earned by the student in the Introduction to Business course, a 3-credit elective course for business and non-business majors.

$G P A$ is cumulative grade point average, on a scale of 0.0 to 4.0 as reported by the college registrar, with no forgiveness factored in for repeated courses.

Introduction to Business course is a 3-credit hour elective course for Business and non-Business majors.

Level-One Institution may award a two-year, or an Associate degree.

Level-Two Institution may award a four-year or a Baccalaureate degree

Multi-Health Systems (MHS) is the license-holder for the EQ-i and firm responsible for the processing of assessment results.

Multi-Health Systems certified counselor is a researcher or psychologist who has completed the certification process administered by MHS to apply the EQ-i and interpret the results for test-takers.

Spring semester is a 16-week semester from January to May.

Traditional-age students are students who attend college upon completion of high school studies, a GED (graduation equivalency diploma) or after a few years of employment, averaging from 18-24 years old. 


\section{CHAPTER II}

\section{LITERATURE REVIEW}

Research in the area of academic success has shown that students with higher emotional intelligence scores also tend to be more successful academically (Parker et al., 2005; Vela, 2004; Walker, 2006). There has been much research done regarding the student's GPA as a predictor for retention in the freshman year (Debarard, Spelmans, \& Julka, 2004). Although academics may occupy a central role in preparing students for college, there are other less-studied factors, which might also contribute to student success, retention, and ultimately, graduation rates. High school preparatory programs are often solely focused on the student's GPA and SAT scores and may fail to recognize the possible impact that emotional intelligence has on students once they have reached college.

Emotional intelligence is a relatively new construct though many of its earlier definitions, particularly social intelligence, have been around for more than a hundred years. In 1909, Dewey stated that

Ultimate moral motives and forces are nothing more or less than social intelligence the power of observing and comprehending social situations-and social power-trained capacities of control at work in the service of social interests and aims. (Landy, 2006, p. 43)

Dewey identified that without the ability to understand and accurately interpret motivation in social settings, society would suffer. This particular writing reveals Dewey's concern with the curriculum (Zeidner et al., 2009). Edward Thorndike, a prominent psychologist, wrote in 1920, "Social intelligence is ability distinct from abstract intelligence, defining it as 'the ability to manage and understand men and women, boys and girls, to act wisely in human relations" (Zeidner et al., 2009, p. 6). 
Some studies have suggested that perhaps women are more likely to have emotional intelligence in areas of "empathy, awareness of the feelings of others, and coping with stress through 'tending and befriending', all components central to emotional intelligence" (Zeidner et al., 2009, p. 20). Perhaps female college students have an advantage resulting in greater persistence and overall success in school. The challenge to determine whether emotional intelligence and gender are correlated has had mixed results in previous studies (Izaguirre, 2008; Jaeger \& Eagan, 2007; Parker et al., 2005).

\section{Emotional Intelligence and College Students}

Only in recent years have there been various publications on the impact of emotional intelligence on college students (Bellack, 1999; Elder, 1997; Jaeger, 2003, Liptak, 2005; Ramos-Sanchez \& Nichols, 2007), including doctoral studies (Feldman, 2003; Holt, 2007; Vela, 2004, Walker, 2006; Westphal, 2007), showing a positive correlation between academic success and higher emotional intelligence. There are, however, very few studies of emotional intelligence in community college students. One small study examined emotional intelligence related to at-risk students (La Civita, 2003). Another study (Izaguirre, 2008) found that the research did not support the existence of a relationship between overall emotional intelligence and GPA, but some aspects of emotional intelligence did bear a significant relationship with higher academic achievement.

Community college students typically have more academic challenges than students admitted to 4-year institutions. Many are unprepared in reading, mathematics, and English, so remedial courses are part of the entry level curriculum of all community colleges as faculty and administrators strive to bolster students' preparation for college- 
level work. Community college students are also admitted in an open door environment and students are tested for appropriate academic levels, either remedial or preparatory, depending on a number of factors including previous secondary studies, native language, previous college experience, first time in college, and first generation in college, among others.

\section{Emotional Intelligence as its Own Construct}

Psychologists in particular recognized that successful human interactions and endeavors were not solely a product of academic prowess or IQ, but a result of using general intelligence along with other skills or abilities. Throughout the 20th century, identifying and framing what those other skills or abilities were has challenged scholars. In 1983, Howard Gardner published Frames of Mind addressing the possibility that intelligence not only be measured for abstract reasoning or $g$, general intelligence, but for a number of other possible areas of competency, including interpersonal and intrapersonal awareness, musical or mathematical ability, spatial, word, naturalist, or kinesthetic aptitude.

The real breakthrough in the general public's awareness of emotional intelligence as a separate construct came as result of Daniel Goleman's 1995 book, Emotional Intelligence, which remained on the New York Times bestseller list for more than a year (Haws Publications, n.d.), sold over five million copies, and is available in 40 languages. That exposure created mass appeal as readers from school administrators to corporate executives hoped to tap into this transformative paradigm and effect positive change in what seemed to be every aspect of human existence. The original furor and unbridled enthusiasm has subsided as the field has matured and exposed what other researchers had 
been doing in the field of emotional intelligence 10 to 15 years before Goleman's bestseller was published.

Some years later, researchers are also able to more effectively separate the serious research from pop culture. Emotional intelligence is an appealing concept and subscribing to its apparent virtue is easy. As a matter of fact, many see it as a handy answer to why smart students fail or why average students thrive. Initially, it did seem to be a panacea, but 15 years after Goleman's publication (1995), serious researchers such as Zeidner et.al (2009) have emerged to state that there is substance beyond the touchyfeely appeal of emotional intelligence. It is not as easy to define and operationalize as was once thought; even within the realm of academic and scientific research, the major theorists have important differences.

So, how do admissions officers, advisors, and parents of college-bound students determine readiness for college beyond their academic profile and test results? Once students have been deemed college-ready based on their high school GPA and SAT/ACT scores, interviews, and applications, how do admissions officers determine which of these students are likely to persist and succeed in college? Even in the case of open access at the community colleges, those scores and results are often used in the community college as well for admission to the Honors Institute or Phi Theta Kappa.

Historically, there have been numerous publications that examine the reasons why students do not persist in college (Astin, 1975, 1993, 1999; Bean, 1980, 2003; Hu \& St. John, 2001; Ishitani, 2006; Johnson 1997; Longwell-Grice \& Longwell-Grice, 2007; Lufi, Parish-Plass, \& Cohen 2003; Pascarella \& Terenzini, 2005; Tinto, 1987). Tinto's (1987) Leaving College examines four individual aspects of which he identifies as "roots 
of individual departure" (p. 47) and those factors are adjustment, difficulty, incongruence, and isolation. These four factors may be related to emotional intelligence.

Research shows that approximately $30 \%$ of those "academically ready" students will not persist to the second year of college (ACT 2007a, 2009). The cost on all fronts (financial, emotional, and public) is enormous, and there may be an aspect that has not been considered in terms of retention from first to second year. The answer may lie in the assessment of students' emotional intelligence. Certainly, the number of studies in many fields relating an emotional intelligence component has increased exponentially since the publication of the best seller, Emotional Intelligence (Goleman, 1995). In his book, Goleman states:

My concern is with a key set of other characteristics, emotional intelligence: abilities such as being able to motivate oneself and persist in the face of frustrations; to control impulse and delay gratification; to regulate one's moods and keep distress from swamping the ability to think; to empathize and to hope. Unlike IQ, with its nearly one-hundred year history of research with hundreds of thousands of people, emotional intelligence is a new concept. No one can say exactly how much of the variability from person to person in life's course it accounts for. But what data exist suggest it can be as powerful, and at times, more powerful, than IQ. (p. 34)

The idea that anyone of any intelligence level has a chance to be recognized in a realm that was previously less acknowledged, or rewarded, is certainly appealing to the great majority of people watching their intelligent and acclaimed peers garner the admiration of, and subsequently receive, a status of privilege from teachers, administrators, supervisors, and the community at large. Determining whether there is any substance to the field of emotional intelligence and its usefulness in the realm of traditional age community college students is the focus of this study. 
Chickering (1993) identified managing emotions as one of the seven vectors in college student development. In Pascarella and Terenzini (2005), Chickering's vector is further described as follows

Students of any age must recognize and wrestle with emotions that can interfere with the educational process, including "anger, fear and anxiety, depression, guilt, shame and dysfunctional sexual or romantic attraction (Reisser, 1995). Development occurs when students learn to control impulses and to develop appropriate responses (both immediate and long-term) for handling intense, potentially disruptive emotions. (p. 21)

Emotional development has been of interest to researchers throughout the 20th century.

"Emotional intelligence is a relatively new and growing area of behavioral investigation; having matured recently with aid of lavish international media attention" (Matthews, Zeidner, \& Roberts, 2002, p. 3). There is tone of suspicion in this quote as these authors' critical eye explore whether or not emotional intelligence is indeed a science or a myth, a science that can be validated by outside measurements and existing research or a myth that allows many to feel better about themselves, their children and their colleagues. The research that Matthews et al. present is extensive, balanced, and fair. The authors provide a crucial objective third party validation of the research, measurements, and publications on this new field of emotional intelligence.

\section{Leading Theorists}

John Mayer of the University of New Hampshire and Peter Salovey of Yale University are recognized as pioneers in this developing field. In the introduction to Key Readings on the Mayer and Salovey Model (Salovey, Brackett, \& Mayer, 2004), the authors share their excitement and as well as their concern for this relatively new field:

Research on EI is still in its beginnings stages. After all, it was introduced to a broader psychological audience just 13 years ago, and reliable and valid measures of the construct have only been used in scientific investigations for about 5 years. 
The most widely used scales of analytic intelligence (IQ), the Wechsler Intelligence scales, are the product of almost 100 years of clinical assessment and research. Therefore, there is much to be learned about EI and the fate of EI is, in phase, in the hands of educators, theorists and investigators who will explore the topic in greater detail. (p.iii)

One argument against emotional intelligence questions whether parents, educators, and the public in general are looking for a justification to introduce a feel-good fad for educational and professional settings. Much like the reaction to The Bell Curve:

Intelligence and Class Structure in American Life (Herenstein \& Murray, 1994), which "argued for the importance of intelligence in understanding social class in modern societies" (Matthews et al., 2002, p. 6) and whose authors implied that citizens of higher economic and social status were indeed more intelligent, Goleman (1995) may have set off a firestorm by "implying that emotional intelligence served as an egalitarian rebuttal to Hernestein and Murray's arguments." He goes on to say, "in contradistinction to IQ, EI was believed to offer much hope for individuals characterized by low levels of cognitive ability" (Matthews et al., p. 7).

Although Goleman (1995) was certainly successful in popularizing the idea that there may be more to the success equation beyond raw intelligence in an educational or professional setting, the term emotional intelligence was actually used 5 years earlier, in published studies by Mayer and Salovey (1990) for the first time. Goleman has been criticized for oversimplifying the definition of emotional intelligence. Zeidner, Matthews, and Roberts (2009) state that "The ECI (Emotional Competence Inventory) then assesses competence rather than EI, for which Goleman fails to provide an independent measure" (p. 14). Goleman has nonetheless been very effective in getting not only the attention of the general public, but educational researchers as well. 
Academicians have been reluctant to fully recognize or embrace Goleman's work as either real or legitimate in the fields of Psychology or General Education.

Critics (Matthews et al., 2002) state that "Goleman's empirical research, in collaboration with Boyatzis and others, seems to lag that of other researchers on the assessment of EI, though it may represent a promising future development" (p. 13). Invariably, however, serious researchers subject to peer-review cite Goleman $(1995,1998$, 2002) in their studies when conducting any kind of study related to emotional intelligence (Bar-On, Maree, \& Elias, 2007; Lufi, Parish-Plass, \& Cohen, 2003; Matthews et al., 2002; Nelson \& Nelson, 2003; Parker et al., 2005; Reiff, Hatzes, \& Bramel, 2001; Schutte \& Malouff, 2002).

In addition to the pioneers, Goleman (1995,1998, 2002), Bar-On (1997, 2000, 2004, 2007) and Salovey and Mayer (1990, 2004), many other researchers have recognized emotional intelligence as its own construct warranting serious consideration. Numerous studies tying emotional intelligence and research in higher education have begun to take hold just in the last few years (Berenson, Boyles, \& Weaver, 2008; Crossman, 2007; Jaeger \& Eagan, 2007; Parker et al., 2005). This trend, however, has not been without its critics, skeptics, and naysayers either (Ciarrochi, Chan, \& Caputi, 2000; Day \& Carroll, 2007; Schulte, Ree, \& Carretta, 2004; Van Rooy, Viswesvarab, \& Pluta, 2005).

\section{Emotional Intelligence and The Big Five}

One of the biggest criticisms of the emotional intelligence construct is that abilities or competencies measured seem to overlap the Big Five Personality dimensions (Ridgell \& Lounsbury, 2004; Schulte et al., 2004; Van Rooy et al., 2005) introduced by Thurstone in 1933 ("Thurstone, Louis Leon"). The five dimensions include openness, 
conscientiousness, extraversion, agreeableness, and neuroticism. The NEO Personality

Inventory-Revised (Costa \& McCrae,1985) is based on this construct:

It is based on decades of factor analytic research with both clinical and normal adult populations. The five domains measured by the instrument provide a clear and concise description summarizing and individual's emotional, interpersonal, experiential, attitudinal and motivational styles. (para. 2)

According the website Psychological Assessment Resources(2008), there are limitations

to the Big Five in the following aspects:

There are limitations to the scope of Big Five as an explanatory or predictative theory. It is argued that the Big Five does not explain all of human personality. The methodology used to identify the dimensional structure of personality traits, factor analysis, is often challenged for not having a universally-recognized basis for choosing among solutions with different numbers of factors. Another frequent criticism is that the Big Five is not theory-driven; it is merely a data-driven investigation of certain descriptors that tend to cluster together under factor analysis. The Big 5 was opposed by some researchers in psychology, such as situationists who emphasize the importance of context on personality rather than fixed personality traits. Other emphasize the interaction of the traits and context specific factors in determining personality. (para. 4)

There does seem to be some overlap between emotional intelligence constructs and The Big Five, certainly in the areas of interpersonal and motivational tendencies. Zeidner, Matthews and Roberts, (2009, p.184-5) have identified that there is duplicate testing but have not gone as far as to say that The Big Five is attempting to measure the same attributes as the emotional intelligence constructs. However, the authors of emotional intelligence constructs, Reuven Bar-On (2004) in particular, emphatically state that the EQ-i is not a personality test. "It is important to stress that the EQ-i was developed to measure this particular construct and not personality traits or cognitive capacity" (McCrea, 2000, p. 364). 


\section{Assessment Instruments: ECI, MSCEIT and EQ-i}

There is much debate regarding emotional intelligence from its definition to its significance in the realm of educational research.

Currently the pendulum has swung toward a view that the intellect has been overvalued, at the expense of emotions leading to lack of self-understanding and impoverished shallow relationships. Thus the interest generated by the current EI construct is phase of the current zeitgeist of modern Western society, which is increasingly recognizing the importance of emotions. (Matthews et al., p. 8)

For Matthews et al. (2002), “Goleman's conceptualization of EI and its biological and psychological roots appear at present to be too open-ended and loosely specified to constitute a good scientific theory, although in the future, it may develop to the point of being empirically testable" (p. 15).

The basis for further study has certainly been laid out. Goleman, along with two other researchers, Boyatzis and Rhee, have grouped emotional intelligence attributes into four groups of competencies within four major categories, including self-awareness, selfmanagement, social awareness, and social skills (Boyatzis, Goleman, \& Rhee, 2000, p.

243). These clusters and particular competencies are grouped in the theoretical and empirical clustering of competencies in the emotional intelligence model known as the Emotional Competence Inventory (ECI). "The ECI is a multirater instrument that provides self, manager, direct report and peer ratings on a series of behavior indicators of emotional intelligence, based on the emotional competencies identified by Goleman" (Matthews et al., 2002, p. 215).

Matthews et al. (2002) point out that "commercialization of the inventory through the Hay/McBer Group is a high priority and there may be a perception that the scales might be compromised with this information" (p. 215). One of the biggest challenges for 
the ECI in the academic community is the lack of "convergent or discriminate validity" (p. 217). Matthews et al. concluded their evaluation of the ECI stating,

Considering it assesses so many disparate concepts, it is likely that the ECI will have some utility. Even here, however, reliability is a cause for concern, as is the fact that more sophisticated techniques exist for assessing constructs comprising it. In sum, it is difficult not to be cynical of this measure, given the lack of publicly assessible data supplied by its creators and the constellation of old concepts packaged under its new label. (p. 218)

In summary, although there seems to be something worthwhile to consider in the realm of emotional intelligence, there is also a series of issues surrounding the ECI that challenge researchers, including a possible conflict of commercial interest and a lack of demonstratable results as evaluated by the academic community at large.

Mayer and Salovey, highly respected in the field of emotional intelligence research, are responsible for first using the term "emotional intelligence," in 1990 in published studies, although the term itself first appeared in an unpublished study in 1986 (Payne). Goleman's (1995) publication of his book by the same name 5 years after Mayer and Salovey may have initially misled readers and the public that this construct and research was his. Goleman brought considerable attention to the field and openly acknowledged fellow researchers, particularly, Mayer and Salovey, for laying the groundwork.

The Mayer-Salovey-Carruso conceptualization of EI (2000) has been "the most influential in its scientific genesis" (Matthews et al., 2002, p. 16). These researchers were the first to publish in peer-reviewed psychological journals in 1990 and their research became one of the foundations of Goleman's book in 1995.

Work on EI is as an outgrowth of two areas of psychological research that emerged toward the end of last century. In the 1980's, psychologists began to examine how emotions interact with thought and vice versa (e.g. Bower, 1981; 
Isen, Shalker, Clark \& Karp, 1978; Zajonc, 1980). (...) At the same time, there was a gradual loosening of the concept of intelligence to include a broad array of mental abilities rather than a monolithic "g" (e.g., Cantor \& Kihlstrom, 1987; Gardner, 1983; Sternberg, 1995). (Salovey et al., 2004, p. i)

Salovey and Mayer (1990) described the conceptualization of emotional intelligence by dividing it into three broad categories: Appraisal and expression of emotion (which includes verbal and non-verbal in self and non-verbal perception and empathy in others); regulation of emotion (includes in self and in others); and utilization of emotion (includes flexible planning, creative thinking, redirected attention and motivation). They define emotional intelligence as "the subset of social intelligence that involves the ability to monitor one's own and others' feelings and emotions to discriminate among them and to use this information to guide one's thinking and actions" (Salovey \& Mayer, 1990, p. 5).

Ten years later, Mayer, Salovey, and Caruso (2000) developed their own performance based assessment instrument called the Mayer-Salovey-Caruso Emotional Intelligence Test (MSCEIT). The authors describe its function as "operationalizing the four branch model of EI" (Salovey et al., 2004, p. ii). In their key readings on the Mayer and Salovey Model, the authors seek to distinguish their original conceptualization from other constructs. Their work has been both a blessing and a curse to the field of psychology because the reader and researcher must separate the scholarly research from the pop psychology of emotional intelligence that is ubiquitous.

Arguing that other conceptions of EI are misleading, these researchers suggest that their specific use of the term stresses the concept of an intelligence that processes and benefits from emotions. From this perspective, EI is composed of mental abilities, skills or capacities. They have developed an extensive conceptual model. (Matthews et al., 2002, p. 17) 
Mayer, Salovey, and Carruso (2000) present their conceptual model within the framework of an intelligence system, rather than limiting it to the emotional clusters or competencies as defined by Boyatzis, Goleman and Rhee (2000) and Bar-On (2000). "According to Mayer \& Mitchell (1998), an intelligence system consists of a capacity for inputting information and a capacity for inputting information and a capacity for processing information, through both immediate manipulation of symbols and reference to expert knowledge" (Matthews, et al., 2002, p. 17).

Mayer, Salovey and Carruso (2000) purport that "EI cuts across the cognitive, and emotional systems and is at one time unitary and multidimensional, being subdivisible into four branches: emotional perception/identification, emotional facilitation of thought, emotional understanding and emotional management" (p. 17). The MSCEIT is an abilitybased assessment and unlike the other two instruments discussed here, it is not a selfreport assessment. The MSCEIT is designed to measure the four branches of EI as defined by its authors (Mayer, Salovey \& Caruso, 2000): emotional perception (identifying emotions in faces, designs, music and stories), emotional facilitation (translating feelings and using emotions to make judgments), emotional understanding (defining emotions, complex emotional blends, emotional transitions and emotional perspectives), and emotional management (managing one's and others' emotions).

Another leading researcher in the field of emotional intelligence is Reuven BarOn $(2000,2004)$, who "has constructed the first commercially available operational index for the assessment of EI" (Matthews et. al, 2002, p. 15). The authors state "Bar-On's conceptualization of EI is not that far removed from Goleman's in that he appears to invoke clusters of established personality traits" (p. 15). Bar-On (1997) defines 
emotional intelligence as "an array of non-cognitive capabilities, competencies, and skills that influence one's ability to succeed in coping with environmental demands and pressures" (p. 14).

Bar-On reports a series of validation studies that are quite impressive in scope. The EQ-i has been normed in a large, diversified North American sample $(\mathrm{N}=3,831)$ and the scales seem to be statistically reliable in North American and other samples worldwide. There is also some evidence from single studies that the EQ-i predicts other criteria, such as academic success in university students, presence in clinical disorders and a response to alcoholism. (Matthews et al., p. 16)

Bar-On's EQ-i assesses five broad subtypes of EI. It is interesting to note that Bar-On is also compelled to group competencies or traits.

The first is intrapersonal intelligence, which is composed of emotional selfawareness, assertiveness, self-regard, self-actualization, and independence. The second is interpersonal intelligence, which includes empathy, interpersonal relationship, and social responsibility. The third higher-order construct of the EQ-i is adaptability, which divides into problem solving, reality testing, and flexibility. Fourth is stress management, which comprises stress tolerance and impulse control. Finally, the EQ-i contains measures of general mood, which is composed of happiness and optimism. (Matthews et al., 2002, p. 15)

Boyatzis, Goleman, and Rhee's (2000) (ECI) as well as Bar-On's (EQ-i) $(2000,2004)$

models assess abilities and competencies that are, in many cases, identical in name. The difference, according to Matthews, Zeidner and Roberts (2002), is Bar-On's ability to demonstrate the validity of his construct. Bar-On (2007) states,

The development of the EQ-i proceeded in six phases over a period of 17 years: (i) identifying and logically clustering various emotional and social competencies, skills and facilitators thought to impact human performance and psychological well-being based on my clinical experience and review of the literature; (ii) clearly defining the individual key clusters of competencies and skills that surfaced; (iii) initially generating approximately 1,000 items based on my clinical experience, review of the literature and on input from experienced healthcare practitioners; (iv) determining the inclusion of 15 primary scales and 133 items in the 1997 published version of the instrument based on a combination of theoretical considerations and statistical findings generated primarily by item analysis 
and factor analysis; (v) initially norming the final version of the instrument on 3,831 adults in North America in 1996; and (vi) continuing to collect data, norm and validate the instrument across cultures around the world which is an ongoing endeavor. (http://www.reuvenbaron.org/) One difference in the three leading instruments is identified in the research literature as ability-based or trait-based emotional intelligence. The MSCEIT is a traitbased measurement, as opposed to the ECI, which has been identified as a mixed model (Matthews et al.2002, p. 12) or the EQ-i, which is an ability-based measurement. The Boyatzis, Goleman and Rhee (2000) ECI model is derived from the earlier research of Salovey and Mayer (2000), as is the Bar-On (2000) EQ-i model. All theorists recognize the need for grouping concepts by type of ability, trait, or competency, and all seem to agree that these competencies play a role in personal and psychological development of an individual.

A significant difference between the MSCEIT and the other two assessments is that it is not self-reported. While the ECI and EQ-i are self-reports, which certainly has its limitations (Derkson, Kramer, \& Katzko, 2002), the MSCEIT is scored according to how participants assess a number of situations. The MSCEIT includes visual assessments and participants are asked to interpret what they see. What is striking is that all three constructs have groupings of traits or abilities into very similar semantic descriptions. Nearly all of the current literature on emotional intelligence that appears in peer-reviewed journals in the fields of college student development and counseling (Hamachek, 2000; Hernon \& Rossiter, 2006); education (Berenson, Boyles, \& Weaver, 2008; Coll \& Stewart, 2008; Kingston, 2008; McCracken, 2008; Shapiro, 1997); business and computing (Ashkanasy \& Dasborough, 2003; Bélanger, Lewis, Kasper, Smith, \& Harrington, 2007; Cherniss \& Goleman, 2001; Daus \& Ashkanany, 2005; Goleman, 
1998, 2002; Lorenzetti, 2006), and nursing (Bellack, 1999; Glass, 2007; Radcliffe, 2007;

Young-Ritchie, Laschinger, \& Wong, 2007), among others cite one, or all three, of these theorists in their studies.

\section{Emotional Intelligence and Higher Education}

Why do some students seem better-equipped to handle the dynamic world of higher education while others seem to struggle? The research may lead to the development of a profile of an emotionally intelligent student who is more likely to persist beyond the first year of college and successfully persevere through the many challenges of college when a high IQ or competitive test scores may not be enough. Those same skills, once proven to be effective contributors to college success, could be woven into the curricula of discipline and non-discipline related courses that support students both in career and technical fields, such as nursing and law enforcement, as well as those pursuing traditional 4-year degrees such as engineering, business, and social sciences.

There has been a notable increase in the number of dissertations both in the community colleges as well as 4-year institutions dedicated to the field of emotional intelligence and college student success in recent years (Feldman, 2003; Holt, 2007; Izaguirre, 2008; LaCivita, 2003; Vela, 2004; Walker, 2006; Westphal, 2007). There have also been published articles on this same topic questioning whether emotional intelligence can be linked to academic success in college (Bastian, Burns, \& Nettlebeck, 2005; Buckhold, 2001; Elder, 1997; Freudenthaler \& Neubauer, 2005; Roberts, Zeidner, $\&$ Matthews, 2001). There are at the same time also serious concerns about the construct's validity as evidenced by other researchers (Barchard \& Christensen, 2007; 
Krus \& Helmstadter, 1987; Livingstone \& Day, 2005; Roberts et al., 2001). Despite these concerns, there seems to be growing support for the possible application of emotional intelligence assessment in the field of higher education.

Researchers are interested in linking emotional intelligence assessments to a number of factors including academic performance, freshman GPA, ethnicity, gender, and learning disabilities among others as an additional dimension worthy of consideration in student success. Academic success is measured in terms of end-of-course grades, which are compiled to compute the student's GPA. Identifying students with lower emotional intelligence might help advisors and admissions officers take a more proactive, rather than reactive approach, in student admission and advising, as well as in the design of student success courses. Even a small increase in retention would result in enormous financial savings, not to mention the obvious other benefits that retention would bring to all stakeholders.

A study of first year college students and emotional intelligence (Castro-Johnson, \& Wang, 2003) sought to identify the levels of emotional intelligence between an Honors-student population and non-Honors peers and determine whether those measures were predictive of first semester college GPAs in addition to the traditional predictors of high school GPA and SAT scores. The authors chose a widely used instrument, MCSEIT, for their sample. One hypothesis was to dispel the notion that academically gifted students were less competent in the realm of emotional intelligence than their nonHonors peers. The study included 300 Honors students and 230 non-Honors students. The average SAT score for the Honors students were more than 200 points higher than the non-Honors students. The mean scores for both groups respectively were 1291.39 
and 1089.91. The average GPA for the Honors students was 4.28 compared to the nonHonors students' GPA of 3.67. Honors students achieved an overall mean GPA of 3.40; non-Honors students achieved a mean GPA of 3.25. The interesting aspect of this comparison is that the women Honors students had a higher mean GPA of 3.38 compared to the men whose mean GPA was 3.27 .

The authors concluded that gender was a significant factor in both groups. "In line with the results reported by Schutte et al (1998), we also found that women had higher overall levels of EI than men" (Castro-Johnson, \& Wang, 2003, para. 24). They go on to say "none of the EI measures was predicative of first-semester college GPA in nonHonors students." They also concluded that the Honors students' adaptive behaviors, such as dealing with test anxiety and thus preparing more for the test, support their academic endeavors, whereas non-Honors students are not as adaptive therefore producing poorer results in terms of test scores. "This suggests that Honors students are able to effectively use their emotions (Branch 2 scores) in ways that promote academic success" ( Castro-Johnson, \& Wang, 2003, para. 36). Another claim made in the conclusions section stated "The fact is that Honors students function at a higher level of emotional intelligence than their non-Honors peers" $(2003, \uparrow 25)$. The authors conclude by stating that "Honors programs that have freshmen orientation seminars and residence life activities should take advantage of their students' high level of emotional intelligence when fostering an Honors sense of identity and community” (2003, ๆ 26).

Castro-Johnson, \& Wang (2003) pointed out that either instrument can be used to state what the authors hypothesized from the incipient stages of their research. It is possible that the authors may have been biased in favor of the Honors students, beginning 
with the way the test was made accessible to the students (Honors: in booklet form during a required Honors freshmen symposium, whereas Non-honors students received the test during a Psychology class in booklet form or via the Internet, as an extra credit opportunity). The Honors students were already held in high regard and that sense of inclusion proven in the Hawthorne studies (Elton Mayo's research at Chicago's Western Electric Plant from 1927-1932) showed that recognition and involvement have a direct impact on motivation.

The Honors' group understood the impact of their participation (Castro -Johnson $\&$ Wang, 2003). The non-Honors group was smaller and was doing an extra credit assignment. To conclude that Honors students (defined only by higher SAT scores and GPAs) are more emotionally intelligent based solely on the Castro-Johnson, \& Wang study may be problematic.

In Walker's (2006) study, 1205 undergraduate students, at a 4-year research intensive university were given the Bar-On EQ-i: Short. This brief version is 51-item self reported assessment: a shorter version of the EQ-i. Walker reports that all students took the test as first-year students, during orientation in a non-regulated location throughout campus during the 4-day orientation program. Walker examined correlations between emotional intelligence and gender, ethnicity, ACT scores, GPA, number of terms completed, and number of hours failed within the first four semesters. Students were originally recruited in $2000(N=870)$ and $2001(N=944)$ and asked to complete the EQ-i short form (Bar-On, 2000). The 51-item version (short form) "renders only the total EQ score, the five composite scale scores, the Positive Impression Scale score and 
Inconsistency index. The five composite scales are intrapersonal, interpersonal, stress management, adaptability and general mood" (Bar-On 2004, p.6).

Thirty-two months after first completing the EQ-i short form, 200 students who were still attending the university were contacted at random and asked to participate in a follow up study on "personality and academic success" (Walker, 2006, ). Walker reports there is "indeed a significant relationship between emotional intelligence and academic success in college"(p.1). The results of the follow up study indicate that "the overall pattern of results suggests that the improvement of EI-levels in the present study was more than can be attributed to increased age" (p. 18). All composite areas tested, with the exception of the Interpersonal composite group (includes empathy, social responsibility, and interpersonal relationships), improved significantly from Time 1 to Time 2.

In Nelson and Nelson's (2003) work, the authors examined 165 students' emotional intelligence and discovered that the emotional skills of time management, goal achievement, and assertive communication were significant factors in freshmen achievement and retention.

Another study, (Parker et al., 2005, p. 67-78) had two goals as expressed by the authors, which were "to examine the long term stability of EI-related abilities over several years-something that had yet to be reported in the literature. A second goal was to examine the impact of a major life-transition (the transition from high school to university) on emotional intelligence levels." This sample included 238 young adults (47 men and 191 women) attending a small Ontario university. All students were traditional age $($ mean age $=19.17)$, having graduated from high school in the previous 2 years, and 
all were full time students. Ninety-three percent of the participants identified themselves as White. The authors also acknowledge that there are factors, including the persistence in a program, as well as gradual maturation, which may account for this improvement. "It is unclear, for example, whether, the documented change in EI is phase of a gradual maturation process that occurs in most adults, or a statistical artifact of collapsing data from various cohorts at different stages of important life-transitions" p. 20).

Although the study (Parker et al., 2005) approaches the research question of the role of emotional intelligence in traditional age college students, several aspects are troubling. Ninety three percent of the Time 2 participants were White (Caucasian) college students. That limits the ability of the authors to make conclusions about all college students' emotional intelligence because cultural background and racial identity may also play a phase in a student's level of emotional intelligence. No comparison was made between the White and non-White participants.

The sample was overwhelmingly represented by females by a 4:1 margin (Parker et al., 2005). Gender may also play a role in one's level of emotional intelligence in some of the composite areas tested. The third area, which is troubling, is the fact that the researchers relied on the 51-item version rather than the 133-item version of the Bar-On EQ-i test, which measures the subscales (15) of the five principle areas tested. Finally, the authors acknowledge relying on other studies they themselves conducted to validate or reinforce their findings.

A study completed at the Department of Adult, Community College, and Higher Education, North Carolina State University (Jaeger, 2003), focused on graduate students and examined the possibility of introducing an emotional intelligence component in the 
curriculum of public administration. The researcher used the Bar-On EQ-i (133-item), which is the same instrument in this study. Although the population is graduate students, the design of the study is very similar to the one proposed in phase two of this research. Jaeger's study presented an opportunity to explore the relationship between emotional intelligence competencies and academic skills in college students.

That research indicated two critical findings:

- Emotional intelligence can be improved through instruction in a classroom setting.

- Emotional intelligence is positively correlated with academic performance.

The author did not intend to suggest that evidence of a behavioral change was identified in the study. Significant changes in knowledge of emotional intelligence did occur, which may or may not lead to behavioral changes. Students at different levels of college studies may benefit from the awareness of emotional intelligence and its possible role in their academic success. Jaeger noted that research in the field of emotional intelligence and its personal impact on students' own emotional intelligence is in its infancy and there are few published studies. Jaeger's results indicate that exposure to emotional intelligence through the curriculum did raise the students' own emotional awareness and there did seem to be link to academic achievement.

Since limited empirical research has focused on emotional intelligence in the collegiate environment, this study is only the first step in what is necessary to determine whether there is evidence of an important role for emotional intelligence in graduate professional education. (Jaeger, 2003, p. 636) 


\section{Community College Students and Emotional Intelligence}

Perhaps, traditional age college students in a community college setting will also benefit from an awareness of and instruction in emotional intelligence in an introductory course aimed at first and second year college students. This study also incorporates similar strategies of teaching emotional intelligence by incorporating a number of readings, discussion topics, and film into the curriculum. The invention in the treatment groups was hoped to yield statistically significant results. Although the populations are different (graduate students versus community college traditional age students), the methodology for increasing the emotional intelligence assessment is quite similar.

Research on emotional intelligence and community college students is scarce. Two studies (Izaguirre, 2008; La Civita, 2003) involving community college students and the use of the EQ-i assessment instrument are included in the research. These studies are important because they examine the population of community college students, although in La Civita's (2003), the focus is on at-risk students. In Izaguirre's (2008) study the relationship among emotional intelligence, academic achievement, and demographic characteristics is examined. In both studies, the researchers used the Bar-On EQ-i 133item inventory, which was proposed for this study as well.

Although most research has been done in a 4-year university setting, La Civita's (2003) work focused on the relationship between emotional intelligence factors and academic achievement of at-risk community college students. Factors including academic history, socio-economic background, and college-level readiness in math, English, and reading would certainly have been factors that would influence the outcome 
of the students. The study included 80 participants at a community college in southeastern Florida.

This study examined the relationship between emotional intelligence (EI) and the academic achievement of at risk community college students. Specifically, this study examined the relationship of the EI factors of independence, problem solving and stress tolerance with the grade point averages (GPAs) of at-risk community college students as measured by the Bar-On Emotional Quotient Inventory (EQ-i) and personal data of gender, ethnicity, and GPAs were gathered from 80 at-risk students who participated in the study. (LaCivita, 2003.)

La Civita chose to use the subscales (of the EQ-i) of independence, problem-solving, and stress tolerance as independent variables and the students' GPAs as the dependent variable, which revealed that the selected subscales were not significant in predicting the academic achievement of at-risk students. The study is small; the population is different from the one in this research. LaCivita (2003) states that "Future research that addresses the interrelatedness of the intellectual and emotional elements of at-risk student achievement and retention will further determine the relationship between these constructs" (2003).

The other study (Izaguirre, 2008) examined the relationship among emotional intelligence, academic achievement, and demographic characteristics in 199 first-year community college students. Izaguirre also used the EQ-i 133-item inventory as the assessment instrument, but the research focused on the fifteen subscales, rather than overall emotional intelligence. Some of the findings in this quantitative study revealed a "predicative relationship among academic achievement and (the subscales) of Independence, Empathy, Social Responsibility, Flexibility and Problem-Solving”. Izaguirre focused on additional demographic factors such as employment and marital and parental status for the study. Results showed students who had been divorced or were 
employed scored higher in the Adaptability (Flexibility) subscale. There were also reported differences between the genders in the Interpersonal emotional intelligence subscale. The findings did not support the existence of a relationship between overall emotional intelligence as measured by the EQ-i and the academic achievement as measured by the GPA. However, there was a relationship found between the academic achievement and the subscales of Social Responsibility and Problem Solving. This study aimed to examine overall emotional intelligence, which is the composite of fifteen subscales. The overall emotional intelligence scores were correlated with traditional factors of academic success, including a student's GPA, attempted and completed credit hours as well the grade obtained in the Introduction to Business course. Results regarding gender have been mixed and inconclusive, so the researcher also examined the correlation between overall emotional intelligence and gender.

Don Hamachek (2000) states that

People seldom fail as bosses, workers, parents, teachers, or in relationships generally because they know too little about the world outside the self. More often they stumble because of what they do not know or fail to understand about their intrapersonal feelings and motives, the world inside the self. (p. 41)

So, would it be logical to add the element student to the list mentioned above? If students have more self-knowledge, a key competency in Emotional intelligence, might they be more likely to succeed in school? Hamachek (2000) goes on to say that

EI is another way (not another way in place of IQ, but alongside it as a valued addition) of developing a working definition of what constitutes rounded, intelligent behavior. EI is an expression of one self-knowledge and selfunderstanding. IQ reflects what people take from the world in terms of information, knowledge and problem-solving skills. Perhaps EI can be best thought of according to what people give back to the world in proactive selfmanagement (rather than reactive), heightened sensitivity to the feelings and views of others, improved interpersonal relationships, and the willingness to look 
in the mirror when searching for answers to troublesome personal problems rather than peering out a window for someone else to blame. (p. 94 )

If students began their college careers with this mindset, they would be positioned at a considerable advantage from many professionals already in the workplace. Not only would the skills support their quest for staying in school and completing a degree, but they would be well-groomed for the real world, by supporting themselves economically, as well as managing all kinds of interpersonal relationships successfully.

\section{Conclusion}

If indeed it turns out that emotional intelligence does play a significant role in identifying well-prepared or at-risk first year college students, it could feasibly become part of the mainstream admissions process, or in the case of community colleges, another resource to support student persistence. Colleges and universities would certainly be interested in raising the $66 \%$ success rate (ACT, 2009) when enrolling continuing students. If testing students for EI and identifying at-risk students, and subsequently providing the necessary coaching or training, results in raising the retention rate, then the institution has done a better job in serving students by keeping them in a degree program and on the path to completion.

The institution will also have been more effective in preparing students for life after college because more of those students will be employable for positions requiring a college education. Lowering the dropout rate also has a significant impact on an institution's cost center because if a greater number of students stay in school, then the need to fill those vacancies is eliminated. According the Florida Department of Education's 2011-2012 Business Plan, the compounded impact of having students remain 
in school, complete a degree, and be gainfully employed is evident as stated in this excerpt regarding the reduction of social costs:

In addition to generating state revenue through increased economic activity, Florida's college graduates also reduce costs for the state. Graduates have a greatly reduced use of social services, particularly welfare and unemployment. They are also less likely to engage in crime. Taxwatch's report examined the social savings from 11 studies of community colleges, both here in Florida and nationally. The level of savings varied by study, but the average was $\$ 1,353$ in avoided costs per full-time equivalent (FTE) student. Applying this to the FCS 2009-10 FTE enrollment of 359,890 produces $\$ 486,944,565$ in cost avoidance for the state. (p. 6)

Another direct benefit is to the taxpayers, who through the federal and state governments provide education dollars that go into the institution. It is a more effective and efficient use of those finite and limited funds. 


\section{CHAPTER III}

\section{METHODOLOGY}

In this chapter, the purpose of the study, its significance, and the research design are outlined. The design included an ex post facto study examining the correlations between measures of academic success and the results of an emotional intelligence assessment. Within the study there was a quasi-experimental design included to test the possibility that overall emotional intelligence can be increased by a treatment method. In the correlational aspect of the study, the relationship between emotional intelligence and four traditional aspects of academic success (GPA, attempted-to-completed credit hour ratio, grade in the course, and persistence or graduation after one full time) were examined. The research examined the possibility that there was a positive correlation between a student's overall emotional intelligence and the grade earned in a given course. A student who attempts and completes credit hours at a higher rate was hypothesized to have a higher emotional intelligence assessment score than one who had a more prominent pattern of withdrawals or failures.

\section{Participants}

The study was made up of 111 traditional age male and female community college students enrolled in four sections of an Introduction to Business class. Students in the study were enrolled in a section that met either from 9:30 to 10:45 a.m. or from 11:00 to 12:15 p.m. on Tuesday and Thursday during a 16 week traditional term.

Students at the college are ethnically and racially diverse, representing 157 countries, including White Non-Hispanics, Hispanics, and African Americans, and international students from the Caribbean and Latin America. The four sections of the 
Introduction to Business (GEB 1011) also include students representing a wide range of socio-economic backgrounds. Most of the traditional age students have some working experience usually in the food services industry or retail establishments; overall, however, students are still naïve regarding the demands, skills, and knowledge needed to become successful business managers and owners. Students began the business course with dreams of being their own bosses and becoming independently wealthy, which they expressed on the first day of class when they introduced themselves. During the semester, students were encouraged to interview small business owners and managers in their neighborhoods and communities to determine the kind of personal profile, education, and knowledge needed to successfully pursue a career in this field. It is through this exposure, as well as the course curriculum, that they began to realize what was required to start-up, manage, and sustain a successful business in terms of technical ability, as well as the needed conceptual and interpersonal relations skills.

There are no pre-requisites for enrolling in this course, so anyone with a business interest might be enrolled in this class. Some students had already decided on a business major while others were exploring the possibility of incorporating a business aspect into their technical or career studies. Other students were undecided majors at the time of the study. Four sections (first two in the spring, two additional in the fall) were chosen from the Department of Business Administration. There are currently several thousand students enrolled in A.A., A.S., A.A.S., or certificate programs with a business component.

The students in this study enrolled in an introductory course in the business administration track: GEB 1011. Students may be seeking an A.A. hoping to transfer to a 
4-year degree awarding institution while others may be seeking a career or technical certificate, or an A.S., or an A.A.S. degree. Students enroll in this course often with an exploratory mindset to determine whether a career in one of the business fields (accounting, economics, finance, marketing, or management) would be a potential major program of study. Some students may also enroll with the goal of becoming entrepreneurs or business owners, using the course to support their careers and technical studies.

Non-cognitive capabilities, competencies and skills, which include emotional selfawareness, interpersonal skills, stress management, and general mood, are all highly regarded among successful business people in the field of emotional intelligence (Cherniss \& Goleman, 2001; Goleman, 2002; Stein \& Book, 2006), and there is an abundance of resources available for students to read, examine, and discuss in a business setting. Cherniss (1999) of the graduate school for Applied and Professional Psychology at Rutgers University presents a persuasive case for the inclusion of emotional intelligence training in a wide spectrum of organizations from the U.S. Air Force to L'Oreal.

Introduction to Business (GEB 1011) was chosen as the treatment course because it is an introductory course typically taken by new business majors or students with undecided majors who are still exploring career choices. The course provides a natural avenue for access to emotional intelligence studies in the discipline. Students are able to read, discuss, and debate the management, leadership, and behavior of individuals in business settings. It was also chosen because it is convenience sample because the researcher was also the professor in all four sections. 
Students in the four sections were not informed prior to registration that they would be asked to participate in a research study involving emotional intelligence. Enrollment in one section or the other was influenced by individual preferences restricted by availability of seats in one section or any other section, scheduling conflicts with other classes the students may have wanted to take, campus preference, or other factors such as work schedules or transportation issues. The four sections in this study were taught by the researcher eliminating the preference for one instructor over another. Only students who completed the pretest and posttest emotional intelligence assessment were considered in this study.

Students who enrolled in the four sections learned that they would be involved in a research project involving emotional intelligence during the first week of classes. The researcher provided all students with a general understanding of emotional intelligence as well as current information regarding research and findings in first and second year college students' emotional intelligence. The students also had the opportunity to hear about the possible connection between various aspects of academic success, including grades, course outcomes, retention in the program of study, and persistence in individual courses, with higher emotional intelligence assessments. Although no students requested a change in section, all students were given the option of participating in the study or being placed in another GEB 1011 section, which was not included in the research. The students, to the best of the researcher's knowledge, had only a superficial awareness of emotional intelligence. 
Students did not receive any type of material or monetary compensation for their participation. Participating students in both groups received extra credit equivalent to 3\% of the overall grade in the course as an incentive for participation in this research.

\section{Setting}

The research was conducted at a large urban multi-campus community college in Southeast Florida. The college is one of the largest in the country and has an articulation agreement in place with the state university system. Students who complete an A.A. degree are guaranteed acceptance into one of the state universities. Transfer students comprise approximately $40 \%$ of the college population (See Appendix E); other students are enrolled in an A.S. program, an A.A.S. program, or certificate program. The college is currently serving over 65,000 part-time and full time students annually.

In addition to serving local students, the college also has several affiliates and partnerships abroad, including Singapore, Sri Lanka, Ecuador, Spain, Peru, Mexico, and Vietnam. The programs in Peru, Singapore, Sri Lanka, and one of the programs in Ecuador are accredited by the Southern Association of Colleges and SchoolsCommission on Colleges, and students who complete those programs receive an A.A. from the college. Students from the college may also choose to study abroad in a number of international sites including Mexico, Germany, England, and Egypt, among others. An emphasis on global education and diversity is strongly promoted in all local and international programs and is reflected through the curriculum.

The Honors College and Dual-Enrollment programs at the college foster an environment of scholarship, community service, and a strong commitment to personal 
growth and development. Students enrolled in either of these programs may also register for this course and comprise part of the sample for the study.

The college underwent a substantive change from a Level One (highest degree awarded is an Associates' degree) to a Level Two (highest degree awarded is a Baccalaureate degree) institution in 2009. Four-year programs include a B.S. in Teacher Education and a B.A.S. in Supervision and Management. The course in which the participating students are enrolled (GEB1011- Introduction to Business) is considered a general elective and is transferable for a B.A. or a B.S. degree or to the college's newest B.A.S. degree programs.

State articulation agreements between Florida's community colleges and the 4year public universities have created a relatively comfortable starting point for many aspiring A.A. students who hope to pursue a 4-year degree with a major in business administration, finance, economics, marketing, or related degree programs. Introduction to Business (GEB 1011) is a 3-credit elective course, which is included in the A.S. and A.A. programs in Business Administration offered at this college. The course description, listed in the institution's catalogue, is as follows:

This course provides a basic study of business activity and how it relates to our economic society. Topics covered include how businesses are owned, organized, managed and controlled. Course content emphasizes business vocabulary, areas of business specialization, and career opportunities.

There is no prerequisite, and students from any degree or certificate program may enroll in this course as part of their elective requirements. Due to the amount and level of reading required to be successful in this course, it is not usually taken by students who are enrolled in their first semester of college, and it is not recommended for students requiring remediation in reading or English. 
Students in the research sections attended a traditional face-to-face class two days a week for 1 hour, 15 minutes, a total of 2 hours, 30 minutes a week. In addition, the course was web-enhanced, allowing for online delivery of content including quizzes, discussions, homework assignments, and e-mail correspondence within the particular class. Students were expected to spend at least an additional 3 hours per week reading, completing assignments, participating in structured discussions online, and studying for weekly quizzes. Enrollment was capped at 35 students per section.

The college-wide success rates, as shown in Appendix F, provide an indication of the academic success of the students at the college. According the Office of Institutional Research at the College (2009-2010), the attrition rate for all students is about 11\%. These are students who withdraw from courses prior to completion. Students who receive a grade of D or F are categorized as "unsuccessful" and, depending on the semester, make up approximately $13 \%$ of the population. The remaining $75-76 \%$ typically complete the course with a grade of A, B, or C, and are considered successful. Student success rates in terms of completion and grade attainment for Introduction to Business (GEB 1011) are consistent with all other courses offered at the college as shown, with an attrition rate of approximately $11 \%$, and an $\mathrm{A} / \mathrm{B} / \mathrm{C}$ grade attainment of $75 \%$. About $14 \%$ of students who take courses at the college and finish receive a $\mathrm{D}$ or $\mathrm{F}$ grade. 


\section{Research Design}

There were actually two research designs within this study. One was ex post facto examining correlations between four measures of academic success and scores on an instrument measuring emotional intelligence. The second was a quasi-experimental design concerning treatment groups that received an intervention: a curricular component and instruction on emotional intelligence; control groups that did not receive the treatment.

Students' GPA, total attempted -to-completed credit hour ratio, individual grades in the course, and persistence in college enrollment were correlated to their emotional intelligence assessment, using the Bar-On (2004) 133-item EQ-i (Emotional Quotient Inventory). Because the EQ-i assessment includes a measure of self-management, impulse control, problem-solving skills, interpersonal relations, adaptability, and stress tolerance, all required for academic success, it was hypothesized that students who demonstrated greater success in the more traditional aspects of academic success would also have higher emotional intelligence, as shown in previous studies (Izaguirre, 2008; Jaeger, 2003; Vela, 2003; Walker, 2006).

\section{Research Instrumentation}

To assess the students' emotional intelligence, participants were given the EQ-i (Emotional Quotient Inventory) developed by Reuven Bar-On (2004) and licensed to Multi Health Systems. It has been used in hundreds of settings and with thousands of participants since its development in the early 1980s. The technical manual, Bar-On 
Emotional Intelligence Inventory (2004), provides the following historical and current

overview of the use of this instrument in research:

The first experimental phase of the author's research was carried out between 1983 and 1986 in South Africa as phase of his doctoral studies, and the second stage was carried out in Israel from late 1986 until late 1993. The third and current stage of research began in the first phase of 1994. This stage involves the continued examination of the EQ-i's ability to describe and measure emotional intelligence on more diverse and larger population samples. Collaborative research projects have been and are being conducted in Argentina, Canada, Germany, Great Britain, India, Israel, Nigeria, the Philippines, South Africa, Sweden and the United States. The Bar-On approach to describing and assessing emotional intelligence has been examined on over 10,000 people at scores of testing sites around the world. (pp. 1-2)

The EQ-i is described in the technical manual (Bar-On, 2004) as follows:

The EQ-i comprises 133 brief items and employs a five point response set (ranging from "Not True of Me" to "True of Me"). It takes approximately 30 to 40 minutes to complete the EQ-i, but there are no imposed time limits. The reading level in English has been assessed at the North American sixth grade level, based on the Flesch formula (Flesch, 1948). The EQ-i is suitable for individuals 16 years of age and older. The assessment renders four validity scale scores, a total EQ score, five composite scale scores, and $15 \mathrm{EQ}$ subscale scores. (p. 3)

The technical manual (Bar-On, 2004) states:

The EQ-i can be used in educational settings, such as high schools, technical schools, colleges and universities, to help school psychologists and counselors identify students who are unable to adequately cope with scholastic demands that could lead to dropping out of school and/or the possible development of emotional problems. (p. 9)

Bar-On (2004) goes on to state that

In research settings, the EQ-i can be applied in educational, clinical, medical, business and management science research. Research projects using the EQ-i have been and are currently being conducted in all these areas. (p. 10)

The researcher is confident that this instrument has been researched and used in a number of professional and investigative settings that demonstrate that the EQ-i is both reliable and valid. As stated in the literature review (Chapter 2), "Bar-On reports a series of 
validation studies that are quite impressive in scope. The EQ-i has been normed in a large, diversified North American sample $(N=3,831)$ and the scales seem to be statistically reliable in North American and other samples worldwide" (Matthews et al., 2002, p. 16).

This assessment has been used in a number of studies and has been normed as follows:

The results of the assessments have been normed to compare individual assessments with participants of the same age. There were significant differences in the age groups indicating that people generally improve their level of emotional intelligence with age with the peak resulting in the fourth or fifth decade of life. With respect to gender, no differences appeared between males and females regarding overall emotional intelligence, although there do to appear to be some differences in some of the individual subscales: females tend to have greater interpersonal skills, greater empathy and tend to be more socially responsible while males tend to have greater intrapersonal skills (self-regard, emotional selfawareness and confidence); males also manage stress better and tend to be more adaptable. When considered as a whole, stronger skills tend to compensate for weaker ones resulting in comparable overall emotional intelligence between males and females. (Bar-On \& Parker, 2000, p. 367)

In terms of reliability, a number of studies were carried out to determine the internal consistency and retest reliability of the EQ-i.

The Cronbach alpha coefficients are high for all subscales, ranging from a "low" of .69 (Social Responsibility) to a high of .86 (Self-Regard) with an overall average internal consistency coefficient of .76 . These results indicate very good reliability, especially considering that all internal consistency procedures tend to underestimate the actual reliability (Guilford \& Fruchter, 1978). (Bar-On, 2004, p. 87)

The results from the assessment are reported on a scale from 50-150, with 100 being the mean or average score. A score between 85 and 115 would be the average range for a participant compared to other participants of the same age and gender. The five composite factors of Intrapersonal, Interpersonal, Adaptability, Stress Management, and 
General Mood are broken down into a total of 15 subscales. A three-day training session is required by Multi-Health Systems to use the EQ-i in research and clinical settings. The researcher was certified in 2008 and was trained to interpret the outcome of the assessments for the participants in this study.

When examining emotional intelligence, the validity of the instrument chosen was a paramount concern. The validity of EQ-i's overall emotional intelligence assessment and its factorial components have been rigorously tested as described in the technical manual:

Nine types of validity studies were conducted: content, face, factor, construct, convergent, divergent, criterion-group, discriminant, and predicative validity. These particular validity studies were specifically carried out to see if the items appear to be (face validity) capturing the essence of each scale and subscale (content viability), to examine the degree to which the inventory's original structure is confirmed (factor analysis), to verify the extent to which the subscales are measuring what they are supposed to be measuring rather than something else (construct, convergent, divergent, and criterion-group validity), and to assess the extent to which they can identify and differentiate among people who are more emotionally intelligent (discriminant validity); and if they can predict emotionally intelligent behavior in the future (predicative validity). (Bar-On, 2004, p. 89)

The instrument has been deemed to be a valid assessment when participants take the appropriate amount of time to answer the inventory (more than 10 and less than 40 minutes); have not tried to create a positive or negative impression, which is indicated on the results; have not answered internally consistent items in a contradictory manner, also indicated in the results report. Another aspect regarding validity is concerned with the omission of items. Depending on the number of subscale questions, a cut-off of one to three omitted items has been established (Bar-On, 2004, p. 41). 


\section{Three-Phase Study}

The structure of the study was divided into three phases: the first phase (preintervention) examined the correlation between two traditional measures of academic success (attempted-to-completed credit ratio and GPA) to the pretest emotional intelligence assessment, initially for 45 of the participants from the spring semester, and then for 82 participants, which included the fall participants. The second phase (intervention) was a quasi-experimental design with a control and treatment group. The treatment group received a curriculum infused with emotional intelligence content relevant to the workplace and business settings in the form of readings, group discussions, and film in addition to the traditional curriculum. The control group received only the traditional curriculum. The third phase (post-intervention) was an analysis of all the participants' posttest assessments in emotional intelligence as measured by the EQ-i, controlling for the pretest scores through the use of an ANCOVA.

\section{Phase One (Pre-Intervention)}

Forty-five of the 54 students from the two spring sections were included in the first phase of the study. Only students who had a GPA history in the college, as well as an established attempted-to-completed credit hour ratio history before the intervention, were included. A Pearson $r$ correlational study was conducted to determine the relationship of the students' pre EQ-i assessment score to the GPA and to the attemptedto-completed credit hour ratio. A positive correlation was hypothesized between the students who had higher pre-EQ-i scores and higher GPAs as well as a higher ratio of attempted-to-completed credit hours.

The most commonly used technique is the product-moment correlation, usually referred to as the Pearson $r$. The Pearson $r$ is used when both variables to be 
correlated are expressed as continuous data such as ratio or interval data. Since most instruments used in education, such as achievement measures and personality measures, are treated as being interval data, the Pearson $r$ is usually the most appropriate coefficient for determining relationship. (Gay \& Airasian, 2000, p. 329)

The results of an emotional intelligence assessment (EQ-i) of the 45 students during the first month of the semester were correlated with their cumulative GPA at the beginning of the semester in which they registered for GEB 1011. The ratio of students' overall attempted and completed credit hours at the onset of the semester were correlated with their pretest EQ-i score. The students with higher overall assessments, above the average score of 100, were expected to also have higher GPAs and greater retention rates in terms of attempted and completed credit hours. (When the fall groups were added to the study, those students $(N=37)$ were also assessed on the pretest EQ-iscore and its correlation to an established GPA and attempted-to-completed credit hour ratio thus yielding a sample size of $N=82$.

This stage of the research examined the correlation between the pre-test assessment score of the EQ-i and traditional measures of student success (cumulative GPA and attempted/completed credit hours) at the onset of the semester of all four sections.

Correlational research attempts to determine whether, and to what degree, a relationship exists between two or more variables. The purpose of a correlational study is either to establish a relationship (or lack of it) to use relationships to make predictions. A correlation is a quantitative measure of the degree of correspondence between two or more variables. (Gay \& Airasian, 2000, p. 12)

The department of Institutional Research at the College has recently established a "no-forgiveness" GPA for research purposes only. Currently students who take a course and fail it can repeat the course and the subsequent passing grade replaces the prior grade 
thus boosting the student's GPA. For research purposes, this modified grade would not reflect the reality that it actually took the student two, or even three, attempts to pass the same course. Likewise, the department of Institutional Research had established a more realistic accounting of attempted versus completed credit hours. Students who transfer in credits from another accredited institution show up as having attempted and completed the total number of actual credits being attempted plus the transfer credits the first semester. This creates an unreliable view of a student, for example, that may show 45 attempted and completed credit hours his/her first semester, which might actually be 30 transfer credit hours and 15 actual credit hours from that semester. Only the actual credit hours attempted and completed (for example, 15) at the college would count in this variable.

Because some of the components that make up the total emotional intelligence assessment score include aspects of self-management, self-confidence, flexibility, adaptability, and impulse control, the expectation was that students who have higher emotional intelligence scores (EQ-i) overall would also be more successful academically in terms of GPA and credit completion. Students with GPAs lower than 2.0 were expected to have lower than average EQ-i assessment scores as well. Conversely, it was also hypothesized there would also possibly be a strong positive correlation between higher EQ-i assessment scores and higher GPAs.

The following phase of the study examined the effect of treatment on the two groups. The alpha was set at $p<.05$, with an effect size of 0.5 and a power of 0.98 for the 54 participants in the spring groups. G*Power 3.10 was used to determine the power, and SPSS 13 was used to determine the statistical significance of the intervention as well 
as the homogeneity of groups with equal variance not assumed for the independent samples $t$-tests.

\section{Phase Two (Intervention)}

The two spring sections of students $(N=54)$ participated in a quasi-experimental research design. A quasi-experimental design, in which "the investigator uses control and experimental groups but does not randomly assign participants to groups" (Creswell, 2003, p.167) was selected for the research. The hypothesis was tested at the $p<.05$ to determine if the mean EQ-i score of the treatment group was significantly higher than the mean EQ-i score of the control group.

The results of the quasi-experimental design of the spring semester intervention are discussed in Chapter 4. Significant gains in emotional intelligence assessment scores were expected in the treatment groups when compared to the control groups. The proposal plan was that if the results from the first two groups resulted in a statistically significant difference, the treatment would be replicated in the following fall semester.

The students registered for either a 9:30 -10:45 a.m. or an 11:00 - 12:15 p.m. class on campus on Tuesdays and Thursdays. Before the semester began, the researcher decided that the designation of the experimental group was the earlier class and the control group was the later class. A two-tailed paired independent samples $t$-test was conducted on each pair of groups to determine significance at the level of $p<.05$ with an effect size of 0.5 . To lower the probability of a Type II error of rejecting the null hypothesis that the treatment does not affect the total emotional intelligence score when it actually does, $\alpha$ was set at .05. A two-tailed paired $t$-test was conducted on each pair of groups to determine if there was a difference in pre-and post-test scores. For a sample of 
54 (spring participants), a medium effect size and an alpha level set at .05 achieved a power of 0.95 .

On the first day of each of the two semesters, all students were given a traditional overview of the Introduction to Business course content along with the syllabus and a statement of expected outcomes. Students were informed that two sections in the department of business at the campus they were attending had been designated as research groups examining the role of emotional intelligence in first and second year college students. One group (Experimental Group I) received additional instruction in emotional intelligence and examined its possible effects in business settings, as well as learning the traditional Introduction to Business content included in the curriculum.

Emotional intelligence concepts were integrated in readings, homework assignments, class discussions as well as group work in class. The other group (Control Group I), received the traditional readings, homework assignments, discussion topics, and class group work with no mention of emotional intelligence in the curriculum. Neither group knew at the onset of the semester which group had been designated as the experimental group or the control group. Although no students requested a change in class section, all students were given the opportunity to opt out of the research: either to be enrolled in a non-research group or opt out of participation and remain in the same class. All students remained in their assigned groups and participated in the assigned groups.

The treatment consisted of integrating various aspects of emotional intelligence throughout the course curriculum. Students in the experimental group read excerpts from The EQ Edge: Emotional Intelligence and Your Success (Stein \& Book, 2006). This text 
was selected as it has been used in a number of first year experience programs and student success skills (SLS) courses around the country, including those at Georgetown University, the University of Minnesota, Gallaudet University, and several others. Administrators in higher education at these institutions presented their research at the first symposium of Emotional Intelligence and Higher Education at Georgetown in October, 2008. The text is presented in an accessible format describing case studies in professional settings and includes many student-centered activities including surveys, discussion questions, and journaling activities. Ten different chapters focusing on various aspects of emotional intelligence were assigned, and students wrote a reflective essay on the content of each assigned chapter. Students were encouraged to relate the narrative in the text to personal examples they had experienced either at work or in their personal lives. Students in the control group did not read The EQ Edge excerpts, but were given traditional assignments from the Introduction to Business text.

Different aspects of emotional intelligence such as independence and self-regard were integrated in the appropriate places in the business curriculum. For example, when covering the units on business ownership and entrepreneurship, students reflected on the profile of successful business owners and their relationship to the emotional intelligence competencies of independence and self-regard. When covering the units on socioeconomic models of business, students were asked to reflect on their own sense of social responsibility and then relate it to a corporate model. One firm, Procter \& Gamble, was featured in class for its Loads of Hope initiative, which was launched after Hurricane Katrina. Students in the experimental groups learned about the impact of empathy and social responsibility through this model and others. 
All students also had the opportunity to see two films: Greed, a documentary hosted by John Stossal (ABC News, 1998) and Wall Street (1987), a commercial film starring Michael Douglas, Martin Sheen, and Charlie Sheen. In the documentary, Stossal focuses on business titans throughout the last century, including Vanderbilt and Rockefeller, known as the "robber barons", as well as modern moguls Bill Gates and Ted Turner, among others. Students had the opportunity to identify and discuss certain aspects of emotional intelligence, which may have contributed to their success or to their reputations. For example, in the documentary, Greed, Ted Turner abruptly leaves the interview after becoming angry with the reporter, John Stossal. Students were asked to reflect on the effectiveness of Turner's actions and develop other alternatives, which might have helped Turner better communicate his position to Stossal during the interview. These scenarios helped students understand the importance of self-control and emotional self-awareness in business and professional settings.

In the film Wall Street (1987), a fictionalized version of "an insider trading scheme gone awry," students focused on the main characters' emotional intelligence that led to their success and downfall in different scenes in the film. The control group also saw the two films but discussion was limited to the content of the films as it related to the current business atmosphere with no mention of emotional intelligence. These additional elements covered during the course are laid out in Table 1 and the document is an addendum to the syllabus. 
Table 1

Course Syllabus

Schedule Assigned Tasks $\quad$ Learning Outcomes

Take the pre EQ-i;

(given in a lab during class time)

Students may receive feedback on results by

Weeks

$1-2$ scheduling an individual appointment with

the professor

Read The EQ Edge (Stein \& Book) pgs 9-34; content will be discussed in class.

Read The EQ Edge (Stein \& Book) pgs 55-92

Weeks on self-awareness and assertiveness; students will also watch the film Wall Street.

3-4 For HW: Choose one of the concepts covered and write a short (1 page) reflective essay to be turned in for credit.

Read The EQ Edge (Stein \& Book) pgs 93111 on independence and self-regard.

Weeks These characteristics will be discussed with 5-6 the chapters on small business ownership and entrepreneurship.

For HW: Choose one of the concepts covered and write a short (1 page) reflective essay to be turned in for credit.

Read The EQ Edge (Stein \& Book) pgs 123-

Weeks 139 on empathy and $150-160$ on interpersonal relationships.

7-8 For HW: Choose one of the concepts covered and write a short (1 page) reflective essay to be turned in for credit.
Students will gain a basic emotional intelligence and be able to actively participate in class discussion.

Students will be able to clearly articulate the concepts of emotional selfawareness and assertiveness; they will be able to identify those qualities in the main characters in the film, Wall Street.

Students will be able to relate the emotional intelligence readings to leading entrepreneurs in business, both today and in the past.

Students will be able to provide concrete examples of how empathy and successful interpersonal relationships have a positive impact on business, particularly in sales. 
Read The EQ Edge (Stein \& Book) pgs 140149 on social responsibility; students will

Weeks also see the documentary Greed, hosted by John Stossal.

For HW: Choose one of the concepts covered and write a short (1 page) reflective essay to be turned in for credit.

Read The EQ Edge (Stein \& Book) pgs 160171 on problem-solving; students will be

Weeks asked to work in small groups to discuss a business case.

For HW: Choose one of the concepts covered and write a short (1 page) reflective essay to be turned in for credit.

Read The EQ Edge (Stein \& Book) pgs 189Weeks 214 on stress tolerance and impulse control. Students will write a short reflective essay on managing stress effectively will support their managerial aspirations.

Weeks

15-16 (given in a lab during class time)
Students will be able to relate the model of socioeconomic versus the economic model of business to current industries and firms; and present specific characteristics of historical giants in business that added to their success in terms of EI.

Students will be able to apply an effective problemsolving strategy to a business case using elements contained in the reading.

Students will be able to critically assess their own situation and effectiveness in stress management and how impulsive decisions can have disastrous effects in a business setting.

Students will have the opportunity to compare their pre and post test scores by scheduling an appointment with the instructor if interested. 
Once the EQ-i pretest assessment was completed, the participants, from either the control or the experimental group, were able to request a feedback session from the researcher to interpret the assessment score. The interpretation was provided only to the individual participant who completed the assessment in the privacy of the researcher's office. Students were asked to email the professor to set up an appointment. A written report of the student's results was available in an Adobe format for the student. Once students had a chance to read the results with the researcher while attending a feedback session, they received the report via email. Students did not receive their reports unless they first attended a feedback session to prevent erroneous conclusions made without the benefit of interpretation. No recording devices were used. The feedback session took about 30 minutes.

There was a cost of approximately $\$ 15.00$ per student involved in the processing of each assessment by Multi-Health Systems (MHS), which was absorbed entirely by the researcher.

Because the two spring sections yielded a statistically significant result from the intervention, two additional groups were chosen for a follow up intervention in the fall. The two fall groups yielded a sample size of 57 participants who were able to take both the EQ-i pretest and posttest. To lower the probability of a Type II error of rejecting the null hypothesis that the treatment does not affect the total emotional intelligence score when it actually does, $p$ was set at $<.05$. An effect size of .5 achieved a power of .98 for the fall sample. 


\section{Phase Three (Post-Intervention)}

During the third phase (post-intervention), the researcher used the data from all the students who participated in both the spring and fall sections and attempted to show whether a positive (or negative) correlation existed between the second emotional intelligence scores (post EQ-i) and traditional measures of success (cumulative GPA, attempted-to-completed credit hour ratio, grade in the course, and persistence in the program). Students' overall GPA, as defined by the College's Institutional Research Department, were correlated with the second measure of overall emotional intelligence (assessed at the end of the research semester) to determine if students who had a higher GPA also had a higher emotional intelligence score on the EQ-i . A second measure of students' current ratio of attempted-to-completed credit hours, as defined by the college's Institutional Research Department, was correlated to their overall emotional intelligence (assessed at the end of the corresponding research semester) to determine if persistence and follow-through in studies could be correlated to emotional intelligence scores using the EQ-i.

Students' overall emotional intelligence scores at the end of the research semester was the dependent variable in an ANCOVA controlling for all the students' pretest emotional intelligence scores. An ANCOVA was chosen because "Through the use of an ANCOVA, the researcher is able to increase the precision of the research by partitioning out the variation attributed to the covariates, which result in small error variance" (Hinkle, Wiersma \& Jurs, 2003, p. 496). In this study, therefore, the EQ-i pretest scores could be controlled to achieve a more accurate posttest result in the four groups.

An additional definition states that 
A one-way analysis of covariance (ANCOVA) evaluates whether population means on the dependent variable [post EQ-i score] are the same across levels of an independent variable [GPA], adjusting for differences in the covariate [the pre EQ-i score and pre GPA]. The independent variable divides individuals into two or more groups or levels, while the covariate [pre-EQ-i score/pre GPA] and dependent variable [post EQ-i score] differentiate individuals on quantitative dimensions. (Green \& Salkind, 2004, p. 207)

The posttest EQ-i assessment scores for all students $(N=111)$ were correlated with traditional measures of academic success to determine if there was a significant relationship between emotional intelligence scores and students' GPA, the ratio of attempted-to-completed credit hours, grade in the academic course, and their persistence in enrollment or graduation at the end of the following major term. For the spring participants, the results of students' post-EQ-i scores were correlated at the completion of the following fall term; for the fall participants, it was correlated at the completion of the following spring term to determine if students with higher EQ-i scores were more likely to persist or graduate in the following major term.

The dependent variable, as defined by the Bar-On Emotional Quotient Inventory Technical Manual 2004, in this study was the overall post EQ-i assessment defined as "including an array of non-cognitive abilities, competencies and skills which influence one's ability to succeed in coping with environmental demands and pressures" (p. 15).

All students, in both the control and experimental groups, took the EQ-i assessment developed by Reuven Bar-On (2004), which is currently licensed to MHS. The delivery of the assessment is online. The participants' responses were assessed and scored electronically by MHS and delivered to the researcher's account. Access to the account is password protected. The password is assigned by the researcher, not MHS. Students were assigned to either control or experimental groups, depending on the 
schedule, with a unique code designated by researcher. Students identified themselves by using the last four digits of their student identification numbers. (The student identification numbers are randomly generated by the Registrar and are not related to other identifiers such as Social Security Numbers or names.) Participants were also asked to identify their genders and ages. It is assumed that all students accurately reported their four-digit numbers, genders, and ages. All students participating in the research took the online EQ-i assessment during the first month of classes and again during the last 2 weeks of the semester in a laboratory setting supervised by the researcher.

The Institutional Research department at the college provided all data for the students included in this sample. Students' identities were protected through encryption

\section{Research Questions}

1. Is there a significant relationship between academic success (higher GPA, higher ratio of attempted-to-completed credit hours) and pre-interventions emotional intelligence as measured by the Bar-On EQ-i?

This question generated other questions:

a. Is there a significant relationship between pre-intervention EI and GPA?

b. Is there a significant relationship between pre-intervention EI and attempted to completed credit hour ratio?

2. Is there a significant increase in emotional intelligence scores after a semesterlong academic intervention?

This question generated other questions:

a. Can emotional intelligence be taught as estimated by the treatment effect? 
b. Are the EQ-i gains significantly different between a control group and an experimental group?

c. Can the study be replicated, as estimated by treatment effect?

3. Is there a significant relationship between academic success and post-intervention emotional intelligence as measured by the EQ-i?

This question generated other questions:

a. Is there a significant relationship between the post-intervention emotional intelligence as measured by the EQ-i and the cumulative GPA?

b. Is there a significant relationship between post-intervention emotional intelligence as measured by the EQ-i and course grade?

c. Is there a significant relationship between post intervention emotional intelligence as measured by the EQ-i and attempted-to-completed course credits?

4. Is there a significant relationship between gender and emotional intelligence as measured by the EQ-i?

This question generated other questions:

a. Which gender has higher pre-intervention emotional intelligence?

b. Which gender has higher pre-intervention emotional intelligence in the experimental group?

c. Which gender has higher pre-intervention emotional intelligence in the control group?

d. Does intervention have a greater impact on either gender's results? 
e. Are the gains more significant for male or female students' postintervention? 


\section{CHAPTER IV}

\section{RESULTS}

Two groups of Introduction to Business, GEB 1011 students, enrolled in the traditional spring term of 16 weeks, participated as the first pair of experiential and control groups. These groups have been designated Experimental Group I and Control Group I for this study. Both groups were comprised of traditional age students, male and female, attending a Tuesday-Thursday traditional face-to-face class in a web-enhanced delivery format. The professor met with the class for 48 contact hours in addition to using a learning management system to deliver materials online for supplemental instruction. All homework assignments were delivered and returned to the students through the e-learning platform. The researcher was the professor in both sections.

\section{Phase I (Pre-Intervention)}

Of the 54 students included in Experimental Group I and Control Group I, 45 had an institutional history in terms of an established GPA and an attempted-to-completed credit hour ratio. The students' pre-EQ-i assessment scores were correlated to their GPA at the beginning of the spring term. The mean GPA for the 45 students was 2.36 and the mean EQ-i score for the same students was 104.2 yielding a result of $r=0.179, p<.05$, a low positive correlation. The mean attempted-to-completed credit hour ratio was $83 \%$ and when correlated with the pre-EQ-i score yielded a result of $r=0.162, p<.05$, which was also a low positive correlation (See Appendix G). The result was unexpected and although statistically significant, it may not have been meaningful. To answer the second research question, the researcher decided to continue with Phase II, to determine if the curricular intervention made a difference in students' overall emotional intelligence 
scores. The treatment phase of the first two groups did yield a statistically significant result, so two additional groups were added to the research in the following semester. (The results of the treatment are discussed in Phase II.) In an effort to replicate the results from the first intervention, the research design for the two additional groups was identical: same course, location, schedule, delivery format, and professor.

\section{Demographics for all Participants}

There were 111 students included in the study as shown in Figure 1. Sixty-five males and forty-six females participated. Male students averaged 20.2 years and female students averaged 20.8 years. Only those students in the four sections who were able to complete both the pretest EQ-i and posttest EQ-i were included in this study.

Table 2

Numbers, Gender and Mean Age of Students Participating

\begin{tabular}{llll}
\hline Group & $n$ & Male & Female \\
\hline
\end{tabular}

$\begin{array}{lllll}\text { E-I } & 31 & 17 & 14 & 21.0(3.0) \\ \text { C- I } & 23 & 15 & 8 & 19.4(1.6) \\ \text { E-II } & 28 & 18 & 10 & 20.8(2.9) \\ \text { C-II } & 29 & 15 & 14 & 20.5(2.7)\end{array}$

Note: E-1 (Experimental Group I); C-1 (Control Group I); E-II (Experimental Group II); C-II (Control Group II) 


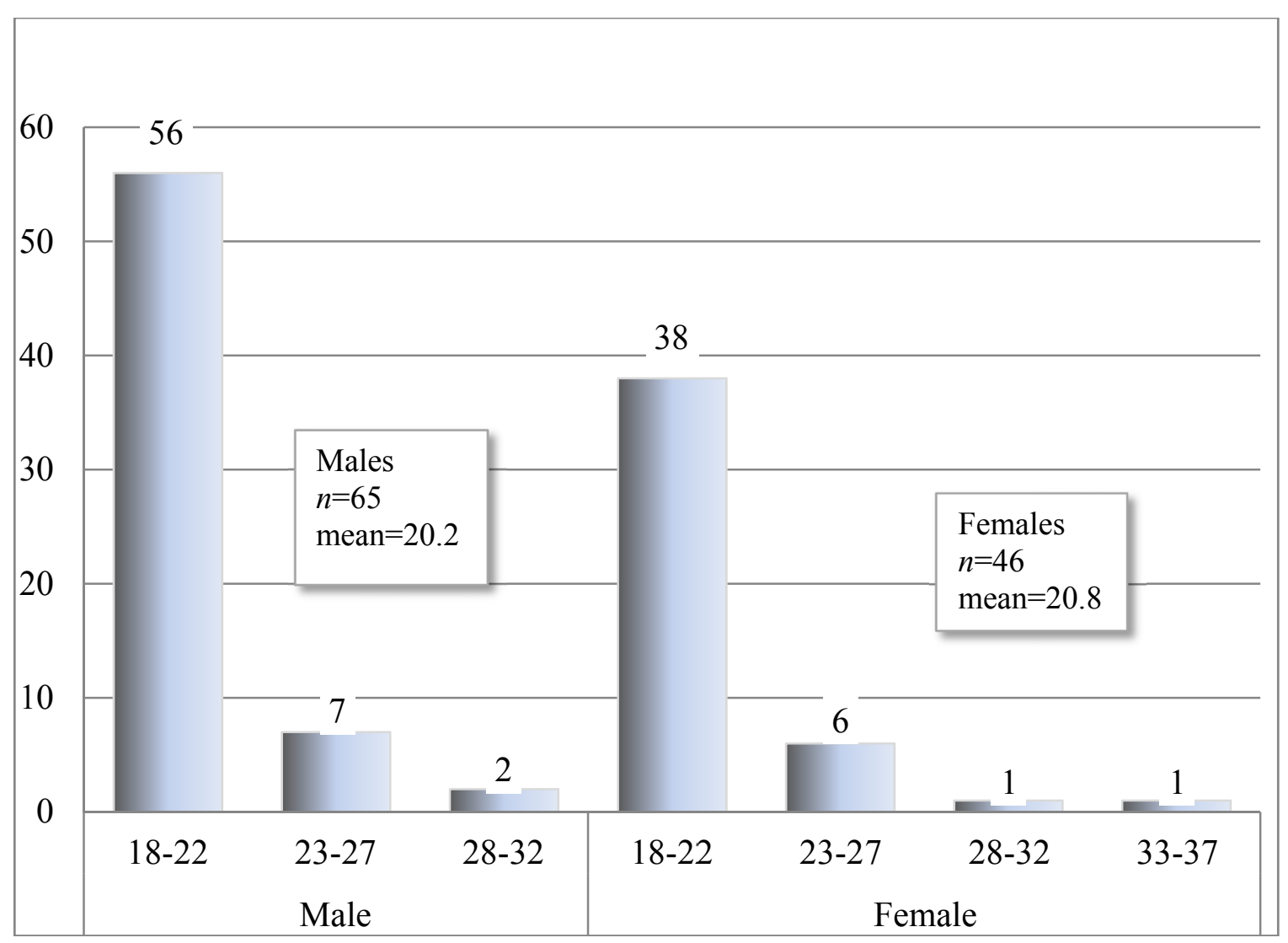

Figure 1. Number of male and female participants by age.

\section{Pre-Intervention of all Groups}

In the first phase of the three-phase study, students who had an academic history in terms of credit hours earned and an incoming institutional GPA were included. Of the 111 students, 29 of those were attending the college for the first time and were omitted from the first phase (pre-intervention) of the study. The two traditional measures of academic success, which were correlated with their incoming EQ-i pretest, were (a) incoming GPA and (b) attempted-to-completed credit hour ratio for the remaining sample of 82 students.

The sample had an average GPA of 2.44. This included all courses and attempts. The department of Institutional Research provided the actual earned GPA rather than the 
modified version that was based on forgiveness for repeated attempts. In the case of the attempted-to-completed credit hour ratio, only courses that were attempted at the college were included. Transfer credits from other institutions were not included in the attempted-to-completed credit ratio.

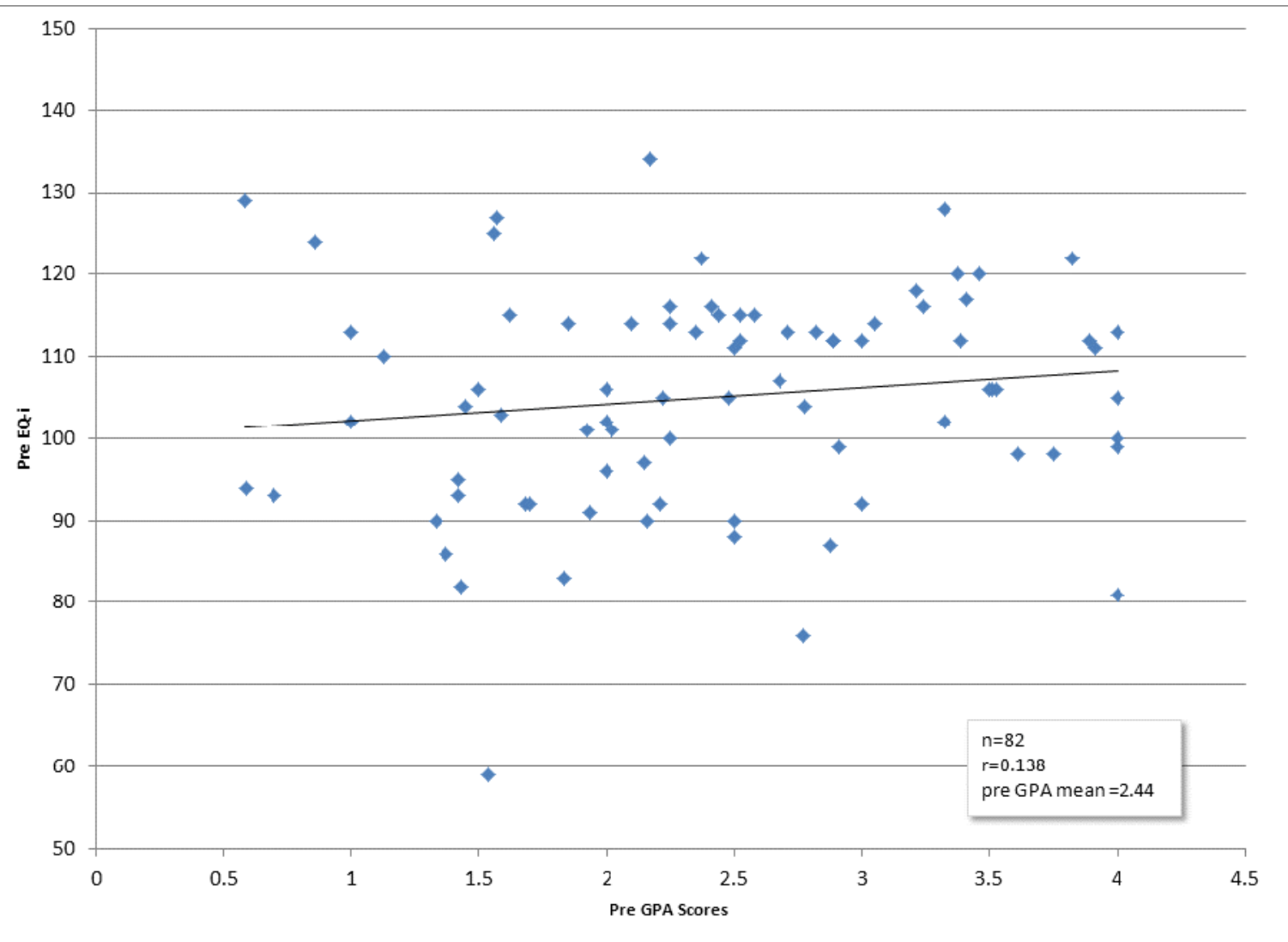

Figure 2. Pre EQ-i and pre GPA scores.

Table 3

Pre EQ-i Scores, Pre-GPA and Pre-Attempted-to-Completed Credit Hour Ratio

Pre EQ-i and Pre-GPA $\quad n \quad M \quad$ (SD)

$\begin{array}{lccc}\text { Pre-EQ-i } & 82 & 104.2 & (13.1) \\ \text { Pre-GPA } & 82 & 2.44 & (0.91) \\ & & & \\ \text { Pre-Attempted-to-completed Credit Ratio } & 82 & .82 & (0.19)\end{array}$


Student data was correlated and illustrated in a scatter plot as depicted in Figures 2 and 3. The correlation between the students' EQ-i pretest score and their GPA was low with a positive correlation, $r=0.138, p<.05$. The same was true in the case of the attempted-to-completed credit hour ratio with a low positive correlation, $r=0.090, p<05$. In this sample, each measure of academic success as measured by the GPA or the attempted-to- completed credit hour ratio was associated with the students' incoming EQ-i assessment scores.

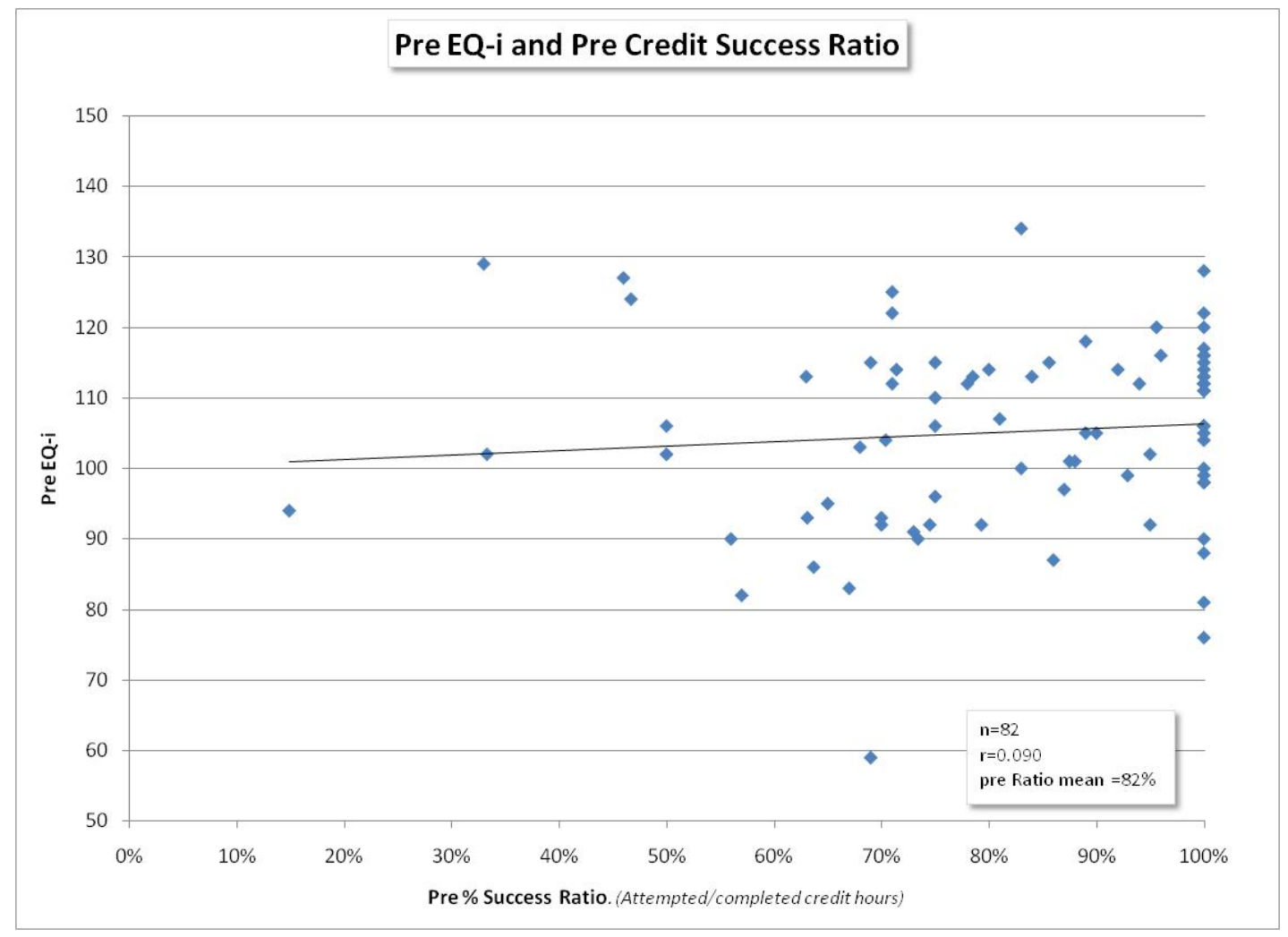

Figure 3. Pre EQ-i and pre attempted to completed credit ratio.

\section{Phase Two: Intervention}

In the second phase of the study, both sets of research groups (Experimental and Control Groups I and II) participated in a quasi-experimental design. All four groups 
took the 133-item Bar On EQ-i to determine pretest scores. A power analysis for a twotailed paired $t$-test was conducted for Experimental and Control Groups I to determine power and effect size for a sample of 54. A medium effect size and alpha of $p<0.05$ was used. The power was 0.95 with an effect size of 0.5 . The power analysis for this pair is illustrated in Appendix H. A second power analysis was conducted for Experimental and Control Groups II for a two-tailed paired $t$-test to determine power and effect size for a sample of 57, a medium effect size and alpha set at $p<0.05$. The power of the test is 0.95 with an effect size of 0.5 and is illustrated in Appendix I. This indicates that the samples are sufficient to avoid a Type II error of rejecting the null hypothesis that the treatment does not affect the total emotional intelligence score when it actually does.

The mean pre-test EQ-i assessment scores for the groups by gender are illustrated in Table 4

Groups, Mean pre-EQ-i Scores, SD, and Gender Breakdown

\begin{tabular}{|c|c|c|c|c|c|c|}
\hline Group & $n$ & $M(S D)$ & $n$ & Male $M(S D)$ & $n$ & Female $M(S D)$ \\
\hline E-I & 31 & $105.8(12.9)$ & 17 & $104.5(14.8)$ & 14 & $107.4(10.5)$ \\
\hline C-I & 23 & $100.9(9.7)$ & 15 & $99.2 \quad(8.6)$ & 8 & $104.1(11.3)$ \\
\hline E-II & 28 & $105.9(14.0)$ & 18 & $104.7(10.0)$ & 10 & $108.0(19.7)$ \\
\hline C-II & 29 & $103.3(14.6)$ & 15 & $108.3(10.7)$ & 14 & $97.9(16.6)$ \\
\hline All & 111 & $104.2(13.1)$ & 65 & $104.2(11.5)$ & 46 & $104.1(15.1)$ \\
\hline
\end{tabular}


The mean EQ-i assessment scores, by gender, are illustrated in Figure 4. Males averaged 104.2 and females averaged 104.1; the sample mean pretest EQ-i score was 105.16.

According to the Bar-On Technical Manual (2004),

The majority of respondents (approximately $68 \%$ will receive scores within 15 points of the mean (i.e. between 85 and 115). An even larger majority (about $95 \%$ with be within 30 points of the mean (i.e. between 70 and 130) and virtually all respondents (approximately 99\%) will receive scores within 45 points of the mean (i.e. between 55 and 145). (p. 39)

For the purposes of this study, it was assumed that $95 \%$ of the sample participants would fall within two standard deviations (i.e., between 70 and 130) and the power was set at $p$ $<.05$. The mean scores within each group were remarkably similar with a range in mean scores from 100.7 to 105.9. The difference in scores by gender at the onset was even closer with only 0.1 separating male from female students.

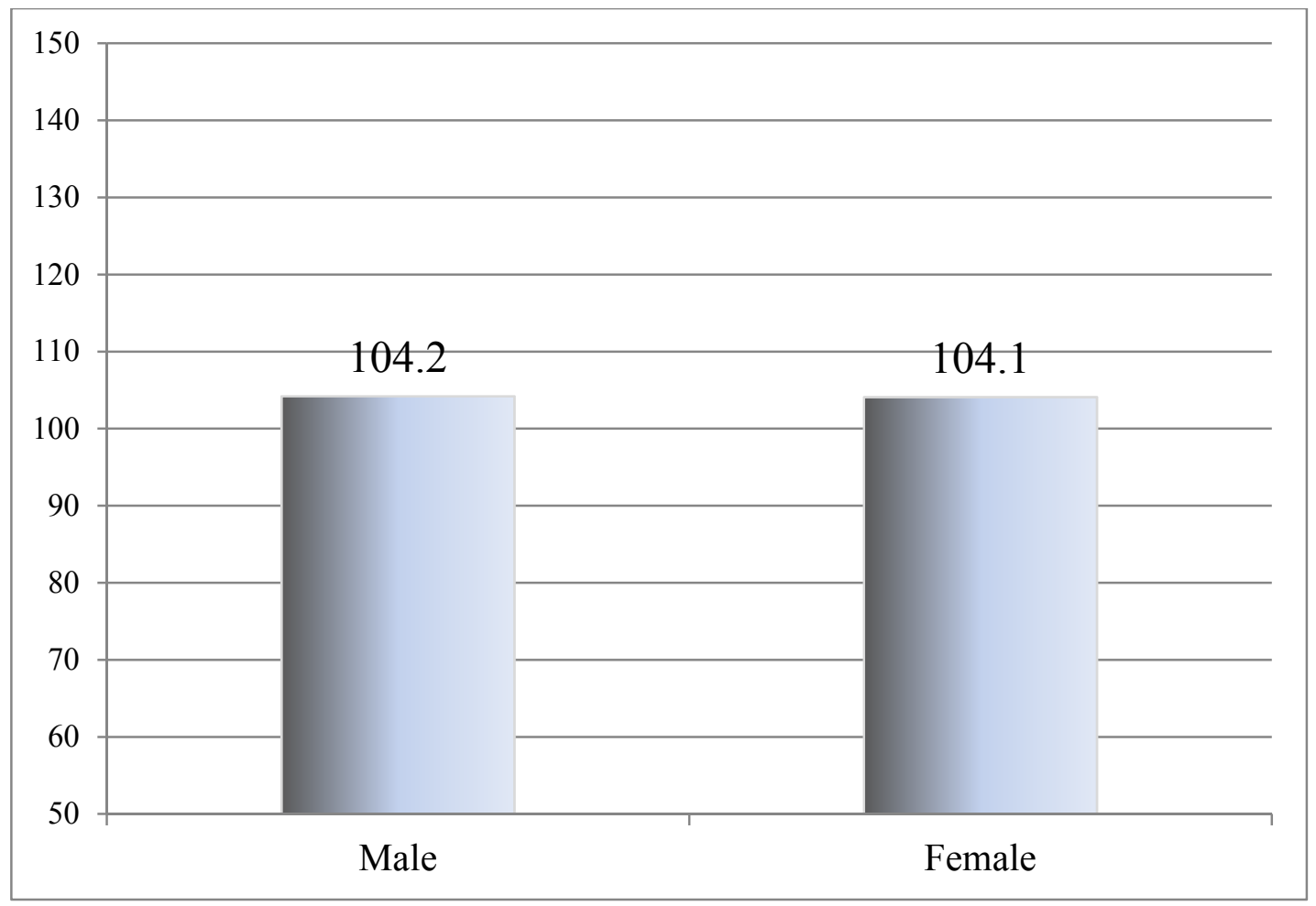

Figure 4. Mean pre EQ-i by gender. 
The first pair of research groups was subjected to the experimental and control conditions; Experimental Group I received the emotional intelligence curricular component described in Chapter 3 (Methodology) in addition to the traditional Introduction to Business curriculum. Control Group I received the traditional curriculum. The students in both groups completed a posttest EQ-i during the last 2 weeks of the semester. A significant statistical difference between pretest and posttest scores in the two groups was achieved in the treatment group with a $p$-value of 0.039 as illustrated in the SPSS output in Appendix J, indicating a significant difference between the group that had received the additional curricular component on emotional intelligence and the control group, which did not.

The second pair of research groups was subjected to the experimental and control conditions in which Experimental Group I received the identical emotional intelligence curricular component as described in Chapter 3. Control Group II received the traditional curriculum. In this semester, a marginal statistical difference between pretest and posttest scores was achieved as the independent samples $t$-test rendered a $p$-value $<0.075$, which approached the $p$ value of $<.05$, but did not meet the threshold. The SPSS output for the second pair is shown in Appendix K. The raw data for all four groups: pre- and post-test is shown in Figure 5. In Control Group II results, the mean assessment score is $<15$, one standard deviation for the EQ-i. The mean scores of the other five tests (the four groups' pretests and posttests) fall within one standard deviation of the population means on the Bar-On EQ-i assessment as shown in Table 4. 
Table 5

Pre and Post Test Scores for all Participants With Mean and SD and Gender Breakdown

\begin{tabular}{lllllll}
\hline Group & $n$ & All & $M(S D) n$ & Male $M(S D)$ & $n$ & Female $M(S D)$
\end{tabular}

Pre-EQ-i scores by group and gender

$\begin{array}{lcccccc}\text { E-I } & 31 & 105.8(12.9) & 17 & 104.5(14.8) & 14 & 107.4(10.5) \\ \text { C-I } & 23 & 100.9(9.7) & 15 & 99.2(8.6) & 8 & 104.1(11.3) \\ \text { E-II } & 28 & 105.9(14.0) & 18 & 104.7(10.0) & 10 & 108.0(19.7) \\ \text { C-II } & 29 & 103.3(14.6) & 15 & 108.3(10.7) & 14 & 97.9(16.6)\end{array}$

Post EQ-i scores by group and gender

$\begin{array}{lcccccc}\text { E-I } & 31 & 111.3(13.0) & 17 & 108.5(14.8) & 14 & 114.7(9.9) \\ \text { C-I } & 23 & 104.8(9.6) & 15 & 103.8(11.0) & 8 & 106.4(6.8) \\ \text { E-II } & 28 & 109.7(13.1) & 18 & 106.8(13.9) & 10 & 114.9(10.1) \\ \text { C-II } & 29 & 102.6(16.4) & 15 & 104.6(15.5) & 14 & 100.4(17.7)\end{array}$

Both Experimental and Control Groups

$\begin{array}{lrrrrrr}\mathrm{E} & 59 & 110.5(13.0) & 35 & 107.6(14.1) & 24 & 114.8(9.8) \\ \mathrm{C} & 52 & 103.6(13.8) & 30 & 104.3(13.2) & 22 & 102.6(14.8)\end{array}$

Note: E-1 (Experimental Group I); C-1 (Control Group I); E-II (Experimental Group II); C-II (Control Group II); E (both experimental groups); C (both control groups). 


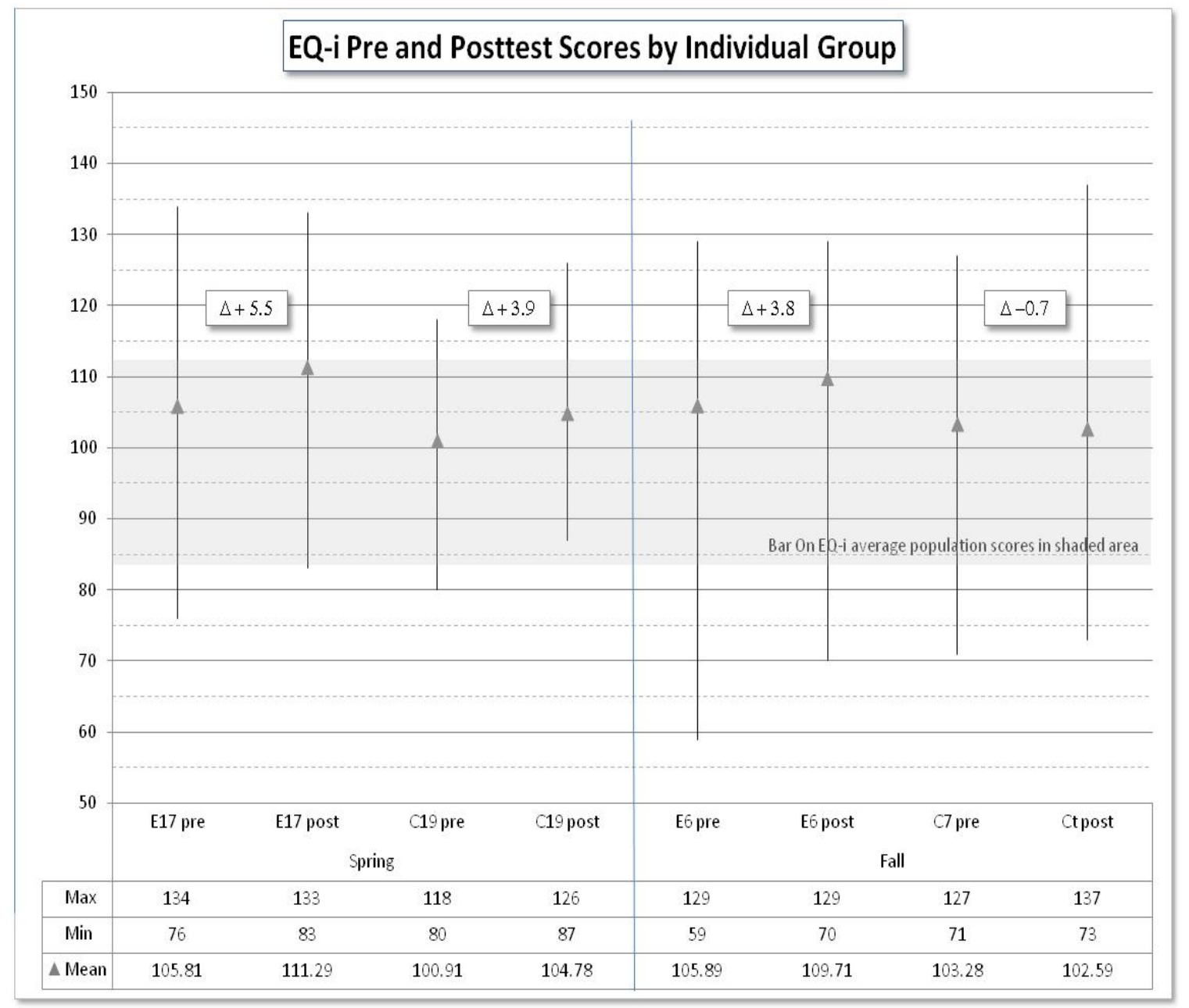

Figure 5. EQ-i pre and posttest scores by individual groups.

Both of the experimental groups and one of the control groups exhibited gains:

Experimental I (+5.5); Control I (+3.9); Experimental II (+3.8) while Control II group showed a loss of 0.7 .

Grouping of both experimental groups and both control groups showed a significant statistical difference between the pretest and posttest results for the male and female students with a $p$-value $<0.05$, as shown in the SPSS output in Appendix L. 
An ANCOVA power set at 0.85 and an effect size of .25 with $p$-value set at $<.05$ was performed on both groups (experimental and control) as shown in Appendix M. The raw data for the two groups, depicting means and gains, is showing in Figure 6 . When grouped together, both the experimental and control groups showed modest gains.

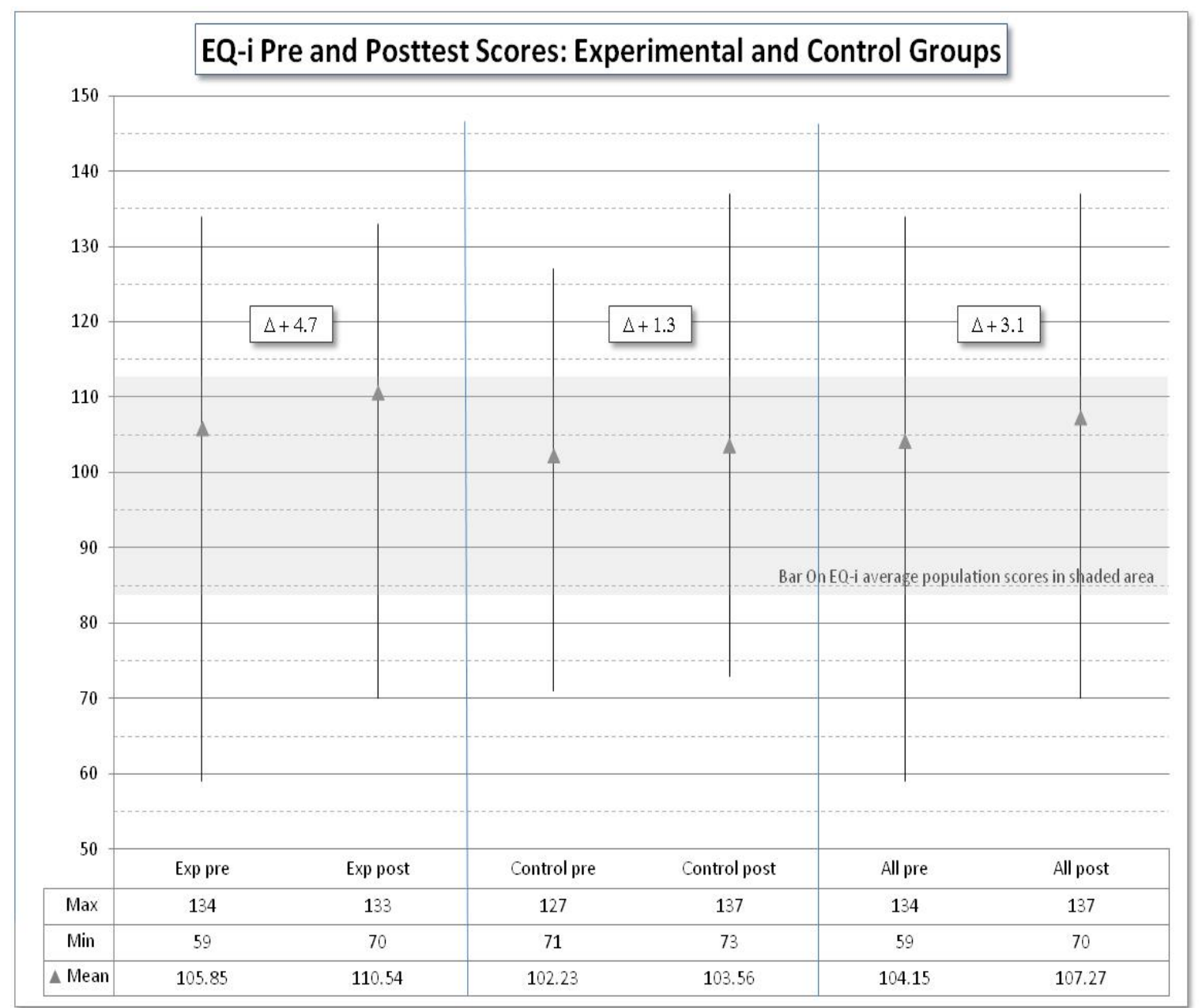

Figure 6. EQ-i pre and posttest Scores: Experimental and Control groups.

The number of students, their mean post EQ-i scores, and the standard deviation for all four groups are shown in Table 6. 
Table 6

EQ Posttest Results, Controlling for Pre-EQ-i Scores

\begin{tabular}{lcccl}
\hline Group & $N$ & Mean & $S D$ & Std. Error \\
\hline E-I & 31 & 111.3 & 13.0 & 1.52 \\
C-I & 23 & 104.8 & 9.6 & 3.1 \\
E-II & 28 & 109.7 & 13.1 & 3.04 \\
C-II & 29 & 102.6 & 13.7 & 2.45 \\
\hline
\end{tabular}

Note: E-1 (Experimental Group I); C-1 (Control Group I); E-II (Experimental Group II); C-II (Control Group II).

The EQ-i posttest between and within 4 groups is depicted in Table 7, indicating a significance of .022 .

Table 7

ANOVA EQ-i Posttest Between Groups

\begin{tabular}{lllllll}
\hline & & $\begin{array}{l}\text { Sum of } \\
\text { Squares }\end{array}$ & $d f$ & $\begin{array}{l}\text { Mean } \\
\text { Square }\end{array}$ & F & Sig \\
\hline EQ-i post & Between Groups & 1173.592 & 3 & 591.197 & 3.35 & .022 \\
& $\begin{array}{l}\text { Within Groups } \\
\text { Total }\end{array}$ & 18910.300 & 107 & 177.293 & & \\
& & 20743.892 & 110 & & & \\
\hline
\end{tabular}


A post hoc test was conducted to examine the EQ-I means between and within the four groups. There was a statistically significant and meaningful difference between Experimental Group I and Control Group II.

Table 8

Post Hoc Test (Bonferroni)

\begin{tabular}{llllll}
\hline Dependent Variable & (I) group (J) group Mean & Dif.Std. & Error Sig \\
EQ Post & & & & & \\
& \multirow{2}{*}{1.00} & 2.00 & 6.59467 & 3.66436 & .448 \\
& & 3.00 & 2.02876 & 3.71778 & 1.00 \\
& & 4.00 & 10.55435 & 3.74703 & $.035^{*}$ \\
& \multirow{2}{*}{2.00} & 1.00 & -6.59467 & & \\
& & 3.00 & -4.56618 & 3.66435 & .448 \\
& & 4.00 & 3.95968 & 3.43986 & 1.00 \\
& \multirow{2}{*}{3.00} & 1.00 & -2.02849 & 3.47145 & 1.00 \\
& & 2.00 & 4.56618 & 3.71778 & 1.00 \\
& & 4.00 & 8.52586 & 3.43986 & 1.00 \\
& 1.00 & -10.55435 & 3.52781 & .104 \\
& & 2.00 & -3.95968 & 3.74703 & $.035^{*}$ \\
& 3.00 & -8.52586 & 3.47145 & 1.00 \\
& & & & 3.52781 & 104
\end{tabular}

Note: Group 1 is experimental group I; group 2 is control group I; group 3 is experimental group II; and group 4 is control group II.

*Significant at the .05 level

\section{Phase-Three: Post Intervention}

In the final phase of the three-phase study, all students' $(N=111)$ post EQ-i scores were correlated with three traditional measures of academic success to determine if there was a significant correlation between emotional intelligence scores and traditional measures of academic success. The first measure of academic success was the students' GPA measured one major semester after completing the Introduction to Business course. Students who took the spring semester were assessed at the onset of the following spring 
semester and students who took the fall semester were assessed at the end of the following spring semester. The students' overall GPA was 2.56 on a 4.0 scale, and the correlation of the GPA to the post-EQ-i scores is depicted in Figure 7. A low positive correlation, $r=0.123, p<.05$, shows a slight positive correlation of the post EQ-i scores with the students' overall post GPA in this sample.

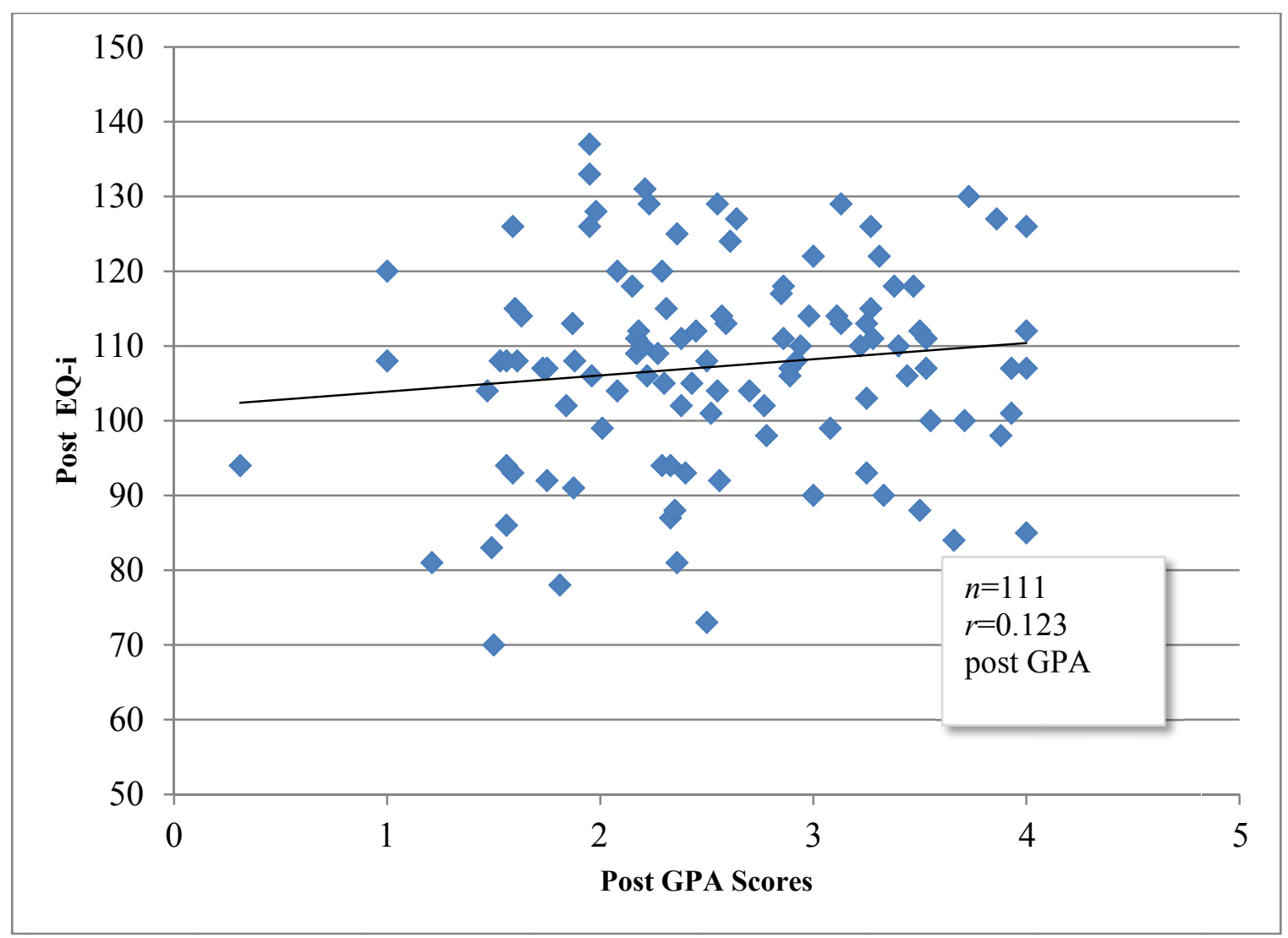

Figure 7. Post EQ-i and post GPA scores.

The second measure of academic success was the attempted-to-completed credit ratio. The data provided by the department of Institutional Research without taking into account transfer credits from other institutions indicates an $84 \%$ retention rate, but the impact of the post EQ-i scores is shown to have a low positive correlation of $r=0.098$ as shown in Figure 8. 


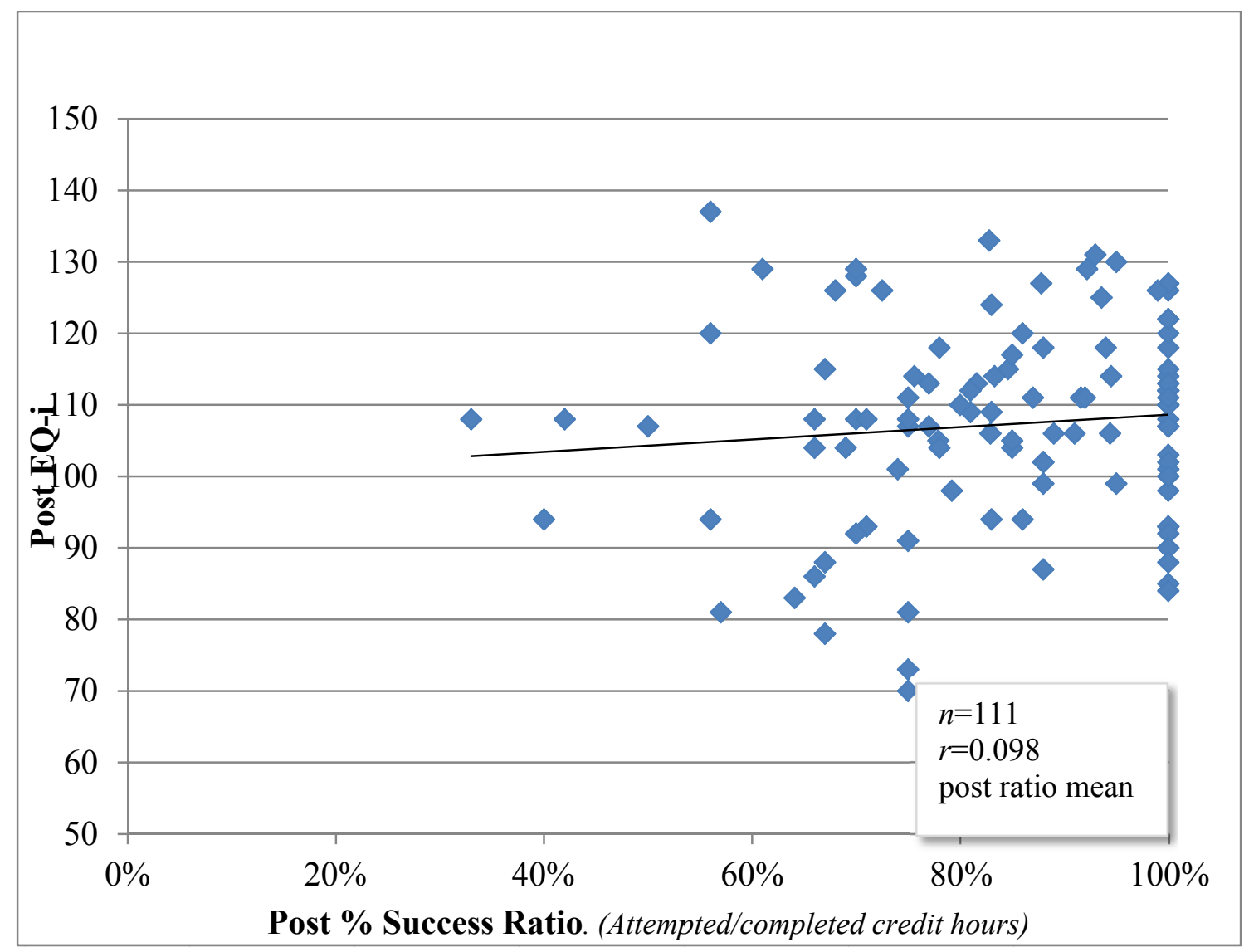

Figure 8. Post EQ-i and post attempted-to-completed credit ratio.

The third measure of academic success was the grade earned in the Introduction to Business course. The mean course grade for all participating students was 3.27 on a 4.0 scale. The level of correlation between the grade in the course and the students' post EQ-i indicated a low positive correlation of $r=0.19$. The scatter plot illustrating this relationship is shown in Figure 9. Table 9 shows the data by group and by gender as it relates to students' GPA and attempted-to-completed credit hour ratio one full semester after the treatment. 


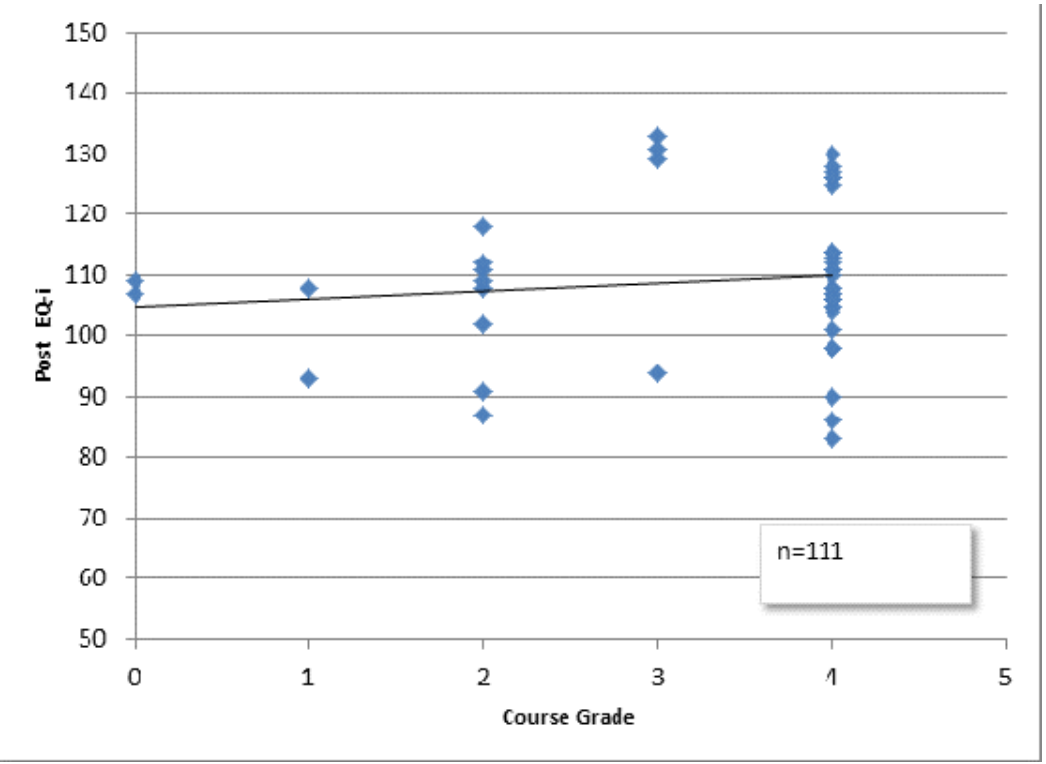

Figure 9. Post EQ-i scores and course grade.

Table 9

Post EQ-i Scores, Post-GPA and Attempted-to-Completed Credit Hour Ratio by Group

\begin{tabular}{lrlll} 
Group & $n$ & Post EQ- i Mean $(S D)$ & Post GPA Mean $(S D)$ \\
\hline E-I & 31 & $111.3(13.0)$ & $($ All $)$ & $2.56(.78)$ \\
C-I & 23 & $104.8(9.6)$ & $($ Male $)$ & $2.49(.65)$ \\
E-II & 28 & $109.7(13.1)$ & $($ Female $)$ & $2.67(.46)$ \\
C-II & 29 & $102.6(16.4)$ & Post CHR* Mean $(S D)$ \\
Group & $n$ & Post EQ- I Mean $(S D)$ & $.84(15.5)$ \\
\hline E-I & 31 & $111.3(13.0)$ & (All) & $.83(.65)$ \\
C-I & 23 & $104.8(9.6)$ & (Male) & $.86(46)$ \\
E-II & 28 & $109.7(13.1)$ & (Female) & \\
C-II & 29 & $102.6(16.4)$ & &
\end{tabular}


*Note: Credit Hour Ratio.

Figure 10. Correlations of Post-EQ-i scores and academic factors (course grade, attempted-to completed credit ratio and cumulative GPA one semester major semester after intervention)

\begin{tabular}{|c|c|c|c|c|c|c|c|c|c|}
\hline & & $\begin{array}{l}\text { Post } \\
\text { EQ-i }\end{array}$ & $\begin{array}{l}\text { Cr.GR } \\
\text { Grade }\end{array}$ & $\begin{array}{l}\text { Post } \\
\text { A-C } \\
\text { CHR }\end{array}$ & $\begin{array}{l}\text { Post } \\
\text { GPA }\end{array}$ & $\begin{array}{l}\text { E-I } \\
\text { Post } \\
\text { EQ-i }\end{array}$ & $\begin{array}{l}\text { E-2 } \\
\text { Post } \\
\text { EQ-i }\end{array}$ & $\begin{array}{l}\text { C-II } \\
\text { Post } \\
\text { EQ-i }\end{array}$ & $\begin{array}{l}\text { C-I } \\
\text { Post } \\
\text { EQ-i }\end{array}$ \\
\hline Post EQ-i & $\begin{array}{l}\text { Pearson } \\
\mathrm{r} \\
\text { Sig. }(2 \\
\text { tailed) } \\
\mathrm{N}\end{array}$ & 111 & $\begin{array}{l}.098 \\
.305 \\
111\end{array}$ & $\begin{array}{c}-.034 \\
.727 \\
111\end{array}$ & $\begin{array}{c}-.010 \\
.921 \\
111\end{array}$ & $\begin{array}{c}1.00 \\
0 \\
.000 \\
31\end{array}$ & $\begin{array}{c}.424 * \\
.025 \\
28\end{array}$ & $\begin{array}{c}-.187 \\
.331 \\
29\end{array}$ & $\begin{array}{c}-.190 \\
.385 \\
23\end{array}$ \\
\hline $\begin{array}{l}\text { Course } \\
\text { Grade } \\
\text { Intro to } \\
\text { Business }\end{array}$ & $\begin{array}{l}\text { Pearson } \\
\mathrm{r} \\
\text { Sig. }(2 \\
\text { tailed) } \\
\mathrm{N}\end{array}$ & $\begin{array}{l}.098 \\
.305 \\
111\end{array}$ & 111 & $\begin{array}{c}.238 \\
* \\
.012 \\
111\end{array}$ & $\begin{array}{l}.474 \\
* * \\
.000 \\
111\end{array}$ & $\begin{array}{c}.161 \\
.368 \\
31\end{array}$ & $\begin{array}{c}.116 \\
.557 \\
28\end{array}$ & $\begin{array}{c}.112 \\
.562 \\
29\end{array}$ & $\begin{array}{c}-.110 \\
.616 \\
23\end{array}$ \\
\hline $\begin{array}{l}\text { Post } \\
\text { Attempted } \\
\text {-to- } \\
\text { completed } \\
\text { Credit } \\
\text { Hour } \\
\text { Ratio }\end{array}$ & $\begin{array}{l}\text { Pearson } \\
\mathrm{r} \\
\text { Sig. }(2 \\
\text { tailed) } \\
\mathrm{N}\end{array}$ & $\begin{array}{l}-.034 \\
.727 \\
111\end{array}$ & $\begin{array}{l}.238^{*} \\
.012 \\
111\end{array}$ & 111 & $\begin{array}{l}.829 \\
* * \\
.000 \\
111\end{array}$ & $\begin{array}{c}.030 \\
.872 \\
31\end{array}$ & $\begin{array}{c}-.193 \\
.324 \\
28\end{array}$ & $\begin{array}{c}.112 \\
.562 \\
29\end{array}$ & $\begin{array}{c}-.110 \\
.616 \\
23\end{array}$ \\
\hline $\begin{array}{l}\text { Post } \\
\text { GPA }\end{array}$ & $\begin{array}{l}\text { Pearson } \\
\mathrm{r} \\
\text { Sig. }(2 \\
\text { tailed }) \\
\mathrm{N} \\
\text { Pearson }\end{array}$ & $\begin{array}{c}-.010 \\
.921 \\
111\end{array}$ & $\begin{array}{c}.474 * * \\
.000 \\
111\end{array}$ & $\begin{array}{l}.829 \\
* * \\
.000 \\
111\end{array}$ & 111 & $\begin{array}{c}.128 \\
.494 \\
31\end{array}$ & $\begin{array}{c}-.077 \\
.696 \\
28\end{array}$ & $\begin{array}{c}.084 \\
.664 \\
29\end{array}$ & $\begin{array}{c}-.051 \\
.816 \\
23\end{array}$ \\
\hline $\begin{array}{l}\text { E -I } \\
\text { Post EQ-i }\end{array}$ & $\begin{array}{l}\mathrm{r} \\
\text { Sig. }(2 \\
\text { tailed) } \\
\mathrm{N}\end{array}$ & $\begin{array}{c}1.000 \\
.000 \\
31\end{array}$ & $\begin{array}{c}.161 \\
.368 \\
31\end{array}$ & $\begin{array}{c}.030 \\
.872 \\
31\end{array}$ & $\begin{array}{c}128 \\
.494 \\
31\end{array}$ & $\begin{array}{c}1 \\
31\end{array}$ & $\begin{array}{c}.424 * \\
.025 \\
28\end{array}$ & $\begin{array}{c}-.187 \\
.331 \\
29\end{array}$ & $\begin{array}{c}-.190 \\
.385 \\
23\end{array}$ \\
\hline $\begin{array}{l}\text { E -II } \\
\text { Post EQ-i }\end{array}$ & $\begin{array}{l}\text { Pearson } \\
\mathrm{r} \\
\text { Sig. }(2 \\
\text { tailed) } \\
\mathrm{N} \\
\text { Pearson }\end{array}$ & $\begin{array}{c}.424 * \\
.025 \\
28\end{array}$ & $\begin{array}{c}.116 \\
.557 \\
28\end{array}$ & $\begin{array}{c}-.193 \\
.324 \\
28\end{array}$ & $\begin{array}{c}-.077 \\
.696 \\
28\end{array}$ & $\begin{array}{c}.424 \\
* \\
.025 \\
28\end{array}$ & 28 & $\begin{array}{c}-.221 \\
.258 \\
28\end{array}$ & $\begin{array}{c}-.116 \\
.598 \\
23\end{array}$ \\
\hline $\begin{array}{l}\text { C -II } \\
\text { Post EQ-i }\end{array}$ & $\begin{array}{l}\mathrm{r} \\
\text { Sig. }(2 \\
\text { tailed) } \\
\mathrm{N}\end{array}$ & $\begin{array}{c}-.187 \\
.331 \\
29\end{array}$ & $\begin{array}{c}-.331 \\
.079 \\
29\end{array}$ & $\begin{array}{l}.112 \\
.562 \\
29\end{array}$ & $\begin{array}{c}.084 \\
.664 \\
29\end{array}$ & $\begin{array}{c}-.187 \\
.331 \\
29\end{array}$ & $\begin{array}{c}-.221 \\
.258 \\
28\end{array}$ & $\begin{array}{c}1 \\
29\end{array}$ & $\begin{array}{c}-.350 \\
.101 \\
23\end{array}$ \\
\hline
\end{tabular}




$\begin{array}{llcccccccc} & \text { Pearson } & & & & & & & & \\ & \mathrm{r} & -.190 & .284 & -.110 & -.051 & -.190 & -.116 & -.350 & 1 \\ \mathrm{C}-\mathrm{I} & \text { Sig. }(2 & .385 & .189 & .616 & .816 & .385 & .598 & .101 & \\ \text { Post EQ-i } & \text { tailed) } & 23 & 23 & 23 & 23 & 23 & 23 & 23 & 23 \\ & \mathrm{~N} & & & & & & & & \end{array}$

**Correlation significant at the 0.01 level

*Correlation significant at the 0.05 level

\section{EQ-i Pretest and Posttest Results by Gender}

A comparison of overall mean scores for all participants was conducted to establish gain scores for each gender. Male students increased their overall EQ-i scores from 104.2 to 106.1 , a gain of 1.9 points. Female students showed a stronger gain from 104.1 to 109.0, a difference of 4.9 points. These results suggest that female students were more sensitive to the concept of emotional intelligence, whether they were in the control or experimental groups. Table 4 shows the mean and standard deviation for each group and the breakdown by gender. Tables 8 and 9 illustrate the $t$-test comparison by gender and the ANOVA posttests by gender. Figure 10 illustrates the gain scores. 


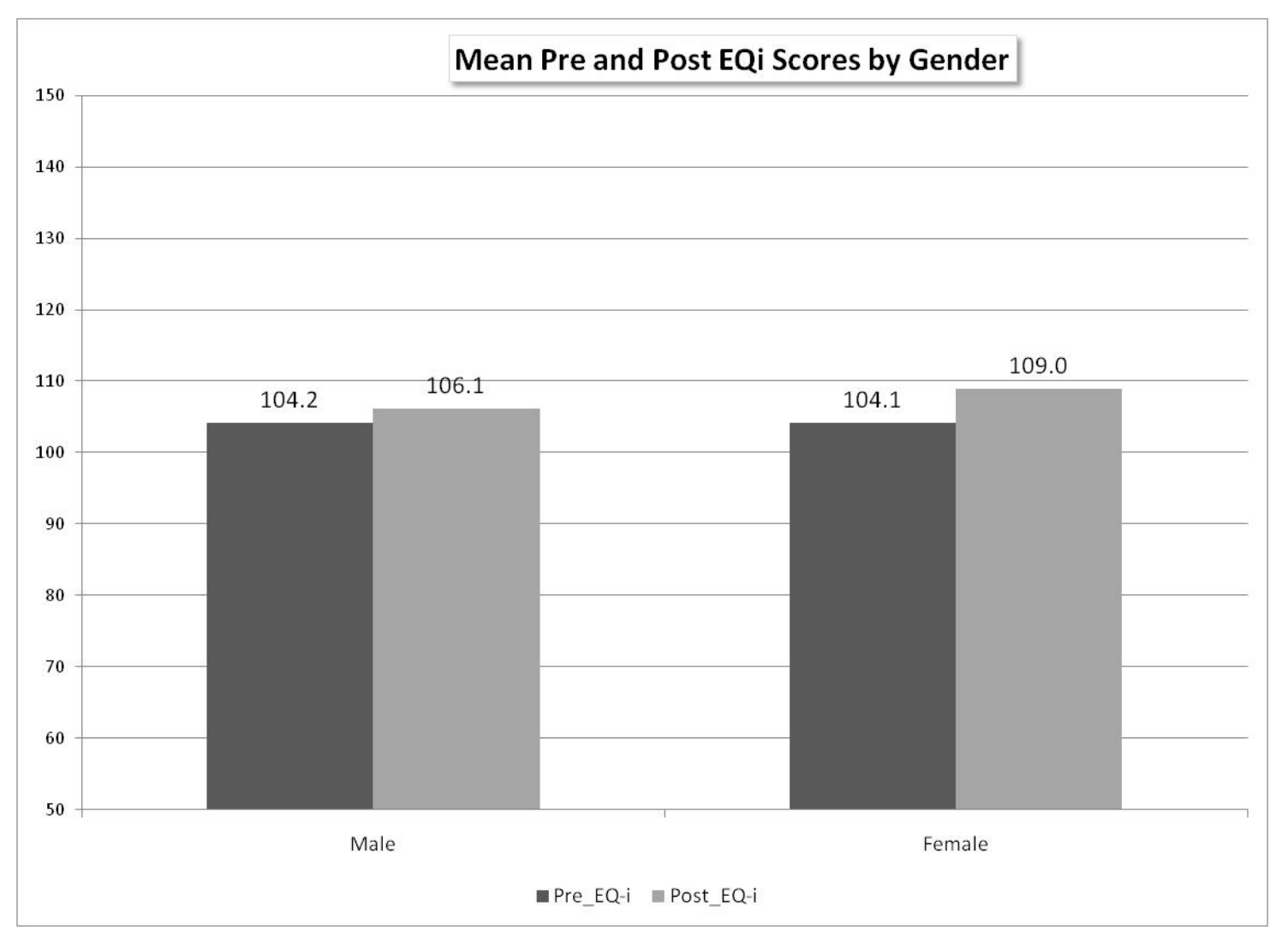

Figure 11. Mean pre and post EQ-i scores by gender.

Table 10

Paired Sample T-Test Pretest and Posttest (Gender)

Mean $\quad S D \quad d f \quad$ Sig. (2 tailed)

Pair 1 male-EQ Pre

103.20

$11.5 \quad 64 \quad .000 * *$

Pair 2 male- EQ Post

105.08

$13.70 \quad 64 \quad .000 * *$

Pair 1 female-EQ Pre

102.09

$15.11 \quad 45 \quad .000 * *$

Pair 2 female-EQ Post

106.96

$13.74 \quad 45 \quad .000 * *$

Pair 1 female-EQ post

106.96

$13.74 \quad 45 \quad .000 * *$

Pair 2 male-EQ post 105.08

$13.71 \quad 64 \quad .000 * *$

Note: **Significant at .01 level 
Table 11

One Way ANOVA EQ Post by Gender

Sum of squares

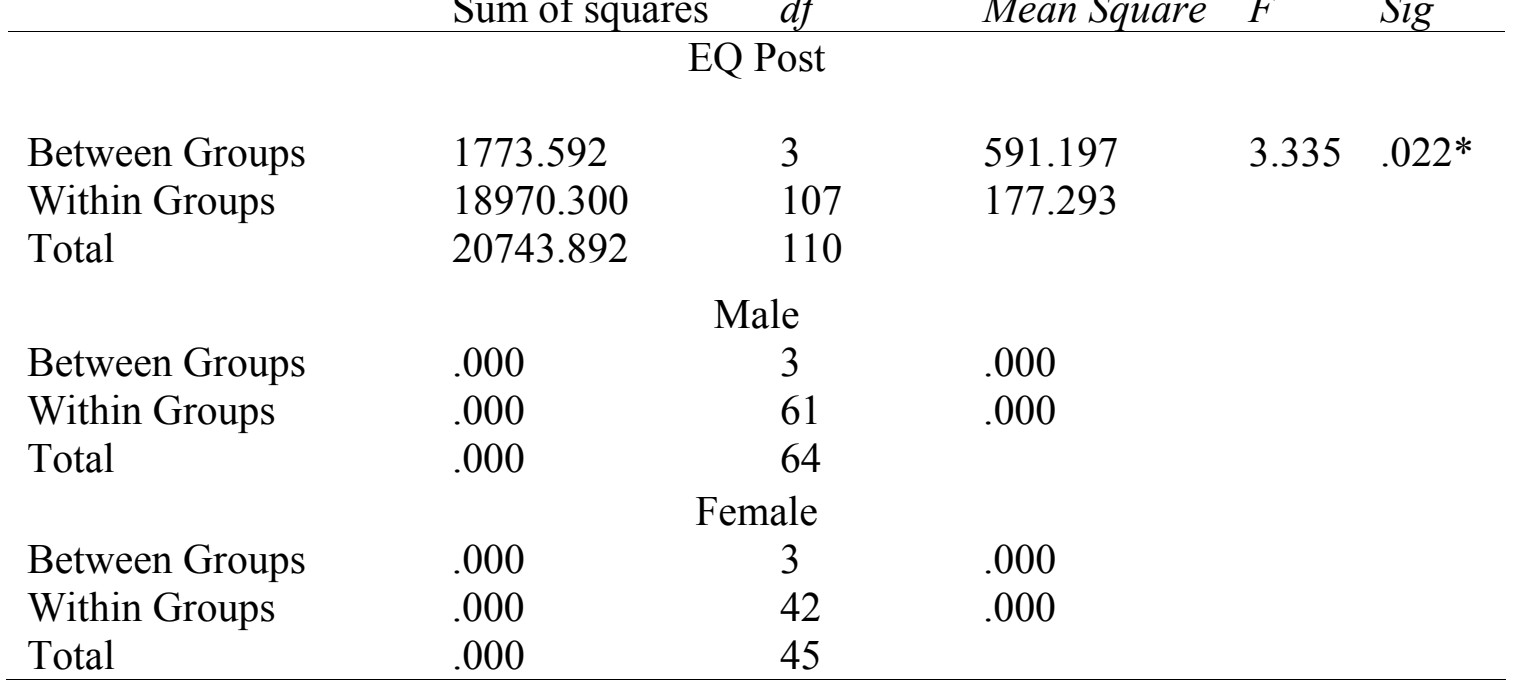

Mean Square

F Sig

The findings demonstrated that in spite of the restricted range population of 111 students in an Introduction to Business course in a 2-year college where many students enter with academic deficiencies; there was a slight positive correlation between traditional measures of academic success (GPA, attempted-to-completed credit hour ratio, grade in the Introduction to Business course and persistence). Large gains in these academic factors were not expected given that they were assessed at the end of one major semester following the treatment. Increases, if any, would be small and gradual. The fact that the intervention in both semesters was meaningful is significant and provides direction for future study. Finally, the larger gains by the women in the study indicate a possible advantage in learning about and utilizing emotional intelligence to support their academic endeavors. 


\section{CHAPTER V}

\section{DISCUSSION}

This research was conducted with the hope of discovering whether higher levels of overall emotional intelligence could be included among the factors that contribute to greater student success. Students entering 4-year institutions must demonstrate greater academic readiness for college, compared to those who opt for a 2-year open access college. Public and private 4-year institutions use a number of criteria to evaluate a student's readiness. Two indicators in particular, the GPA and the SAT or ACT scores are often used to determine a student's readiness to manage the academic rigor of higher education. The feasibility of including an emotional intelligence assessment for incoming or first-year students to help identify students who are academically prepared but still at risk for dropping out are discussed in this chapter.

In associate degree granting institutions, students may enter college much more unprepared in terms of academic readiness. A policy of open admission provides educational opportunity for those students requiring remediation. Student must have completed high school and earned either a standard diploma or GED. The Florida Department of Education (2011) First Time in College Readiness Report indicated that the majority of students in Florida require remediation in one of three areas, (math, reading, or English), full-time students fare better than part-time students, males fare better than female students, and traditional age, younger students, are more college-ready than older students. In spite of the difference in academic readiness, both 2-year and 4year institutions lose approximately $30 \%$ of their first year students and this trend has 
been constant over at least the last three decades. Clearly something beyond academic readiness accounts for this lack of persistence.

This study explored the role of emotional intelligence in college student success at a large, urban community college in southeast Florida. A three-phase research design was developed to address the possibility that traditional measures of academic success could be positively correlated at a significant level with higher emotional intelligence. The four measures of academic success correlated with the students' posttest emotional intelligence assessment, were (a) GPA, (b) attempted-to-completed credit hour ratio, (c) grade in the Introduction to Business course, and (d) the students' persistence or graduation one full term after intervention. In addition, the researcher was interested in determining whether gender had any bearing, as has been suggested in the literature (Zeidner, Matthews, \& Roberts, 2009), in contributing to higher emotional intelligence.

Research in the area of academic success has shown that students with higher emotional intelligence scores also tend to be more successful academically (Holt, 2007; Nelson \& Nelson, 2003, Parker et al., 2005; Vela, 2004; Walker, 2006, Zeidner et al., 2009). There has been much research done regarding the student's GPA as a predictor for retention in the freshman year (Bar-On \& Parker, 2000; Debarard, Spelmans, \& Julka, 2004). The evolution of emotional intelligence as a separate construct has been both recent and relatively swift. Interest in one's emotional development and the role it played in student success could be seen as early in the writings of John Dewey (1909) and Edward Thorndike (1920). Tinto (1987) labeled four factors responsible for college student departure in his work: adjustment, difficulty, incongruence, and isolation. Chickering and Reisser (1993) identified managing emotions as one of the seven vectors 
in college student development. Howard Gardner (1983) published Frames of Mind exploring multiple intelligences and identifying different ways in which people demonstrate talent and excel in addition to IQ. When John Mayer and Peter Salovey published their research in the late 1980s and early 1990s, respectively, a willingness to consider emotional intelligence as a separate construct in the fields of educational research and psychology already existed.

Daniel Goleman's (1995) publication of Emotional Intelligence made the concept of emotional intelligence more accessible and for awhile; it seemed to be the latest fad. Researchers, such as Salovey and Mayer (1990), Bar-On, "who has been involved in defining, measuring and applying emotional and social intelligence since 1980" (Bar On \& Parker, 2000, p.505) and others had been conducting research showing promising results at the same time, and many of those results had gone largely unnoticed outside the academic realms of education and psychology. In the last 15 years, however, the field has matured, and a number of practitioners have emerged with different assessment strategies. In addition to Goleman who developed the Emotional Competence Inventory (ECI) with colleagues Boyatzis and Rhee (2000), and Mayer, Salovey, and Carruso (2000) developed the Mayer-Salovey-Carruso Emotional Intelligence Test (MSCEIT), Reuven Bar-On (1997) also produced his own Emotional Quotient Inventory (EQ-i) based on five areas of emotional intelligence competence. These areas are intrapersonal ability , interpersonal ability, adaptability, stress management, and general mood. This assessment strategy had been widely tested and validated for two decades before it became available for other researchers to use in their own studies. The EQ-i has been used in a number of research studies involving college students and was also used in this 
one. The possibility of focusing on one or more of the subscales, such as "impulse control" or "problem-solving", was considered; however, for this research the overall composite score of all five major areas was used as the students' emotional intelligence pre and posttest scores.

The three-phase study was carried out over two semesters for each pair of research groups. To establish the correlation between the students' GPA and preintervention emotional intelligence score, only students who had been enrolled at the college in the previous semester(s) to the research were considered for Phase 1 . Of the 111 students who comprised the sample, 82 of those had already been enrolled for at least one semester. Those students' $(N=82)$ pretest emotional intelligence scores were correlated with their incoming and established GPA and attempted credit-to-completed credit ratio.

Phase 2 consisted of a quasi-experimenal design with students in the first semester enrolled in one of the two sections of Introduction to Business $(N=54)$; of those, 31 were enrolled in the experimental group and 23 were enrolled in the control group. At the end of the first semester, an ANCOVA of the students' post-treatment emotional intelligence scores was conducted to determine if the treatment had produced a statistically significant result and it had. The following semester, two additional groups, with 29 students in the control group and 28 students in the experimental group, were also selected from the Introduction to Business sections and the same conditions (treatment, professor, schedule, and delivery mode) were repeated. An ANCOVA was performed to determine if the statistically significant effect seen in the previous semester could be replicated and it was. 
Phase 3 consisted of correlating all participants' posttest EQ-i scores with the traditional measures of academic success identified for the study: GPA, attempted-tocompleted credit hour ratio, grade in the course, and persistence or graduation one full semester after the intervention.

\section{Discussion of Overall Findings}

The study yielded many unexpected results. In spite of what has been reported in the literature (Bellack, 1999; Elder, 1997; Jaeger, 2003, Liptak, 2005, Ramos-Sanchez \& Nichols, 2007; Vela, 2003; Walker, 2006), there was little correlation between traditional measures of academic success (GPA, attempted-to-completed credit hour ratio, and grade in the course) and higher emotional intelligence scores. The results showing that the students who had higher GPAs and a higher attempted-to-completed credit hour ratio did not necessarily have higher scores on the EQ-i, and that students whose GPA and attempted-to-completed credit hour ratios were lower may have had higher EQ-i scores seemed counterintuitive. These results are supported by other research, which has found that overall GPA and EI are not correlated (Izaguirre, 2008; Jaeger \& Eagan, 2007; La Civita, 2003). A study conducted by Parker et al. (2004) among 667 high school students reported a moderate correlation of $r=0.33$ between EI scores and academic success, with the correlation slightly higher among females than among males (Zeidner et.al., 2009). The correlation in that study was much higher than the correlation in this study, but this research also found that female students were more likely to have higher initial scores and to increase their overall scores as they moved through the coursework.

The mixed results in this study may have been due to participants in the sample, the size of the sample, or other unidentified factors. A single class with what was 
considered "traditional" students is no longer so easily defined. Students requiring remediation, dual-enrolled students, academically prepared students delaying transfer, students who are new immigrants, students whose native language is not English, working parents, single and married, may all be in the same class and all of these students bring life experiences from their personal histories, cultural and countries of origin that might very well play a role in different aspects of emotional intelligence. Examining the overall composite scores may have diluted the results that examining particular subscales would have revealed. In other words, strong characteristics in one subscale may have compensated for weaker results in other subscales. The analysis of the subscale scores of emotional intelligence as they relate to academic success may well be worthy of further research. Further examination of the literature shows that independence, problem-solving skills, adaptability, and stress tolerance in particular seem to have more highly correlated results to better academic performance (Izaguirre, 2008; Holt, 2007; Jaeger, 2004, La Civita, 2003; Parker et al., 2004; Vela, 2003; Walker, 2003).

During the intervention phase, the first two groups showed a statistical difference in overall emotional intelligence attainment after the treatment. This was remarkable considering that the intervention was only one-semester long and comprised approximately 10 contact hours in class time during the semester. The second two groups failed to meet the same threshold of $p<.05$, but still yielded meaningful results at $\mathrm{p}<.075$, supporting the mixed results cited in the literature (Jaeger, 2003, Jaeger \& Eagan, 2007; Zeidner et al., 2009). Sample sizes were limited by the cost of testing, which was approximately $\$ 15$ a student. Larger samples might have yielded an even 
more precise assessment of the students' emotional intelligence attainment after the semester-long intervention.

One aspect that was supported in the literature and which was reinforced in this study was the fact that women may have an advantage in understanding and using emotional intelligence (Castro-Wang, \& Johnson, 2003; Schutte, 1998; Zeidner et al., 2009) to aid them not only in navigating the world of higher education, but life in general. In the following sections, the summary of findings in each of the three phases, as well as the research questions are addressed.

\section{Phase I: Summary of Findings}

The first phase of the three phase study examined the possible correlation of the students' pretest EQ-i scores with (a) their cumulative GPAs and (b) their attempted-to completed credit hour ratio at a the time they enrolled in the Introduction to Business course. Only the 82 students who had an academic history at the institution were included in the first phase. (Initially, only the 45 students with an established GPA and attempted-to completed credit hour ratio from the spring semester were included in phase 1. At the start of the fall semester, the additional 37 students' data from the second pair of groups was included to reach $N=82$.) Students who transferred in a GPA from another institution, or transferred credits without actually being enrolled in courses, such as first time in college (FTIC) students, were not included in this phase. The correlation between the EQ-i pretest scores with a mean of 105.16 and students' GPA with a mean of 2.44 rendered a positive correlation of $r=0.138, p<.05$; and the attempted-to- completed credit hour ratio mean of $82 \%$ to the pretest scores with a mean of 105.16 rendered an lower positive correlation of $r=.09$. The restricted range population (2-year colleges 
with many underprepared students in an Introduction to Business course) may be a contributing factor in these results. The mean pretest EQ-i assessment scores of the sample of students included in the first phase of the study had a higher than average (but still within the average for the population) EQ-i assessment score at 105.16; but also a higher attempted to completed credit hour ratio of $82 \%$ compared to the college population. The mean GPA in students' official transcripts for this target college population was not used because the sample population GPA was subjected to the "noforgiveness" filter for the purposes of this research. It would seem, however, that with the no-forgiveness factor included, a mean GPA of 2.44 for the sample is probably higher than the population mean. Although it is possible to argue that overall emotional intelligence could be positively correlated to higher GPAs or more persistence and selfmanagement as shown in the attempted-to-completed credit hour ratio, this sample, however, did not show a strong correlation. Further review of students' median ages or other demographic aspects could provide some insight as to why this sample did not yield the expected results based on much of the previous research in other higher education settings (Jaeger, 2003; Vela, 2003).

At the conclusion of the first phase, it was determined that in this sample there was a positive correlation between traditional measures of academic success (GPA and a higher attempted-to-completed credit ratio) and higher emotional intelligence as measured by the EQ-i pretest; however, it was so low that it may not be meaningful.

\section{Phase II: Summary of Findings}

In the second phase of the research, two experimental groups: Experimental Group I and Experimental Group II, in two different semesters, received identical 
treatment, which included infusing the Introduction to Business curriculum with an emotional intelligence component as described in Chapter 3 (Methodology). The other two groups deemed the control groups, Control Group I and Control Group II, received the traditional Introduction to Business curriculum. During the first pairing in the spring semester, the experimental group showed a statistically significant increase in the emotional intelligence assessment scores compared to the control group.

In the fall semester, however, in an attempt to replicate the results from the previous semester and to demonstrate that emotional intelligence could be taught as was shown in an earlier study (Jaeger, 2003), the results did yield a statistically significant increase in the emotional intelligence assessment scores between the experimental and control groups, but the correlation was low. The fact that Jaegar's (2004) study focused on graduate students and this study focused on undergraduates in a community college could explain part of the difference. It was important to include Jaegar's study; it was the only one to include a curricular component, and it also demonstrated statistical significance as did this study. Jaeger's (2004) work with graduate students had some success in this area, but other researchers (Izaguirre, 2008; LaCivita, 2003) have focused on certain aspects or subscales (rather than overall emotional intelligence) of Bar-On's (2004) emotional intelligence construct to demonstrate an increase or improvement.

Upon conclusion of Phase 2 of the research, it was demonstrated that an emotional intelligence component could be infused in the curriculum to cause a significant increase in student's overall emotional intelligence scores as measured by an ANCOVA controlling for the students' pretest scores. Both semester interventions yielded significant results. The spring groups showed significance at the $p<.05$ and the 
fall groups at $p<.075$. The results, therefore, are promising, but one cannot conclusively state that the infused emotional intelligence component in the Introduction to Business course curriculum resulted in a consistent significant statistical difference in students' overall emotional intelligence as measured by the EQ-i posttest at the $p<.05$ threshold.

\section{Phase III: Summary of Findings}

In the third phase of the three-phase study, all students' $(N=111)$ post-score EQ-i assessment scores were correlated with three traditional measures of academic success: the students' GPA, the students' attempted-to-completed credit ratio one major semester after participating in the study; and the grade the students received in the course. One semester after completing the Introduction to Business course, the students' overall mean GPA was 2.56 on a 4.0 scale, and the correlation of the GPA to the posttest-EQ-i scores resulted in a low positive correlation of $r=0.123$.

At the end of one completed major semester after participation in the research, the sample showed an $84 \%$ attempted-to-completed credit hour ratio and the post EQ-i scores resulted in a low positive correlation of $r=0.098$. The attempted-to-completed credit hour ratio was measured one full semester after the research was completed, and $84 \%$ is high especially considering that the data provided by the Department of Institutional Research made no allowances for courses taken and passed at other institutions.

The level of correlation between the grade in the course and the students' post EQ-i also indicated a low positive correlation of $r=0.190$, demonstrating that the post EQ-i scores in this sample yielded a low correlation with the students' grades. In this phase of the study, it appeared that all of the traditional measures of academic success (GPA, attempted-to-completed credit hour ratio and grade in the course) had a low 
positive correlation to the posttest assessment scores as measured by the EQ-i for this sample.

The retention of the 111 students after one major semester was also examined for this research to determine whether students with higher EQ-i scores would also be more likely to persist in their college studies. Students who were enrolled one complete semester after their participation, or had graduated in the term following their participation in the study, were considered "persisters" while those who dropped out immediately following their participation or during one major semester after their participation were identified as "non-persisters." Overall, 97 of the 111 (87\%) students who participated were still enrolled in the college or had graduated. That retention rate is unusually high compared to population data, which shows a much larger drop-off from one year to the next. Again, with this sample, the statistical correlation between the persisters and their EQ-i posttest scores was low.

\section{Findings related to Gender}

Finally, the researcher examined the aspect of gender. The literature has suggested that women may have a greater advantage in terms of particular subscales of emotional intelligence, particularly in empathy. Some studies have suggested that perhaps women are more likely to have emotional intelligence in areas of "empathy, awareness of the feelings of others, and coping with stress through 'tending and befriending', all components central to emotional intelligence" (Zeidner et al., 2009, p. 20). Perhaps female college students have an advantage resulting in greater persistence and overall success in school. This study showed that male and female students were almost equally retained: $87 \%$ of the women and $88 \%$ of the men. Their pretest assessment scores were almost identical: 104.2 for males and 104.1 for females. The 
posttest EQ-i assessments resulted in mean score of 106.1 for all male students, a modest 1.9 point gain; and 109.0 for all female students, a 4.9 gain. The experimental groups mean post scores for male students was 107.6; for female students, it was 114.8. The control groups mean post scores for male students was 104.3; for female students, it was 102.6. The women in the treatment groups showed a 7-point gain (107.7 to 114.8) whereas the men in the treatment groups showed a modest gain of 3.0 points (104.6 to 107.6) from pretest to posttest. These results suggest that women, in this sample, when exposed to the curricular component of emotional intelligence in the Introduction to Business course were able to assimilate the information and learn to use emotional intelligence to raise their own overall emotional intelligence significantly. Although previous studies correlating emotional intelligence and gender have had mixed results in previous studies (Bar-On, 2000; Izaguirre, 2008; Jaeger \& Eagan, 2007; Parker et al., 2005), this research demonstrated that the curricular intervention made a clear difference for female students.

The population of community college students is clearly amorphous with the multiple roles that community colleges play. Community colleges have expanded their roles to include the conferring of 4-year degrees; they have increased their role in the community and governmental relations intensifying vocational and employment-driven programs. Funding at the state level has steadily decreased compelling more academically-prepared students to look for a less expensive means of attaining a quality education through grants and scholarships delaying transfer to a traditional 4-year institution. The majority of community college students at this institution are not unlike those found across the country: close to $80 \%$ require remediation in at least one of three 
areas (English, reading, or math). Students typically are struggling to juggle a multitude of obligations outside the classroom from employment to families. In doing this research, it was expected that traditional age students who had better results in the traditional aspects of academic success would also have higher emotional intelligence. That was not decisively demonstrated in this study.

It might be inferred from the results of this study that in this sample, students who have already demonstrated higher emotional intelligence may also be students who represent the gamut of all those students who attend community colleges. Surely students, who may be raising children, working, financially challenged, or socioeconomically disadvantaged in any aspect, have the same struggles as any other student in those conditions regardless of their ages. Clearly some of the non-traditional characteristics may have some interaction with emotional intelligence and further research on non-traditional students in 2-year degree-granting institutions might yield additional insight in the field of emotional intelligence. As stated in the Choy's (2002) Department of Education report,

The "traditional" student is not typical. Fully three-quarters of all Postsecondary students in 1999-2000 had at least one nontraditional characteristic. The most highly nontraditional students (those with four or more nontraditional characteristics) were concentrated in public 2-year institutions, with two-thirds enrolled in this type of institution. (p. 19)

This viewpoint is supported by Izaguirre's (2008) study, which focused on additional demographic factors such as employment and marital and parental status for that study. Results showed students who had been divorced or were employed scored higher in the Adaptability (Flexibility) subscale. That makes sense because learning to deal with adversity successfully, such as going through a divorce, is likely to increase 
one's ability to adapt. There were also reported differences between the genders in the Interpersonal emotional intelligence subscale. The findings did not support a strong correlation between overall emotional intelligence as measured by the EQ-i and the academic achievement as measured by the GPA.

In terms of the intervention in both semesters, it may be inferred that in order to conclude that higher emotional intelligence can indeed be taught, a much larger sample size would be required. One group of 54 students and another of 57, while statistically sound for this research, are too few to generalize that emotional intelligence can be taught and result in higher overall assessment scores in the population of traditional age students. The cost of training a certified researcher (approximately \$3000) and the cost of individual assessments with reports for participating students at around $\$ 15.00$ each to conduct the EQ-i limited the number of participants. (Two other options, the ECI and the MSCEIT involved even greater costs and were not considered for this study.) Newer generations of assessment instruments are becoming available, and perhaps the cost of assessment will eventually become more accessible for researchers and colleges.

In terms of the traditional measures of academic success and emotional intelligence, it may also be inferred from this study that while higher emotional intelligence is certainly not a barrier to greater academic success, there may be other factors in this population particularly in the socio-economic realm, which have a much more dominant impact or influence in this population.

In terms of gender and emotional intelligence, this sample demonstrated that female students could greatly improve their emotional intelligence once they received the 
treatment. Although their emotional intelligence assessments increased significantly, its correlation with the academic factors measured was not easily detected.

\section{Limitations}

The EQ-i, like many other assessments is self-reported, which could result in less than objective input on the part of the participant. The sample size of $N=111$ limited the amount of data that was collected for this study. The cost of approximately $\$ 15.00$ per student also limited the number of participants in the study as did the initial certification process for the research and interpretation using the Bar-On EQ-i. One of the greatest limitations, therefore, in the study was the instrument itself due to its prohibitive cost. Becoming certified through MHS while seeking either individual or site permission to conduct research is not a practical option for most state or community colleges dependent on public funding and limited tuition income.

The heterogeneous nature of the students who were enrolled in the Introduction to Business course could also be a limitation. Students with a declared A.A. track in Business might have been more focused than those, for example, who were still completing a prep track and contemplating different areas of study at the college. Only sections taught by the researcher participated in the study because only certified researchers or psychologists who have completed the three-day training (with a cost of more than $\$ 1000$ plus expenses) in using the EQ-i assessment instrument would be able to access the tool through MHS. The researcher is the only individual certified to use the EQ-i assessment instrument at the college. Because only students at the main campus participated in this study, population differences at other locations in terms of 
demographics might have yielded different results, and finally, not all students were able to complete both the pretest and posttest assessments, which would have provided additional data.

\section{Policy and Practice}

Emotional intelligence assessment is not limited to the Bar-On 133-item EQ-i; there are other instruments that have demonstrated reliability and validity. The other two mentioned in this study the ECI (Emotional Competency Inventory) and the MSCEIT (Mayor, Salovey and Caruso Emotional Intelligence Test) are more expensive and the training to administer them is also more expensive. At the other end of the cost spectrum, there are free assessments of emotional intelligence offered online at such sites as Queendom. Another self-reporting site can be found on the Internet through Discovery Health Series or others, through "PsychTests." After completing the assessment, one has the option of purchasing a more detailed report. While these free online assessments may be helpful on an individual basis, they are probably not appropriate for most institutional needs especially for those colleges advising thousands of students.

Recognizing the opportunity for emotional intelligence assessment in the collegeage population, MHS has developed at least two new assessments aimed at university students. These assessments, The Emotional and Social Competence InventoryUniversity Edition (a special version of the Boyatzis-Goleman assessment tool) and the EQ-i University version are now available through MHS to certified trainers and researchers. These assessments are costly and fall short of specifically addressing the needs of community college students. 
Although these instruments have been developed for the university population, they may still lack what is needed for the heterogeneous community college population. Reliable and valid, yet cost-effective, instruments, which specialize in the less-thancollege ready population at most community and state colleges, need to be developed. At a research institution, an in-house instrument could probably be developed and tested for reliability and validity to address the needs of community college students. It would involve a significant investment of time, human and financial resources as well, but the need to support this at-risk population may well justify the investment.

Learning more about this population in terms of emotional intelligence assessment could provide additional tools to address weaknesses through curricular intervention. In the meantime, securing a grant to train colleagues in various disciplines (from Nursing to Business) about emotional intelligence and developing curriculum that includes an EI component might be a practical starting point for the college. Many disciplines have peer-reviewed literature relating to EI and engaging faculty in a systematic way through professional staff development to infuse EI concepts and assess results would raise awareness of the various components of emotional intelligence, which first-year students find challenging, including problem-solving, impulse control, and adaptability. Students would benefit from a college-led initiative to develop and include discipline specific modules in these subscales to provide students with more tools and choices when adapting to the environment and rigor of higher education.

As a result of conducting this research, a systematic and consistent inclusion of an emotional intelligence component in the student life skills (SLS) courses at this institution is a strong recommendation. The 3-credit course is required for all students 
who test into two or three prep areas. The majority of the sections $(100+)$ are taught by adjuncts and there are opportunities to standardize the curriculum and include an emotional intelligence component. Since $70 \%$ of the students at this college test into one or more remedial courses to become college-ready, mastering some aspects of emotional intelligence including, but not limited to, problem-solving, initiative, and selfmanagement might prove to be extremely helpful to reduce the frustration level for faculty, advisors, and certainly the students themselves and positively impact retention and academic success. One caveat might be that emotional intelligence could be viewed as helpful only to those who are not college-ready. Research has shown that emotional intelligence training and awareness can benefit many sectors of the population from elementary school (Elksnin \& Elksnin, 2003; Morales, 2008; Obiakor, 2001; Shapiro, 1997; Shelton, 2003) through professional employment (Bellack, 1999; Cherniss, 1999; Cherniss \& Goleman, 2001; Glass, 2007; Goleman, 2002). Clearly as students become more independent learners, their increased confidence will impact their motivation and hopefully their desire to persist in spite of obstacles.

\section{Implications for Future Studies}

This research is important in two aspects: (a) Studies of overall emotional intelligence in community college students are in their infancy, and (b) This study demonstrated the impact of curricular intervention as a treatment method for increasing students' overall emotional intelligence. This approach has been used in only one other study in the literature (Jaegar, 2004) and that did not involve undergraduate students, much less community college students. 
The students' overall emotional intelligence was significantly increased in the limited scope population, which this study addressed, so clearly there are a multitude of opportunities for increasing emotional intelligence in community college settings.

Students who are underprepared academically could benefit from the self-awareness and self-management competencies to more effectively tackle obstacles that might otherwise stop them. Changing one's mindset from defeat to possibility using techniques of selfcoaching could be a significant paradigm shift for many students. Accessing resources on campus through better interpersonal skills, whether it is approaching and interacting with faculty or knowing how to use learning resources available on all college campuses, would certainly help students stay on a path of persistence. Recognizing the benefits of delaying gratification and keeping impulse control in check early in a student's college career would prevent some of the current and on-going expense and frustration. Learning to adapt in an ever-changing world environment is surely a competency that will be required of all students in their careers and lives as the world does indeed become more interconnected and interdependent. For an accomplished and educated adult, much of this seems obvious. To an underprepared college student getting ready to compete in this global environment, it is not obvious. Curricular intervention in emotional intelligence makes a difference and our students need it.

Emotional intelligence is indeed in the early stages of research especially in the realm of higher education. Much more research has been conducted over the past two decades at the two other extremes of the population: in K -12 (Elksnin, 2003; Morales, 2008; Obiakor, 2001; Shapiro, 1997; Shelton, 2003) and in the workplace (Bellack, 1999; Cherniss and Goleman, 2001; Glass, 2007; Goleman, 2002). Traditional age college 
students are adolescents who are becoming adults and making life-changing choices in terms of lifestyle, employment, and career goals. This population provides fertile ground for on-going research as all stakeholders: parents, college administrators, taxpayers, and the students themselves who continue to seek ways to improve success rates in terms of persistence and preparation for the future. Today's students are going to be tomorrow's political and business leaders, medical specialists, teachers, scientists, entrepreneurs, artists, and parents. The urgent need to be academically prepared to compete and thrive in tomorrow's world is not lost on anyone. Perhaps the more we understand about nonacademic aspects, such as emotional intelligence and their contribution to overall success, the better able we may be able address the social, economic, and political challenges that face all citizens. 


\section{REFERENCES}

ABC News Specials. (Producer). (1998). Greed with John Stossal (VHS). Retrieved from http://ABC Newsstore.go.com

ACT. (2007a). ACT institutional data file. Retrieved from http://www.act.org/research/policymakers/pdf/retain 2007.pdf

ACT. (2007b). College readiness: Rigor at risk. Retrieved from http://www.act.org/research/policymakers/reports/rigor.html

ACT. (2009). ACT institutional data file. Retrieved from http://www.act.org/research/policymakers/pdf/retain_2009.pdf

Adelman, C. (1999). Crosscurrents and riptides: Asking about the capacity of the higher education system. Change, 31(1), 20.

Akst, G. (2007). Postsecondary attendance and success patterns: An interview with Clifford Adelman. Journal of Developmental Education, 31(2), 14-16.

Archibald, R. (2008). Why do higher education costs rise more rapidly than prices in general? Change, 40(3), 25-31.

Ashkanasy, N. M., \& Dasborough, M. T. (2003). Emotional awareness and emotional intelligence in leadership teaching. Journal of Education for Business, 79(1), 1822.

Astin, A. (1975). Preventing students from dropping out. San Franscisco, CA: JosseyBass.

Astin, A. (1993). What matters in college? San Francisco, CA: Jossey-Bass.

Astin, A. W. (1999). Student involvement: A developmental theory to higher education. Journal of College Student Development, 40(5), 518-529.

Barchard, K., \& Christensen, M. M. (2007). Dimensionality and higher order factor structure of self-reported emotional intelligence. Personality and Individual Differences, 42(6), 971-985.

Bar-On, R. (1997). The Emotional Intelligence Inventory (EQ-i): Technical Manual. Toronto: Multi-Health Systems.

Bar-On, R. (2000). Emotion and social intelligence: Insights from the emotional quotient inventory. In R. Bar-On \& J. D. Parker (Eds.), The handbook of emotional 
intelligence: Theory, development, assessment and application at home, school and in the work place, p. 363-388. San Francisco, CA: Jossey-Bass.

Bar-On, R. (2004). On emotional quotient inventory [Technical manual]. Toronto, Ontario, Canada: Multi-Health Systems.

Bar-On, R., Maree, J. G., \& Elias, M. J. (2007). Educating people to be emotionally intelligent. Westport, CT: Praeger.

Bastian, V., Burns, N. R., \& Nettlebeck, T. (2005). Emotional intelligence predicts life skills, but not as personality and cognitive abilities. Personality and Individual Differences, 39(6), 1135-1145.

Bean, J. (1980). Dropouts and turnover: The synthesis and test of a causal model of student attrition. Research in Higher Education, 12(2), 155-185.

Bean, J. (2003). Why students leave college. ASHE-ERIC Higher Education Report 30(2) p.43-73.

Bélanger, F., Lewis, T., Kasper, G. M., Smith, W. J., \& Harrington, K. V. (2007). Are computing students different? An analysis of coping strategies and emotional intelligence. IEEE Transactions on Education, 50(3), 188-196.

Bellack, J. (1999). Emotional intelligence: a missing ingredient. Journal of Nursing Education, 38(1), 3-4.

Berenson, R., Boyles, G., \& Weaver, A. (2008). Emotional intelligence as a predictor for success in online learning. International Review of Research in Open and Distance Learning, 9(2), 1-13.

Bowen, H. R. (1999). The intended outcomes of higher education. In J. L. Bess \& D. S. Webster (Eds.), Foundations of American higher education. New York, NY: Simon and Schuster.

Boyatizis, R. E., Goleman, D., \& Rhee, K. S. (2000). Clustering competencies in emotional intelligence: Insights from the emotional competence inventory. In R. Bar-On \& J. D. Parker (Eds.), The handbook of emotional intelligence: Theory development, assessment and application at home, school and in the workplace (p. 343-362). San Francisco, Ca: Jossey-Bass.

Buckhold, J. A. (2001). A short history of g: Psychometrics' most enduring and controversial construct. Learning and Individual Differences, 13(2), 101-14. 
Castro-Johnson, M., \& Wang, A. Y. (2003). Emotional intelligence and academic performance of college honors and non-honors freshmen. (Multiperspectivism in Honors). Journal of the National Collegiate Honors Council, 4(2), 105115. Retrieved online at Academic OneFile at http://find.galegroup.com.ezproxy.fau.edu/gtx/start.do?prodId=AONE\&userGrou pName $=$ gale 15691

Cherniss, C., \& Goleman, D. (Eds.). (2001). The emotionally intelligent workplace. San Francisco, CA: Jossey-Bass.

Chickering, A. W., \& Reisser, L. (1993). Education and identity. San Francisco, CA: Jossey-Bass.

Ciarrochi, J. V., Chan, A. Y., \& Caputi, P. (2000). A critical evaluation of the emotional intelligence construct. Personality and Individual Differences, 28, 539-561.

Codjoe, H., \& Helms, M. M. (2005). A retention assessment process: Utilizing total quality management principle and focus groups. Planning for Higher Education, $33(3), 31-42$.

Coll, K. M., \& Stewart, R. A. (2008). College student retention: Instrument validation and value for partnering between academic and counseling services. College Student Journal, 42(1), 41-56.

Costa, J. \& McCrae, R.R. (1992) NEO PI-R Professional Manual. Odessa, FL: Psychological Assessment Resources.

Costa, J., \& McCrae, R. R. (n.d.). NEO personality inventory-revised (NEO PI-R). Retrieved from http://www3parinc.com/products/product.aspx?Productid=NEOPI-R\#J. W.

Creswell, J. W. (2003). Research design: Qualitative, quantitative and mixed method approaches. Thousand Oaks, CA: Sage.

Crossman, J. (2007). The role of relationships and emotions in students' perceptions of learning and assessment. Higher Education Research \& Development, 26(3), 313327.

Culp, M. (2005). Increasing the value of traditional support services. New Directions for Community Colleges, (Fall), 33-49.doi. 10.1002/cc.204.

Daus, C., \& Ashkanasy, N. M. (2005). The case for ability-based model of emotional intelligence in organizational behavior. Journal of Organizational Behavior, 26(4), 453-466. 
Day, A., \& Carroll, S. A. (2007). Faking emotional intelligence (EI): Comparing response distortion on ability and trait-based EI measures. Journal of Organizational Behavior, 29, 761-784.

Debarard, M., Spelmans, G., \& Julka, D. (2004). Predictors of academic achievement and retention among freshmen: A longitudinal study. College Student Journal, 38(1), 66-80.

Derkson, J., Kramer, I., \& Katzko, M. (2002). Does a self-report measure for emotional intelligence assess something different than emotional intelligence? Personality and Individual Differences, 32, 37-48.

Dewey, J. (1909). Moral principles in education. Boston, MA: Houghton Mifflin.

Ebert Flattau, P., Bracken, J., Van Alta, R., Bandeh-Ahmadi, A., de la Cruz, R., \& Sullivan, K. (2006). The national defense education act of 1958: Selected outcomes. IDA Document D-3306]. Washington, D.C. Science and Technology Policy Institute.

Elder, L. (1997). Critical thinking: The key to emotional intelligence. Journal of Developmental Education, 21(1), 40.

Elksnin, L. K \& Elksnin, N. (2003).Fostering social-emotional learning in the classroom . Education. 124(1), 63-75

Faul, F., Erdfelder, E., Lang, A.-G., \& Buchner, A. (2007). G*Power 3: A flexible statistical power analysis program for the social, behavioral, and biomedical sciences. Behavior Research Methods, 39, 175-191.

Feldman, J. M. (2003). The relationship among college freshmen's cognitive risk tolerance, academic hardiness, and emotional intelligence and their usefulness in predicting academic outcomes (Doctoral dissertation, Temple University). Retrieved from http://www.proquest.com/enUS/products/dissertations/individuals.shtml

Fike, D. S., \& Fike, R. (2008). Predictors of first-year student retention in the community college. Community College Review, 36(2), 68-88.

Florida Department of Education. (2008). The Florida college system. System facts at a glance. Retrieved from http://www.fldoe.org/college/

Florida Department of Education. (2010). The Florida college business plan 2011-2012. Retrieved from http://www.fldoe.org/college/ 
Florida Department of Education. (2011). The Florida college system: College readiness among first time in college students. Retrieved from http://www.fldoe.org/cc/OSAS/Evaluations/pdf/Zoom2011-04.pdf

Freudenthaler, H., \& Neubauer, A. C. (2005). Emotional intelligence: The convergent and discriminant validities of intra- and interpersonal abilities. Personality and Individual Differences, 39(3), 569-579.

Gardner, H. (1983). Frames of mind: The theory of multiple intelligences. New York, NY: Basic Books.

Gay, L. R., \& Airasian, P. (2000). Educational research: Competencies for analysis and application $\left(6^{\text {th }}\right.$ ed.). Upper Saddle River, NJ: Prentice-Hall.

Getting a clearer picture of who graduates, and why. (2006). Recruitment \& Retention in Higher Education, 20(4), 1-6. Retrieved from Education Full Text database.

Giambo, D. A. (2010). High-stakes testing, high school graduation, and limited English proficient students: A case study. American Secondary Education, 38(2), 44-56. Retrieved from EBSCOhost. http://www.ebscohost.com/academic/ebscohost/

Glass, N. (2007). Chapter 6: Investigating women nurse academics' experiences in universities: The importanace of hope, optimism, and career resilence for workplace satisfaction. Annual Review of Nursing Education, 5, 111-136.

Goleman, D. (1995). Emotional intelligence. New York, NY: Bantam Books.

Goleman, D. (1998). Working with emotional intelligence. New York, NY: Bantom Books.

Goleman, D. (2002). Primal leadership: Learning to lead with emotional intelligence. Boston, MA: Harvard Business School Press.

Greene, G. K., Huerta, L. A., \& Richards, C. E. (2007). Getting real: A different perspective on the relationship between school resources and student outcomes. Journal of Education Finance, 33(1), 49-68. Retrieved from Education Full Text at http://vnweb.hwwilsonweb.com

Haifeng, Z., \& Cowen, D. J. (2009). Mapping academic achievement and public school choice under the No Child Left Behind legislation. Southeastern Geographer, 49(1), 24-40. Retrieved from EBSCOhost.

http://www.ebscohost.com/academic/ebscohost/

Hamachek, D. (2000). Dynamics of self-understanding and self-knowledge: Acquisitions, advantages and relation to emotional intelligence. Journal of Humanistic Counseling, Education and Development, 38(4), 230-242. 
Herenstein R., \& Murray, C. (1994). The bell curve: Intelligence and class structure in American life. New York, NY: Free Press.

Hernon, P., \& Rossiter, N. (2006). Emotional intelligence: Which traits are most prized? College and Research Libraries, 67(3), 260-75.

Hinkle, D. E., Wiersma, W., \& Jurs, S. G. (2003). Applied statistics for the behavioral sciences $\left(5^{\text {th }}\right.$ ed.). Boston, MA: Houghton Mifflin.

Holt, S. (2007). Emotional intelligence and academic achievement in higher education (Doctoral dissertation, Pepperdine University). Retrieved from http://www.proquest.com/en-US/products/dissertations/individuals.shtml

Hoover, E. (2008, February 1). Surveys of students challenge "helicopter parent" stereotypes. The Chronicle of Higher Education, p. A22.

H.R. No.107-110, at 1 (2002). 115 STAT. 1425. No Child Left Behind.

Hu, S., \& St. John, E. P. (2001). Student persistence in a public higher education system: Understanding racial and ethnic differences. The Journal of Higher Education, 72(3), 265-286.

Hughes, K. L., Karp, M. M., \& O'Gara, L. (2009). Student success courses in community college: An exploratory study of student perspectives. Community College Review, 36(3). Retrieved online at Academic OneFile via Gale at http://go.galegroup.com/ps/start.do?p=AONE\&u=lincclin_bwcc

Ishitani, T. T. (2006). Studying attrition and degree completion behavior among first generation college students in the United States. The Journal of Higher Education, 77(5), 861-885.

Izaguirre, R. (2008). The relationship among emotional intelligence, academic achievement, and demographic characteristics in first year community college students (Doctoral dissertation, University of the Incarnate Word). Retrieved from http://www.proquest.com/en-US/products/dissertations/individuals.shtml

Jaeger, A.J. (2004). The Place for Emotional Growth in Professional Education. Journal of Public Affairs Education, 10(1), 43-65. Retrieved from Education Full Text database

Jaeger, A. J., \& Eagan, M. K. (2007). Exploring the value of emotional intelligence: A means to improve academic performance. NASPA Journal, 44(3), 512-537.

Johnson, J. (1997). Commuter college students: What factors determine who will persist and who will drop out? College Student Journal, 31, 323-332. 
Kingston, E. (2008). Emotional competence and drop-out rates in higher education. Education \& Training, 50(2), 128-139.

Krus, D. J., \& Helmstadter, G. C. (1987). The relationship between correlational and internal consistency notions of test reliability. Educational and Psychological Measurement, 47, 911-915.

LaCivita, L. K. (2003). An examination of emotional intelligence factors: Their relationship to academic achievement and the implications for retention of the atrisk community college student (Doctoral dissertation, Capella University). Retrieved from http://www.proquest.com/enUS/products/dissertations/individuals.shtml

Landy, F.J. (2006).The long and fruitless search for social intelligence: A cautionary tale. In K.R. Murphy, ed., A Critique of Emotional Intelligence: What Are the Problems and How Can They Be Fixed? Mahwah, NJ: Erlbaum, pp.81-123.

Lipka, S. (2006). After the freshman bubble pops. The Chronicle of Higher Education, 53(3), A34-36.

Liptak, J. J. (2005). Using emotional intelligence to help college students succeed in the workplace. Journal of Employment Counseling, 42(4), 171-178.

Livingstone, H., \& Day, A. I. (2005). Comparing the construct and criterion-related validity of ability-based and mixed-model measures of emotional intelligence. Educational and Psychological Measurement, 65(5), 851-873.

Longwell-Grice, R., \& Longwell-Grice, H. (2007). Testing Tinto: How do retention theories work for first-generation, working-class students? Journal of College Student Retention, 9(4), 407-420.

Lorenzetti, J. (2006, December 15). Better marketing, better retention: working across the student life cycle. Distance Education Report, 10(24), 3,7.

Lufi, D., Parish-Plass, J., \& Cohen, A. (2003). Persistence in higher education and its relationship to other personality variables. College Student Journal, 37(1), 50-59.

Matthews, G., Zeidner, M., \& Roberts, R. D. (2002). Emotional intelligence science and myth. Cambridge, MA: The MIT Press.

Mayer, J. D., Caruso, D. R., \& Salovey, P. (2000). Selecting a measure of emotional intelligence: The case for ability scales. In R. Bar-On \& J. D. Parker (Eds.), The handbook of emotional intelligence: Theory, development, assessment and applications at home, school, and in the workplace. p.320-342.San Francisco, CA: Jossey-Bass. 
Mayer, J. D., \& Mitchell, D. C. (1998). Intelligence as a subsystem of personality: From Spearman's $g$ to contemporary models of hot processing. In W. Tomic \& J.

Kingma (Eds.), Advances in cognition and educational practice (Vol. 5, pp. 43-

75). Greenwich, CT: JAI.

McCracken, H. (2008). Best practices in supporting persistence of distant education students through integrated web-based systems. Journal of College Student Retention, 10(1), 65-91.

McCrea, R. R. (2000). Emotional intelligence from the perspective of the five-factor model of personality. In R. Bar-On \& J. D. Parker (Eds.), The handbook of emotional intelligence: Theory, development, assessment and application at home, school and in the workplace. p. 263-276. San Franscico, CA: Jossey-Bass.

Melguizo, T., \& Dowd, A. C. (2009). Baccalaureate success of transfers and rising 4-year college juniors. Teachers College Record, 111(1), 55-89.

Misra, S., \& McMahon, G. (2006). Diversity in higher education: The three Rs. Journal of Education for Business, 82(1), 40-43.

Morales, E. E. (2008). A focus on hope: Toward a more comprehensive theory of academic resiliency among at-risk minority students. The Journal of At-Risk Issues, 14(1), 23-32.

Nelson, D., \& Nelson, K. (2003). Emotional intelligence skills: Significant factors in freshmen achievement and retention. Anaheim,CA: American Counseling Association.

Neufeld, V., Hoffman, B., \& Phillips, M. (2000). Greed with John Stossal, ABC News. Films for the Humanities and Sciences. Princeton, NJ.

Haws Publications. (n.d.). New York Times best sellers list. Retrieved from http://www.hawes.com/pastlist.htm

National Center for Educational Statistics. (2002). Nontraditional undergraduates. Retrieved from http://nces.ed.gov/programs/coe/analysis/2002a-sa01.asp

O'Gara, L., Karp, M. M., \& Hughes, K. L. (2009). An exploratory study of student perspectives. Community College Review, 36(3), 195-218.

Obiakor, F. E. (2001). Developing emotional intelligence in learners with behavioral problems: refocusing special education. Behavioral Disorders, 26(4), 321-331.

Parker, J. D., Duffy, J. M., Wood, L. M., Bond, B. J., \& Hogan, M. J. (2005). Academic achievement and emotional intelligence: Predicting the successful transition from 
high school to university. Journal of the First-Year Experience \& Students in Transition, 7(1), 67-78.

Pascarella, E. T., \& Terenzini, P. T. (2005). How college affects students. San Francisco, CA: John Wiley \& Sons.

Payne, W. L. (1986). A study of emotion: Developing emotional intelligence, selfintegration, relating to fear, pain and desire. Dissertation Abstracts International, 47, 203.

Pressman, E. R. (Producer), \& Stone, O. (Director). (1987). Wall street: Twentieth Century Fox. Los Angeles, CA

Procter \& Gamble. (2011). Loads of hope. Retrieved from http://www.tide.com/enUS/loads-of-hope/index.jspx

Porter, J. R. (2006). Financial strains keep millions out of college, panel says. The Chronicle of Higher Education, 53(5), A25.

Queendom. "Emotional Intelligence Test." Retrieved from http://www.queendom.com/tests/access_page/index.htm?idRegTest=3037

Radcliffe, M. (2007). People are often illogical but logic isn't everything. Nursing Times, 103(31), 56.

Ramos-Sanchez, L., \& Nichols, L. (2007). Self-efficacy of first-generation and non-first generation college students: The relationship with academic performance and college adjustment. Journal of College Counseling, 10(1), 6-18.

Ravitch, D. (2009). Time to kill No Child Left Behind. Education Digest, 75(1), 4-6. Retrieved from http://www.ebscohost.com/academic/ebscohost/

Reiff, H. B., Hatzes, N. M., \& Bramel, M. H. (2001). The relation of LD and gender with emotional intelligence in college students. Journal of Learning Disabilities, 34(1), 66-78.

Ridgell, S., \& Lounsbury, J. W. (2004). Predicting academic success: General intelligence, "big five" personality traits, and work drive. College Student Journal, 38(4), 607-619.

Roberts, R. D., Zeidner, M., \& Matthews, G. (2001). Does emotional intelligence meet traditional standards for an intelligence? Some new data and conclusions. Emotion, 1(3), 196-231.

Salovey, P., Brackett, M. A., \& Mayer, J. (2004). Emotional intelligence: Key readings on the Mayer and Salovey model. Port Chester, NY: Dude Publishing. 
Salovey, P., \& Mayer, J. D. (1990). Emotional intelligence. Imagination, Cognition \& Personality, 9, 185-211.

Schulte, M., Ree, M. J., \& Carretta, T. R. (2004). Emotional intelligence: Not much more than $\mathrm{g}$ and personality. Personality and Individual Differences, 37(5), 1059-1068.

Schutte, N. S., \& Malouff, J. M. (2002). Incorporating emotional skills content in a college transition course enhances student retention. Journal of the First-Year Experience, 14(1), 7-21.

Shapiro, L. E. (1997). How to raise a child with a high EQ. New York, NY: Harper Collins.

Shelton, C. M. (2003). Emotional awareness: Fundamental to effective teaching. Independent School, 62(3), 66-71.

SPSS Inc. (2004). SPSS ${ }^{\circledR}$ graduate pack (13.0 for Windows) [Software]. Chicago, IL.

Stein, S., \& Book, H. (2006). The EQ edge: Emotional intelligence and your success. Mississauga, Ontario, Canada: John Wiley \& Sons.

Strauss, L. C., \& Volkwein, J. (2002). Comparing student performance and growth in 2 and 4-year institutions. Research in Higher Education, 43(2), 133-161.

Sutherland, J. A., Hamilton, M. J., \& Goodman, N. (2007). Affirming at-risk minorities for success (ARMS). Retention, graduation and success on the NCLEX-RN. Journal of Nursing Education, 46(8), 347-353.

Thelin, J. R. (2004). A history of American higher education. Baltimore, MD: The Johns Hopkins University Press.

Thurstone, L. L. (1887-1955). (n.d.). In Encyclopedia of world biography Retrieved from: http://find.galegroup.com.ezproxy.fiu.edu/itx/start.do?prodId=AONE

Tinto, V. (1987). Leaving college. Chicago, IL: University of Chicago Press.

Trow, M. (1999). Historical, Philosophical, and Sociological Foundations of Higher Education in J. L. Bess \& D. S. Webster (Eds.), Foundations of American higher education.p.7-22. New York, NY: Simon and Schuster.

Van Rooy, D. R., Viswesvaran, C., \& Pluta, P. (2005). An evaluation of construct validity: What is this thing called emotional intelligence? Human Performance, 18(4), 445-462.

Veenstra, C. P. (2009). A strategy for improving freshman college retention. Journal for Quality \& Participation, 31(4), 19-23. 
Vela, R. H. (2004). The role of emotional intelligence in the academic achievement of first year college students (Doctoral dissertation, Texas A\&M University). Retrieved from http://www.proquest.com/enUS/products/dissertations/individuals.shtml

Walker, M. E. B. (2006). Emotional intelligence and academic success in college. (Doctoral dissertation, The University of Southern Mississippi). Retrieved from http://www.proquest.com/en-US/products/dissertations/individuals.shtml

Wartman, K., \& Savage, M. (2008). Parental involvement in higher education: Understanding the relationship among students, parents and the institution. $A S H E$ Higher Education Report, 33(6), 1-123.

Westphal, M. (2007). Emotional intelligence and adjustment in college students (Doctoral dissertation, Columbia University). Retrieved from http://www.proquest.com/en- US/products/dissertations/individuals.shtml

Young-Ritchie, C., Laschinger, H., \& Wong, C. (2007). The effects of emotionally intelligent leadership behaviour on emergency staff nurses' workplace empowerment and organizational commitment. NENA Outlook, 30(2), 24.

Zeidner M., Matthews, G., \& Roberts, R. (2009). What we should know about emotional intelligence: How it affects learning, work, relationships and our mental health. Cambridge, MA: MIT Press. 
Who are we?

\begin{tabular}{lc} 
Colleges Total & 28 \\
\hline Campuses & 62 \\
\hline "Community" Colleges & 9 \\
\hline "Colleges" & 8 \\
\hline "State" Colleges & 11
\end{tabular}

What was the level of funding for Florida's colleges, 2010-11?

\begin{tabular}{|c|c|}
\hline General Revenue & $\$ 890$ million \\
\hline Student Fees & $\$ 851$ million \\
\hline Lottery Funding & $\$ 127$ million \\
\hline Federal Stabilization Funds & $\$ 183$ million \\
\hline
\end{tabular}

What do Florida College System students look like?

Total Unduplicated Annual Headcount, 2009-10

Student Profile, Fall 2010 "award-seeking" students:

\begin{tabular}{|lr|}
\hline Students & 900,000 \\
\hline Full-time students & $39 \%$ \\
\hline Part-time students & $61 \%$ \\
\hline Average student age & 25 years \\
\hline Gender & $59 \%$ female \\
\hline Minority enrollment & $41 \%$ \\
\hline High School (HS) students dual enrolled & 41,991 \\
\hline HS students who earned Associate degrees & 446
\end{tabular}

What happens after high school graduation?

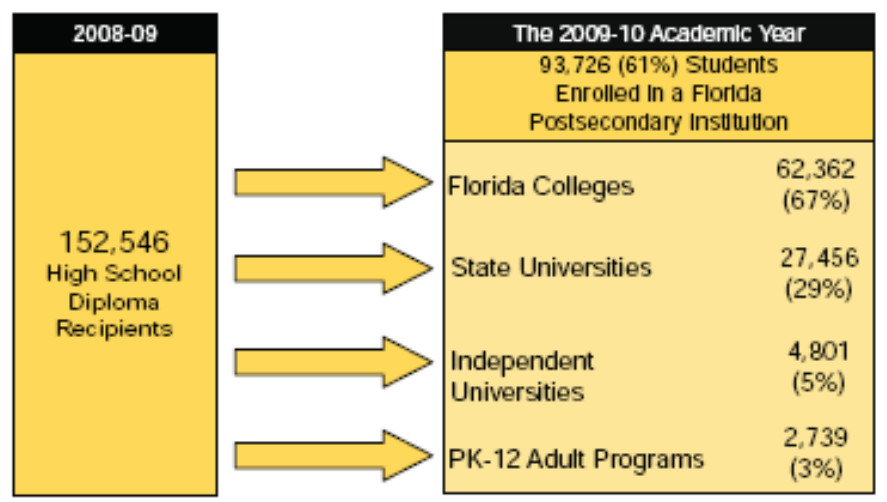

Retrieved from http://www.fldoe.org/cc/pdf/annualreport2011.pdf. The Florida College System Facts at a Glance p. 4 


\section{Appendix B}

\section{SYSTEM FACTS AT A GLANCE}

\section{What degrees do students earn in our system?}
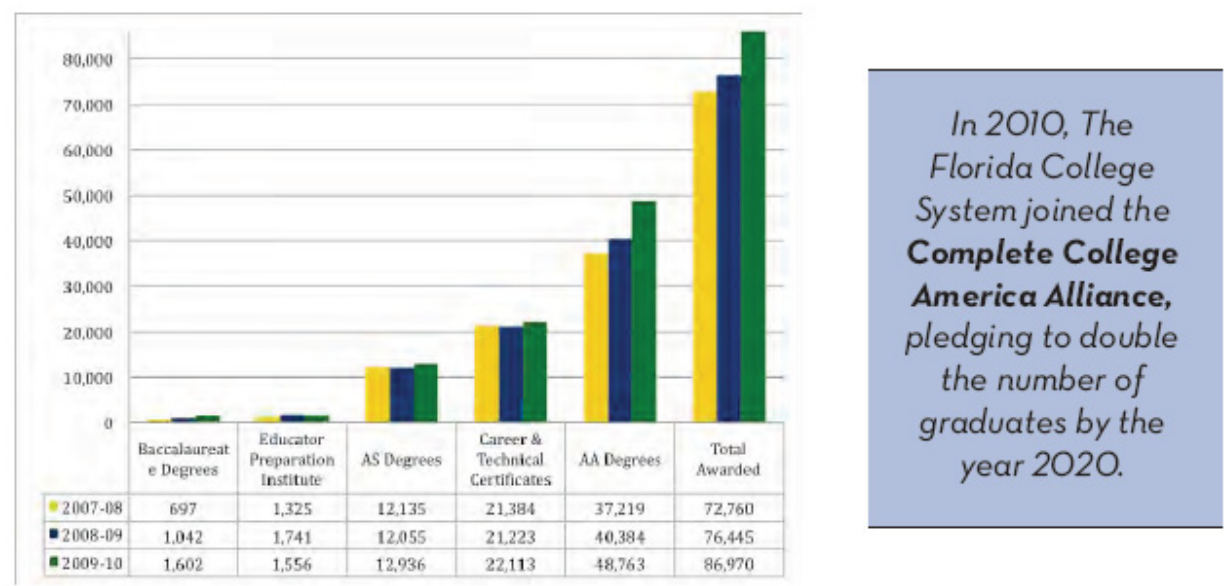

Retrieved from http://www.fldoe.org/cc/pdf/annualreport2011.pdf. The Florida College System Facts at a Glance p.6

\begin{tabular}{|c|c|c|c|c|c|c|c|c|c|}
\hline \multicolumn{10}{|c|}{ Data provided by Institutional Research } \\
\hline \multirow{2}{*}{\multicolumn{2}{|c|}{\begin{tabular}{|c|} 
Term \\
Campus Rollup \\
\end{tabular}}} & \multicolumn{4}{|c|}{ Spring } & \multicolumn{4}{|c|}{ Fall } \\
\hline & & Campus 1 & Campus 2 & Campus 3 & Total & Campus 1 & Campus 2 & Campus 3 & Total \\
\hline \multirow{4}{*}{$\begin{array}{l}\mathbf{A} \\
\mathbf{A}\end{array}$} & Headcount & 12,456 & 6,295 & 7,433 & 26,184 & 13,489 & 7,014 & 8,278 & 28,781 \\
\hline & Credit & 98,430 & 47,028 & 50,924 & 196,382 & 107,064 & 51,148 & 56,471 & 214,682 \\
\hline & Contact & 59,567 & 26,559 & 29,819 & 115,945 & 64,748 & 30,544 & 33,091 & 128,383 \\
\hline & FTE & 3,294 & 1,568 & 1,698 & 6,559 & 3,577 & 1,705 & 1,883 & 7,165 \\
\hline & & \multicolumn{8}{|c|}{ Two Term Totals } \\
\hline & & \multirow{2}{*}{\multicolumn{8}{|c|}{$\begin{array}{ll}\text { Headcount } & 54,965 \\
\text { FTE } & 13,724\end{array}$}} \\
\hline & & & & & & & & & \\
\hline
\end{tabular}


Appendix B

\section{What do Florida's college students look like?}

\begin{tabular}{|l|c|}
\hline $\begin{array}{l}|l| \\
\text { All Students Enrolled in a Course, Lower Division, Non-Credit, and Upper } \\
\text { Division (2009-10) }\end{array}$ & $\mathbf{8 8 7 , 0 7 3}$ \\
\hline Student Profile (Fall 2010 College Credit Students): & $39 \%$ \\
\hline Full-time students & $61 \%$ \\
\hline Part-time students & 25 years \\
\hline Average student age & $59 \%$ \\
\hline Gender (female) & 13,171 \\
\hline Enrollment by Program (2009-10) (During the year, students may enroll in more than one program) \\
\hline Bachelors Degree Program & 333,272 \\
\hline Associate in Arts Degree & 179,039 \\
\hline Continuing Workforce Education & 152,218 \\
\hline College \& Vocational Preparatory & 64,338 \\
\hline Recreation \& Leisure & 103,741 \\
\hline Associate in Science Degree & 55,575 \\
\hline Adult Secondary & 30,817 \\
\hline Vocational Certificates & 21,612 \\
\hline College Credit Certificates & 2,684 \\
\hline Life Long Learning & Additional college students are enrolled: in apprenticeship courses, in courses related to employment, as general \\
\hline freshmen or for other personal objectives.) & \\
\hline
\end{tabular}

\section{How well do Florida college students perform?}

\begin{tabular}{|l|r|}
\hline Total Degrees/Certificates Annually Awarded, 2009-10: & 86,970 \\
\hline Bachelors Degree Program & 1,602 \\
\hline AA Degrees & 48,763 \\
\hline AS Degrees (majority enter the workplace) & 12,936 \\
\hline Vocational \& College Credit Certificates & 22,113 \\
\hline EPI & 1,556 \\
\hline
\end{tabular}

Retrieved from http://www.fldoe.org/cc/facts_glance.asp Florida Colleges. Facts at a Glance 


\section{Appendix C}

First Time in College (FTIC)- degree seeking*

\begin{tabular}{|l|l|l|}
\hline College Ready & Need no prep courses & $27.60 \%$ \\
\hline Needing one prep & English, Math or Reading & $22.00 \%$ \\
\hline Needing two preps & English, Math or Reading & $21.00 \%$ \\
\hline Needing three preps & English, Math and Reading & $29.30 \%$ \\
\hline \multicolumn{2}{|c|}{} \\
\hline More students require three prep courses than those who are college ready \\
\hline \multicolumn{2}{|c|}{ *Data provided by Institutional Research at the College. (2010) } \\
\hline
\end{tabular}


Appendix D

\section{Retention Trends}

1983-2010

Freshman to Sophomore Year

\begin{tabular}{llll}
\hline & $\begin{array}{c}\text { Highest } \\
\%\end{array}$ & $\begin{array}{c}\text { Lowest } \\
\%\end{array}$ & $\begin{array}{c}\text { Current } \\
\%\end{array}$ \\
\hline Two-year public & $55.7(' 10)$ & $51.3(' 04)$ & 55.7 \\
\hline BA/BS public & $70.0(' 04)$ & $66.4\left(' 96,,^{\prime} 05\right)$ & 67.6 \\
\hline MA/MS public & $71.6(' 06)$ & $68.1(' 89)$ & 67.3 \\
\hline PhD public & $78.6(' 10)$ & $72.9(' 08)$ & 78.6 \\
\hline Two-year private & $72.6(' 92)$ & $55.5(' 08)$ & 58.6 \\
\hline BA/BS private & $74.0(' 89)$ & $68.7(' 10)$ & 68.7 \\
\hline MA/MS private & $78.0(' 85)$ & $71.4(' 10)$ & 71.4 \\
\hline PhD private & $85.0(' 85)$ & $80.3(' 10)$ & 80.3 \\
\hline All & & & 66.7 \\
\hline
\end{tabular}

\section{Summary Table: National Persistence to Degree* Rates by Institutional Type}

\begin{tabular}{lccc}
\hline Degree Level/Control & $\mathrm{N}$ & $\mathrm{SD}$ & Mean $\%$ \\
\hline Two-year Public & 439 & 22.2 & 28.3 \\
\hline Two-year Private & 52 & 29.6 & 52.6 \\
\hline BA/BS Public & 46 & 18.8 & 43.0 \\
\hline BA/BS Private & 218 & 22.6 & 55.9 \\
\hline MA/lst Professional Public & 171 & 15.7 & 38.4 \\
\hline MA/lst Professional Private & 357 & 16.5 & 54.8 \\
\hline PhD Public & 213 & 19.3 & 48.7 \\
\hline PhD Private & 181 & 17.9 & 65.1 \\
\hline Total & 1,726 & N/A & 45.0 \\
\hline
\end{tabular}

* Completion in 3 years for Associate Degree; 5 years for BA/BS

** Standard Deviation

Source: ACT Institutional Data File, 2009 


\section{Appendix E}

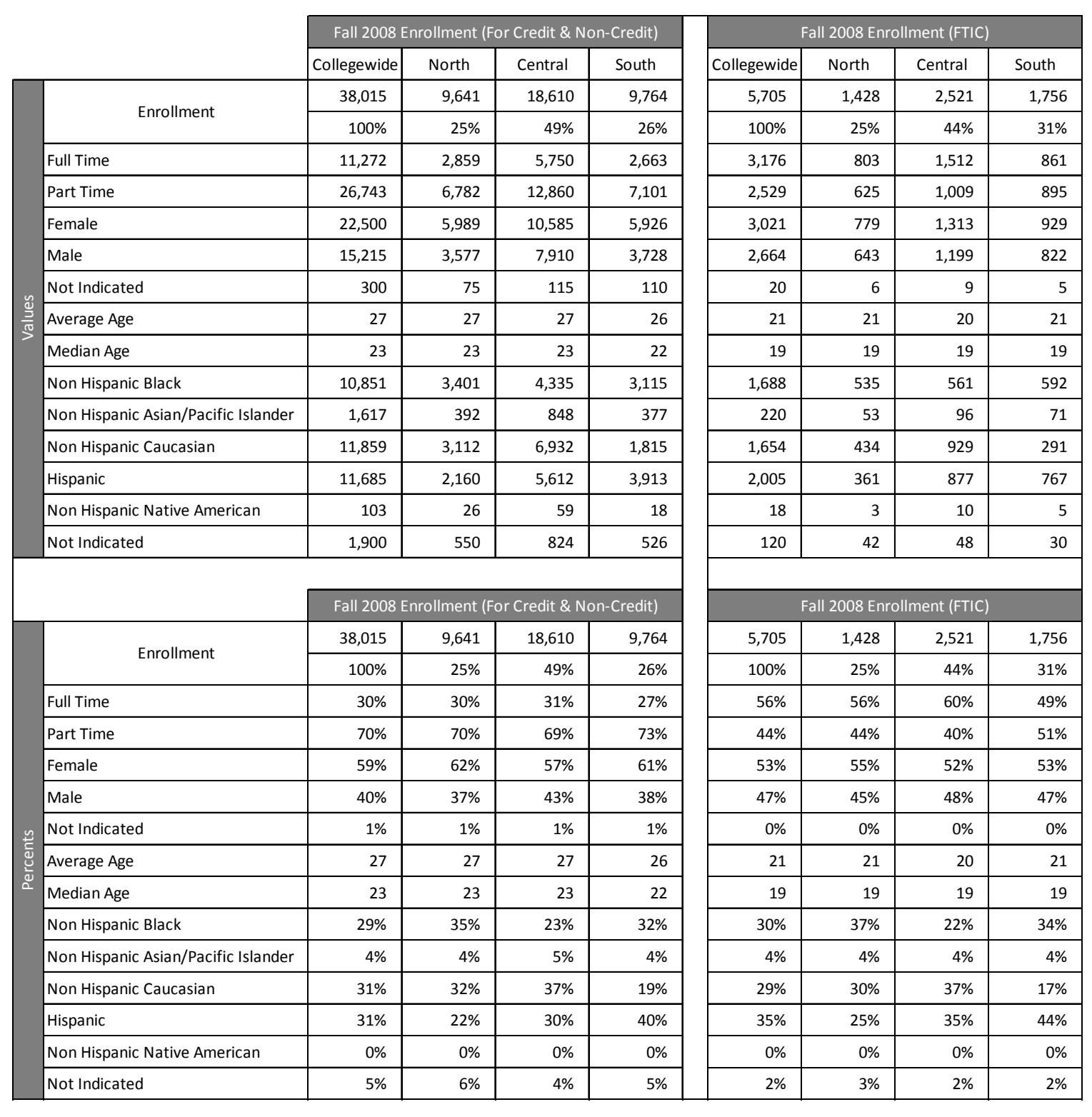


Appendix F

\begin{tabular}{|r|r|r|r|}
\hline \multicolumn{4}{|c|}{ Success Rates } \\
\hline \multicolumn{3}{|c|}{ College-Wide Data (all courses) } \\
\hline Spring & \multicolumn{3}{c|}{ Fall } \\
\hline Total & 104,362 & Total & 101,614 \\
\hline ABC Success & 78,379 & ABC Success & 77,199 \\
\hline ABC $\%$ & $75 \%$ & ABC $\%$ & $76 \%$ \\
\hline Attrition & 12,172 & Attrition & 10,102 \\
\hline Attrition $\%$ & $12 \%$ & Attrition $\%$ & $10 \%$ \\
\hline D/F grades & 13,811 & D/F grades & 14,313 \\
\hline D/F\% & $13.23 \%$ & D/F\% & $14.08 \%$ \\
\hline $75 \%$ success rate & 76\% success rate \\
\hline
\end{tabular}

\begin{tabular}{|c|c|c|c|}
\hline \multicolumn{4}{|c|}{\begin{tabular}{c|c} 
College- Wde Introduction to Business (GEB 1011) En \\
Spring & Fall \\
\end{tabular}} \\
\hline Total & 400 & Total & 401 \\
\hline ABC Success & 299 & ABC Success & 298 \\
\hline$A B C \%$ & $75 \%$ & $A B C \%$ & $74 \%$ \\
\hline Attrition* & 38 & Attrition* & 48 \\
\hline Attrition \% & $10 \%$ & Attrition \% & $12 \%$ \\
\hline $\mathrm{D} / \mathrm{F}$ grades & 63 & $\mathrm{D} / \mathrm{F}$ grades & 55 \\
\hline $\mathrm{D} / \mathrm{F} \%$ & $15.75 \%$ & $\mathrm{D} / \mathrm{F} \%$ & $13.71 \%$ \\
\hline \multicolumn{2}{|c|}{$75 \%$ success rate } & \multicolumn{2}{|c|}{$74 \%$ success rate } \\
\hline
\end{tabular}

\begin{tabular}{|c|c|c|c|}
\hline \multicolumn{4}{|c|}{ Research Groups in GEB 1011: Introduction to Business } \\
\hline \multicolumn{2}{|l|}{ Spring } & \multicolumn{2}{|l|}{ Fall } \\
\hline Total & 68 & Total & 72 \\
\hline ABC Success & 54 & ABC Success & 56 \\
\hline$A B C \%$ & $79 \%$ & $A B C \%$ & $78 \%$ \\
\hline Attrition* & 9 & Attrition* & 6 \\
\hline Attrition \% & $13.23 \%$ & Attrition \% & $8.30 \%$ \\
\hline $\mathrm{D} / \mathrm{F}$ grades & 5 & $\mathrm{D} / \mathrm{F}$ grades & 10 \\
\hline $\mathrm{D} / \mathrm{F} \%$ & $7.40 \%$ & $\mathrm{D} / \mathrm{F} \%$ & 13.8 \\
\hline \multicolumn{2}{|c|}{$79 \%$ success rate } & \multicolumn{2}{|c|}{$78 \%$ success rate } \\
\hline
\end{tabular}

\begin{tabular}{|c|c|c|c|}
\hline \multicolumn{4}{|c|}{ Numbers of students completing both Pre and Post EQ-i } \\
\hline Spring & & Fall & \\
\hline Experimental Group I & 31 & Experimental Group II & 28 \\
\hline Control Group I & 24 & Control Group II & 29 \\
\hline participation & $81 \%$ & participation & $79 \%$ \\
\hline
\end{tabular}

All data provided by Institutional Research 
Appendix G
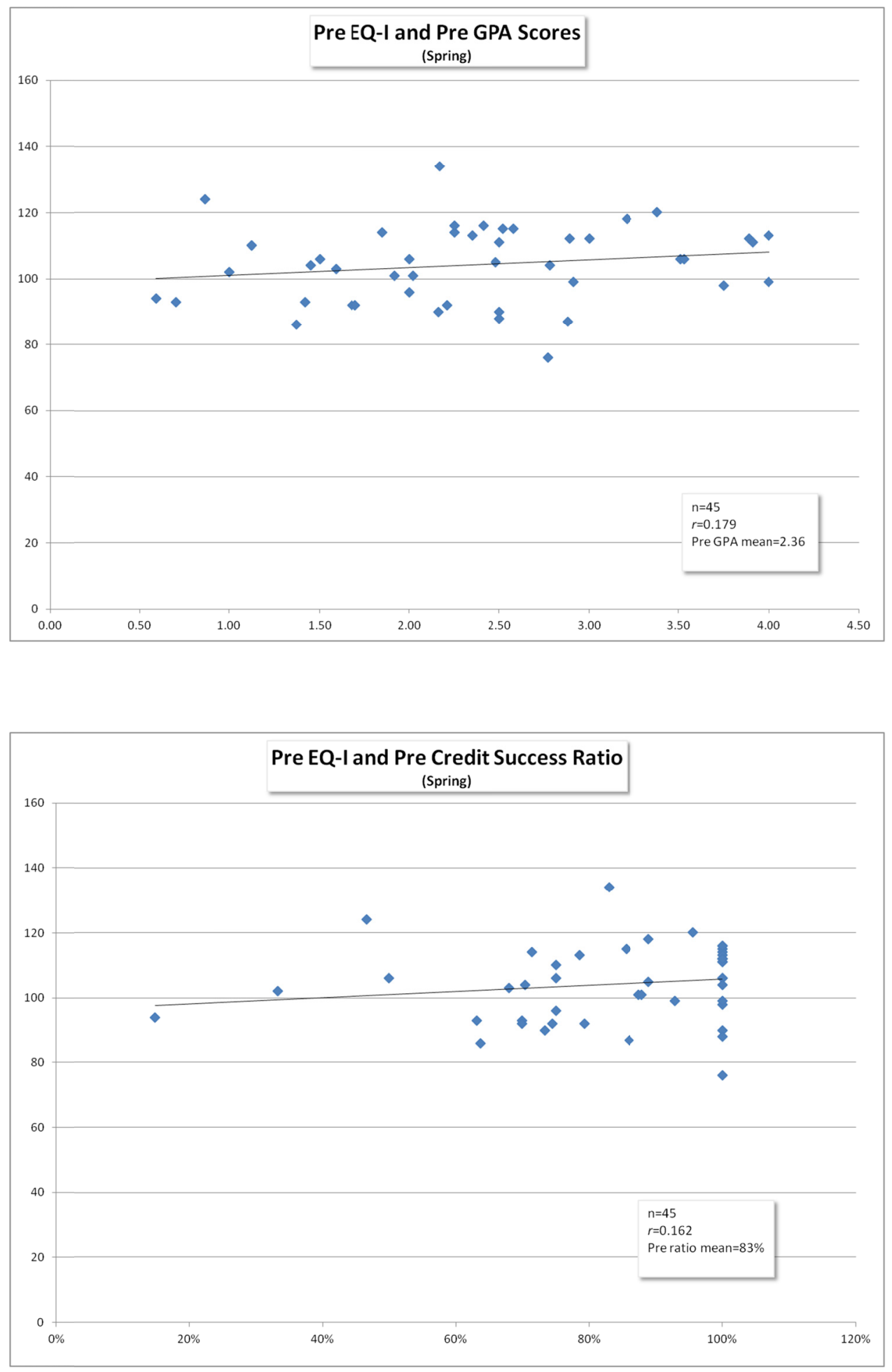


\section{Appendix $\mathrm{H}$}

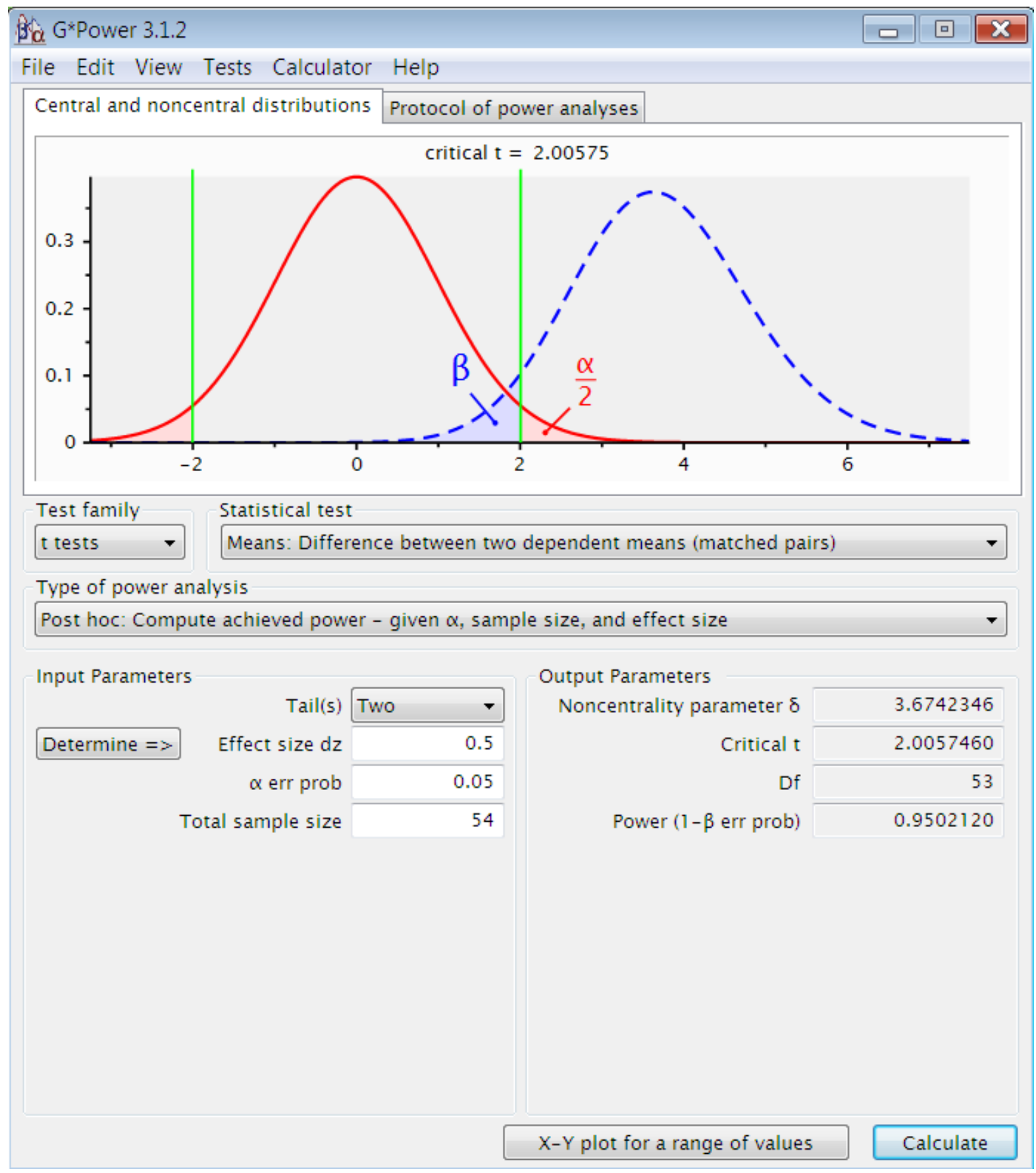




\section{Appendix I}

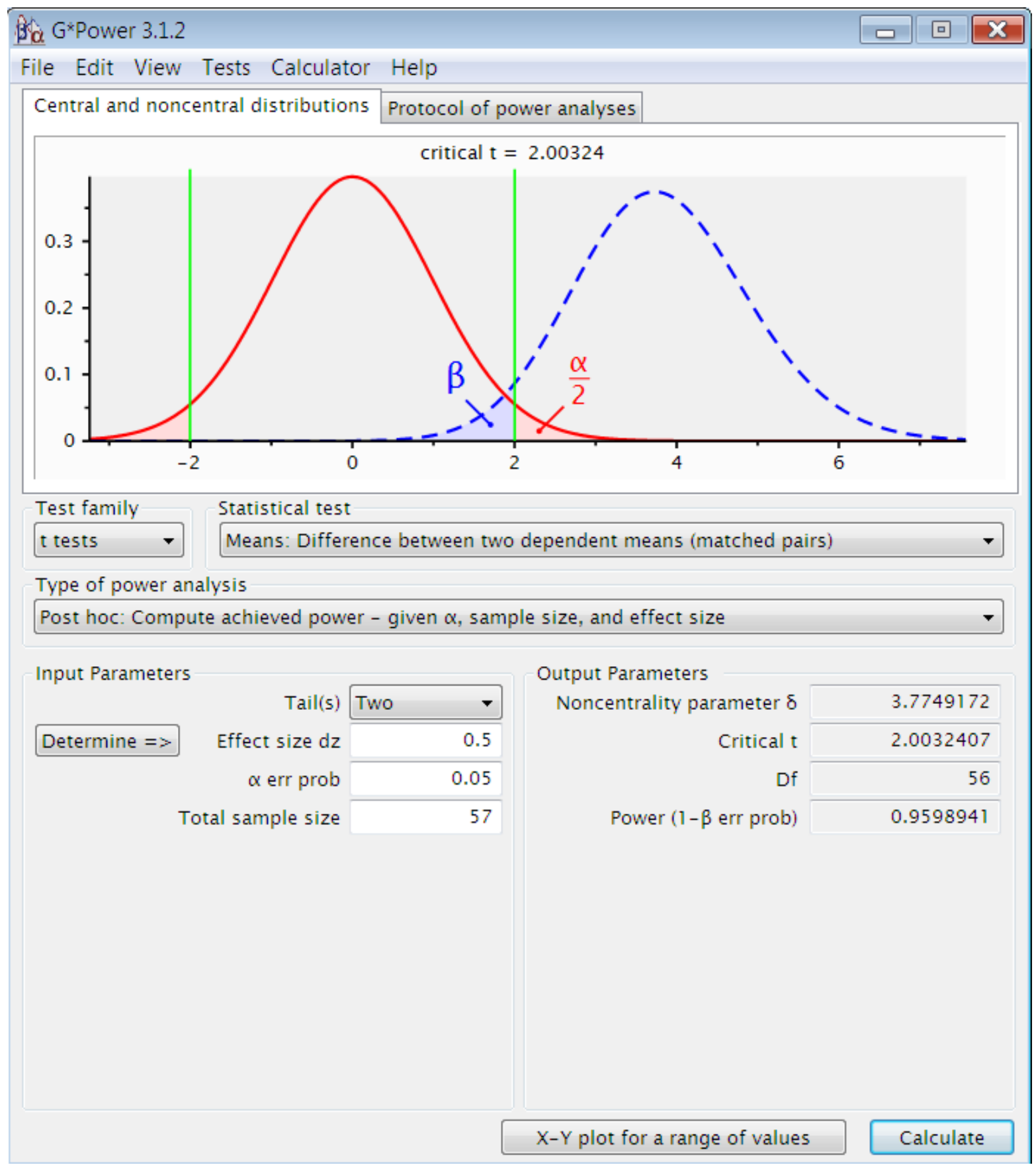




\section{Appendix J}

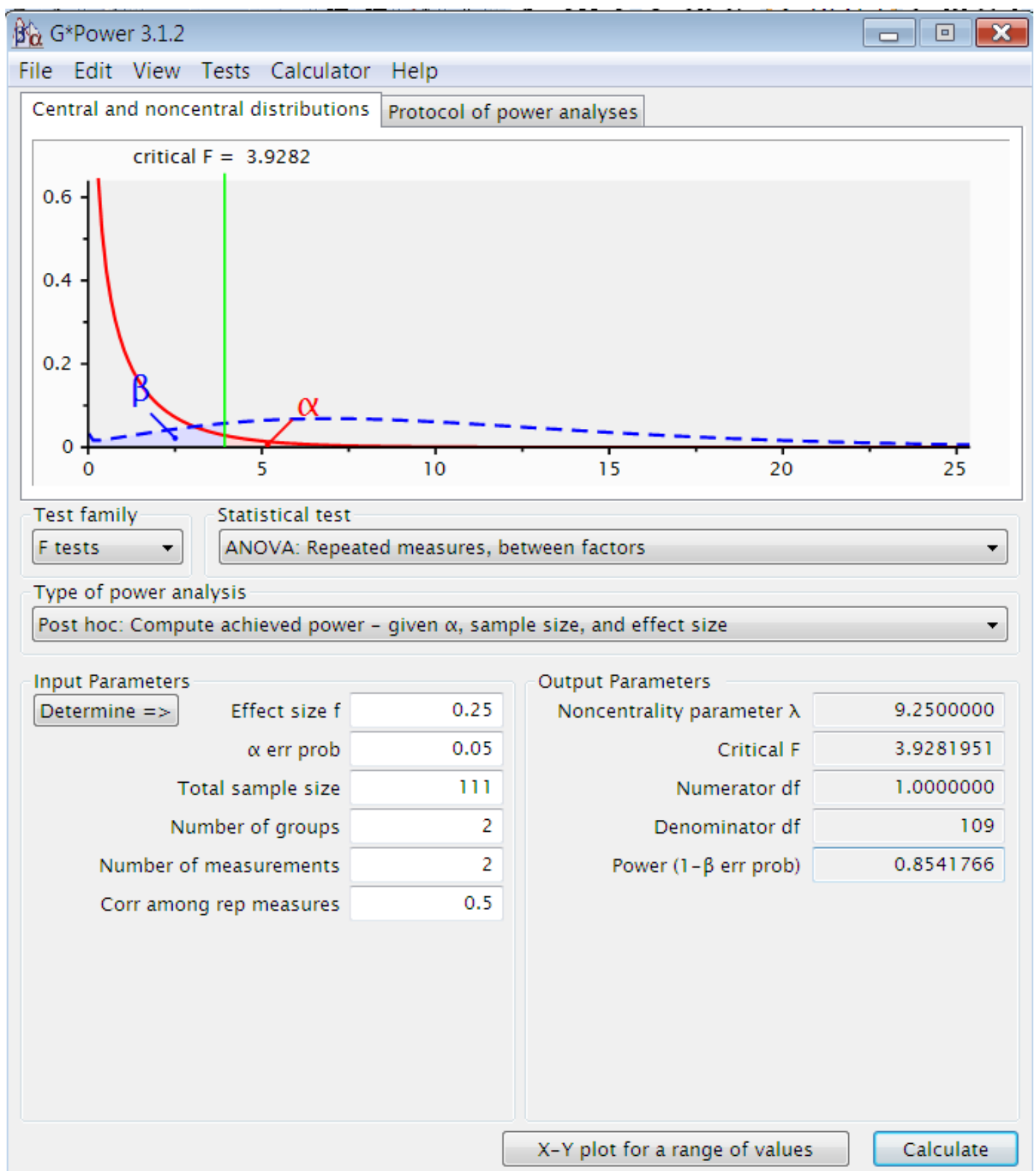


Appendix K

Experimental Group I and Control Group I

Independent Samples Test

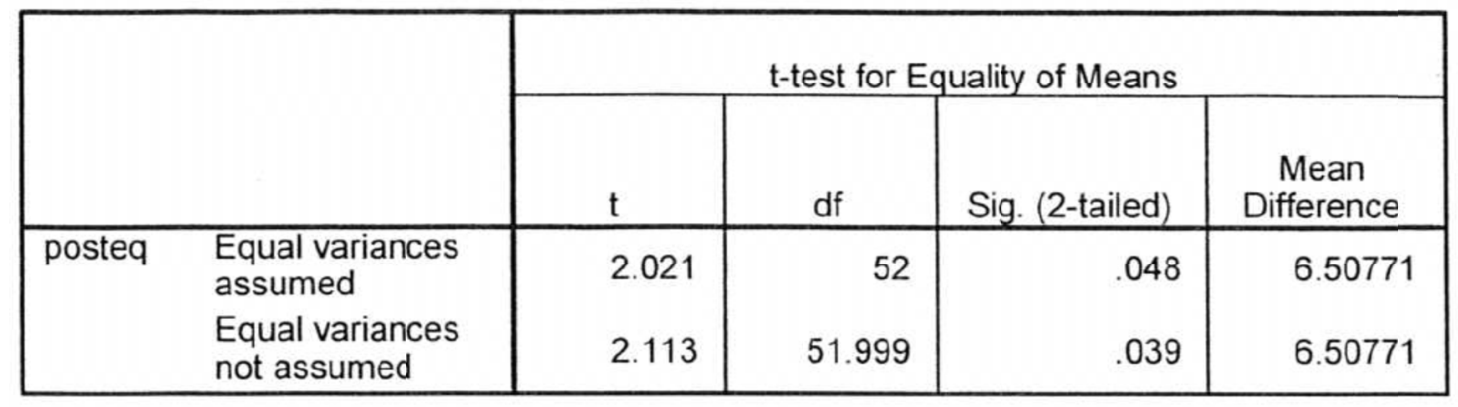

Experimental Group II and Control Group II

Independent Samples Test

\begin{tabular}{|c|c|c|c|c|c|}
\hline & & \multicolumn{4}{|c|}{ t-test for Equality of Means } \\
\hline & & $t$ & df & Sig. (2-tailed) & $\begin{array}{c}\text { Mean } \\
\text { Difference }\end{array}$ \\
\hline \multirow[t]{2}{*}{ posteq } & $\begin{array}{l}\text { Equal variances } \\
\text { assumed }\end{array}$ & 1.808 & 55 & .076 & 7.12808 \\
\hline & $\begin{array}{l}\text { Equal variances } \\
\text { not assumed }\end{array}$ & 1.815 & 53.082 & .075 & 7.12808 \\
\hline
\end{tabular}


Appendix L

ANOVA

\begin{tabular}{|ll|r|r|r|r|r|}
\hline & \multicolumn{1}{c|}{$\begin{array}{c}\text { Sum of } \\
\text { Squares }\end{array}$} & df & Mean Square & F & Sig. \\
\hline eqpost & Between Groups & 1773.592 & 3 & 591.197 & 3.335 & .022 \\
& Within Groups & 18970.300 & 107 & 177.293 & & \\
& Total & 20743.892 & 110 & & & \\
\hline male & Between Groups & .000 & 3 & .000 & & \\
& Within Groups & .000 & 61 & .000 & & \\
& Total & .000 & 64 & & & \\
\hline female & Between Groups & .000 & 3 & .000 & & \\
& Within Groups & .000 & 42 & .000 & & \\
& Total & .000 & 45 & & & \\
\hline
\end{tabular}


VITA

JOYCE WALSH-PORTILLO

1976

B.A. Anthropology

University of South Florida

Tampa, Florida

1976-1991 Interlingua, Language Services

Human Resources Director; Sales and Product

Development Director; EFL professor

1987

M.B.A. Master of Business Administration

University of the Americas

Cholula, Puebla (Mexico)

1991-1997 Free-lance educational consultant

Mexico City

1997-2000 Osiason Educational Trust

Miami, FL

Free lance consultant

2000-2003 Adjunct Professor, Business Administration

Broward College

Davie, FL

2003-2009 Fulltime (Associate) Professor, Business Administration

Broward College

Davie, FL

2006-2011 Doctoral Candidate

Florida International University

Miami, FL

2007 Endowed Teaching Chair Recipient

Causeway Lumber

2009-current Special Assignment as Lead Faculty, General Education Outcomes \& Assessments

Academic Affairs, reporting to the Provost

Broward College, District

Ft. Lauderdale, FL 


\section{PRESENTATIONS}

Walsh-Portillo, J. (January, 2005). Emotional intelligence at work. Broward College Staff and Faculty Development Program. Davie, FL.

Walsh-Portillo, J. (November, 2006). Successful interviewing tips for students. Broward College, Davie. FL.

Walsh-Portillo, J. (June, 2007). Emotional intelligence and leadership. Broward College, Davie. FL.

Walsh-Portillo, J. (May, 2008). Barriers to effective communication. Broward College Professional and Technical Staff Retreat. Davie, FL.

Walsh-Portillo, J. (July, 2008). Emotional intelligence and student success; Sierra Nevada School (K-12); México City, México.

Walsh-Portillo, J. (May,2010). Using emotional intelligence at work. Broward College Professional and Technical Staff Retreat. Davie, FL.

Walsh-Portillo, J., \& Broschard, D. (July, 2010). Transformative assessment: How technology can facilitate faculty participation and promote continuous improvement. SACCR (Southeastern Association of Community College Research) Annual Meeting; Savannah, GA.

Bernal-Dobeck, M., Sahagun, C.. \& Walsh-Portillo, J. (April, 2011). The President's Leadership Academy. Diversity and Inclusion. Broward College. Ft. Lauderdale, FL.

Walsh-Portillo, J., Hefferin, D., \& Hodge, T. (June, 2011). Our new area code is 3.5.1. How monitoring was the best thing that happened to our general education program. State Assessment Meeting; Valencia College, Orlando, FL.

Walsh-Portillo, J. (1998-2011). Raising a child with high emotional intelligence-annual workshop S.E.D.I. for parents and staff. México City, México. 